\title{
COMORBILIDAD EN EL NIÑO Y ADOLESCENTE CON T.D.A.H.
}

Presentada por: Virginia Garrido Fernández

\author{
Francisco Javier Álvarez Rodríguez \\ José Ángel Macías Fernández
}

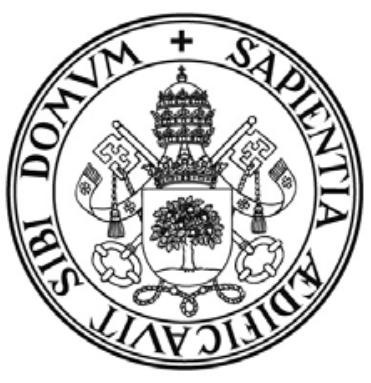

\section{Universidad deValladolid}


Quiero expresar mi agradecimiento al Dr. Francisco Javier Álvarez Rodriguez y al Dr. José Ángel Macías Fernández, directores de esta tesis doctoral, por su apoyo y su generosidad desde el primer momento en que les planteé acometer este proyecto. Por haberme creado un camino de facilidades, incluso sorteando grandes dificultades técnicas y de salud, para permitirme llegar al final de ésta ardua e interesante tarea.

A la Dra. Rocío Gómez, quien me impulso a iniciar este reto, del que ahora me siento tan satisfecha.

A mi marido, que ha sido compañero imprescindible en este trayecto, ayudándome no solo desde el plano técnico de esta tesis, sino como incondicional apoyo psicológico y emocional.

A mi madre, la persona que cuando desespero siempre me recuerda "no te rindas"..., y me inyecta su optimismo y fortaleza.

A mis primos Lorena y Diego, cuyos conocimientos informáticos y estadísticos han sido el faro que ha permitido llevar a buen puerto este proyecto. Gracias Lore, que siempre está ahí y tiene tiempo cuando se la necesita.

A mi padre, de quien aprendí, que la mente domina al cuerpo y no al revés, despertándose así mis inquietudes hacia el estudio de la Psiquiatría.

A mi hija Elvira, que con sus catorce meses aún no tiene edad para comprender por qué su mamá pasa tanto tiempo delante de "esa pantalla brillante", pero se resigna con paciencia. 
Por último, y de manera muy especial a mis pacientes, niños y adolescentes con TDAH que han hecho realidad este trabajo, cuyo afán de superación representa la esperanza y motivación para seguir profundizado en el complejo conocimiento de la enfermedad mental. 
ÍNDICE 1

TÍTULO I. INTRODUCCIÓN GENERAL ................................................................... 4

TÍTULO II. ENFOQUE TEÓRICO............................................................................

CAPÍTULO 1. EVOLUCIÓN EN EL CONCEPTO DEL TRASTORNO DE DÉFICIT DE ATENCIÓN E HIPERACTIVIDAD .........................................................................

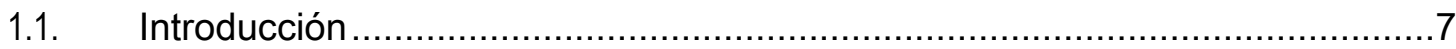

1.2. Desarrollo histórico del concepto del Trastorno de Déficit de Atención e

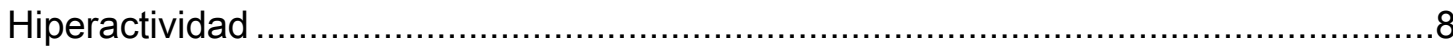

1.2.1. Evolución del conocimiento del TDAH a lo largo de la historia....................8

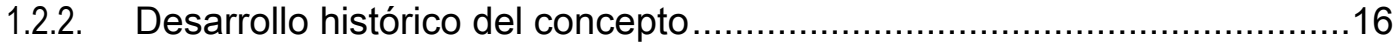

1.3. Avances en el concepto del T.D.A.H...................................................17

1.3.1. Impacto y prevalencia del Trastorno ................................................17

1.3.2. Etiología del Trastorno de Déficit de Atención e Hiperactividad ...............21

1.3.3. Nuevas reflexiones hacia la comprensión de la triada sintomática: Disfunciones ejecutivas. .26

1.3.4. Factores de riesgo y pronóstico en la evolución del Trastorno de Déficit de Atención e Hiperactividad 33

CAPÍTULO 2. COMORBILIDAD. RELEVANCIA EN EL TRANSCURSO DEL TRASTORNO DE DÉFICIT DE ATENCIÓN E HIPERACTIVIDAD. ............................. 36

2.1. Introducción. .36

2.2. Clasificación conceptual de las posibles comorbilidades más prevalentes....40

2.3. Paso a paso por el proceso comórbido 42

2.3.1. Trastornos del lenguaje y aprendizaje .42

2.3.2. Trastornos de la regulación de la excitación-motivación 48 
2.3.3. Trastornos de la regulación social-emocional

TíTULO III. TRABAJO EMPÍRICO 68

CAPÍTULO 1. EXPOSICIÓN DEL TRABAJO EMPÍRICO …..................................68

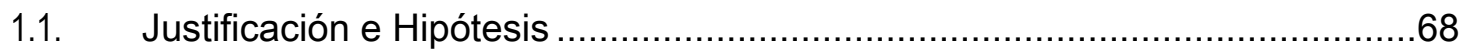

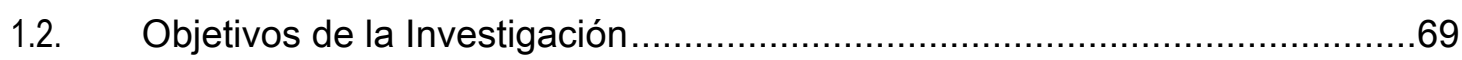

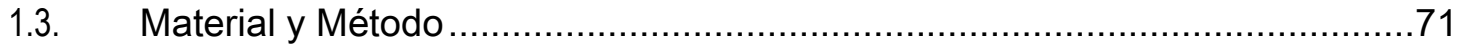

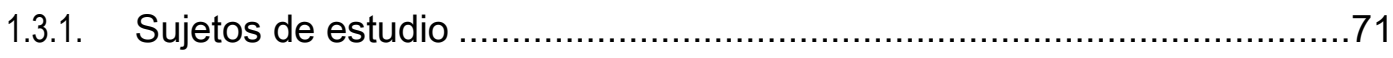

1.3.2. Variables analizadas e Instrumentos de evaluación...............................74

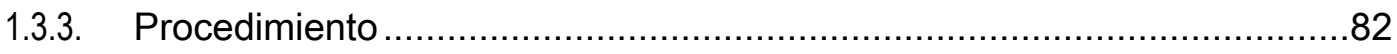

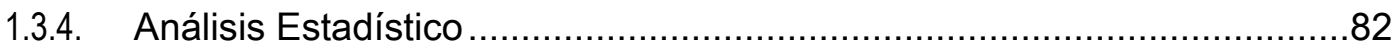

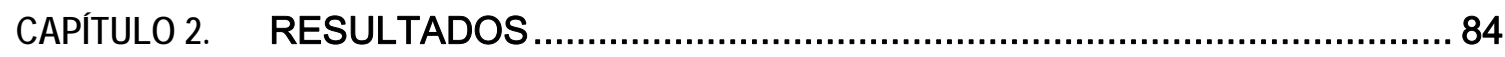

2.1. Descripción socio-demográfica de la muestra.............................................84

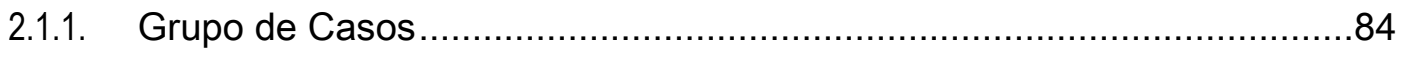

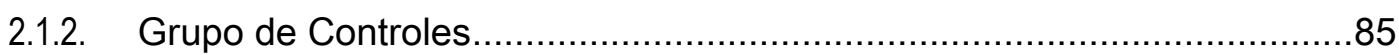

2.2. Resultados por objetivos planteados en nuestro estudio .............................86

2.2.1. Determinar las características clínico-epidemiológicas de los niños y adolescentes con TDAH .86

2.2.2. Evaluar la presencia de comorbilidad psiquiátrica de los niños y adolescentes con TDAH de la muestra y la influencia de las variables sexo, grupo de edad, subtipo, agresividad.

2.2.3. Evaluar los tipos de comorbilidad más prevalentes en los pacientes TDAH y la influencia de las variables subtipo y agresividad..... 100

2.2.4. Analizar la relevancia de la comorbilidad en el cumplimiento terapeútico y en la edad de inicio de la medicación. 126

2.2.5. Elaborar, relacionando entre sí las variables más relevantes del estudio, árboles de decisión que faciliten, en la práctica clínica, la detección precoz de la comorbilidad en el paciente TDAH 
CAPÍTULO 3. DISCUSIÓN Y LIMITACIONES ........................................................ 135

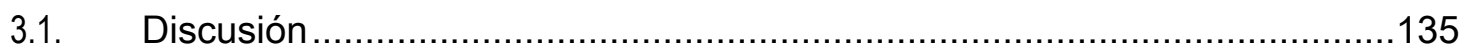

3.1.1. Características Generales de la Muestra............................................135

3.1.2. Discusión por objetivos planteados …….........................................136

3.2. Limitaciones de nuestro estudio ...............................................................153

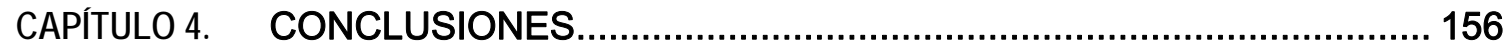

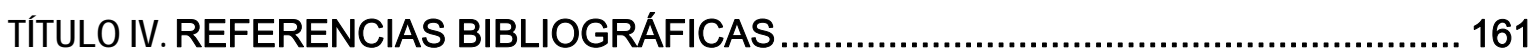




\section{TÍTULO I. INTRODUCCIÓN GENERAL}

El Trastorno por déficit de atención y/o hiperactividad (TDAH) es una patología de alta prevalencia dentro del desarrollo neurológico del niño. Desde el punto de vista profesional genera un elevado número de consultas médicas y es frecuente el desconocimiento social que existe alrededor de este trastorno. Desde el punto de vista ambiental motiva una gran ansiedad familiar y preocupación escolar.

El Trastorno ha suscitado un gran interés social en la última década, debido principalmente a su elevada tasa de prevalencia, a su carácter crónico y al fuerte impacto que ocasiona en el ámbito familiar, escolar y social; Pero sin duda también ha contribuido a la explosión que ha experimentado la investigación sobre TDAH, la frecuente asociación que tiene el trastorno con otras psicopatologías psiquiátricas en general y con dificultades de aprendizaje en particular (Brown, 2000; Miranda, Soriano y García, 2005).

La investigación sobre la etiología del TDAH respalda, que éste posiblemente está determinado por causas de naturaleza biológica. Sin embargo, para obtener una comprensión adecuada de este trastorno, resulta imprescindible contemplar las influencias biológicas desde un enfoque integral, valorando el papel que ejerce el ambiente psicosocial sobre la predisposición biológica al TDAH (Asherson, Kuntsi y Taylor, 2005).

Fundamentándonos en estas consideraciones generales, el trabajo que aquí se presenta es el resultado de un estudio que ha integrado dos fases diferenciadas:

En la primera de ellas, se analizaron los factores de riesgo de los sujetos de estudio, y la importancia de la precocidad en el diagnóstico, tratamiento y seguimiento escolar, familiar y social, en tomando una muestra de niños con TDAH de nuestro área asistencial. 
La segunda fase se centró en el análisis de variables más relevantes de los niños con TDAH, focalizándonos esencialmente en los factores de riesgo de padecer comorbilidad psiquiátrica.

En cuanto a la estructura propiamente dicha, esta tesis presenta una primera parte teórica que incluye, a su vez, dos epígrafes:

El primero de ellos, orientado a situarnos en los conocimientos más actuales que definen el trastorno de déficit de atención e hiperactividad (al que con cierta frecuencia nos referiremos con su nombre abreviado TDAH), haciendo para ello una revisión del concepto de trastorno por déficit de atención con hiperactividad, teniendo en cuenta los antecedentes y las contribuciones más relevantes. También se han analizado los diferentes modelos etiológicos que hoy en día coexisten en la explicación causal del TDAH (genéticos, neurofisiológicos y ambientales).

El segundo epígrafe, se dirige a situarnos en la dimensión teórica del trabajo empírico realizado; Se estudia la importancia de la comorbilidad psiquiátrica en el TDAH, basada en la revisión de la literatura.

El segundo núcleo de nuestra tesis, está dedicado a la exposición del trabajo empírico. Esta segunda parte se inicia con una breve justificación, para pasar inmediatamente al planteamiento del diseño metodológico: objetivos, descripción de la muestra e instrumentos de evaluación y procedimiento. Los apartados siguientes presentan los resultados obtenidos en función de los objetivos planteados. Posteriormente, se desarrolla la discusión de los resultados de nuestro trabajo, valorándolos, a su vez, en cada uno de los objetivos. Se ha hecho una síntesis final en forma de conclusiones. Asimismo se han elaborado árboles de decisión con las variables más relevantes de nuestro estudio, buscando que aporten una proyección práctica de nuestros hallazgos. 
En último lugar, se recogen las referencias bibliográficas utilizadas para la realización del estudio.

Nuestro objetivo, que esperamos haber cumplido, ha sido profundizar en el análisis de las diversas patologías psiquiátricas, que con tanta frecuencia van a acompañar al trastorno. La comorbilidad genera así la compleja constelación psicopatológica y con ello no sólo dificultades diagnósticas sino también terapéuticas.

Sólo partiendo de la comprensión integral y profunda de la psicopatología se va a abordar correctamente "el problema", o mejor dicho, ya que hablamos de comorbilidades, "los problemas", generando así mejores tasas de diagnóstico precoz, respuesta positiva al tratamiento y buen pronóstico. 


\section{TÍTULO II. ENFOQUE TEÓRICO}

\section{CAPÍtUlo 1. EVOLUCIÓN EN EL CONCEPTO DEL TRASTORNO DE DÉFICIT DE ATENCIÓN E HIPERACTIVIDAD}

\subsection{Introducción}

A continuación, hemos realizado un desarrollo histórico del concepto de Trastorno por Déficit de Atención con Hiperactividad (TDAH) hasta llegar a las concepciones actuales, para entender cómo ha sido la evolución a lo largo del tiempo, desde un enfoque parcial, hasta una visión fundamentalmente integradora y multidimensional del trastorno. Actualmente se entiende como una necesidad, el considerar el TDAH como un problema que se estructura como producto de una compleja interacción de factores biológicos, psicológicos y sociales.

Hemos querido profundizar también en el conocimiento de lo que se han denominado como funciones ejecutivas, que recientemente se constituyen como el pilar para la comprensión de las manifestaciones clínicas del TDAH, por su afectación en el paciente que padece el trastorno. Las funciones ejecutivas y la interacción alterada entre las mismas, nos va a permitir entender los fundamentos de la sintomatología.

A continuación, se revisan los agentes que se han identificado en la literatura como de riesgo para el desarrollo de comorbilidad psiquiátrica concomitante. Para concluir, en cuanto al marco teórico del síndrome de déficit de atención e hiperactividad, se ha incluido lo concerniente a indicadores de pronóstico favorable-desfavorable, considerados como de mayor relevancia. 


\subsection{Desarrollo histórico del concepto del Trastorno de Déficit de Atención e Hiperactividad}

\subsubsection{Evolución del conocimiento del TDAH a lo largo de la historia}

El TDAH es un trastorno comportamental de inicio en la infancia que se ha descrito desde la antigüedad, y que ha quedado reflejado en la sociedad a través de documentos literarios o artísticos.

Es difícil filiar los primeros documentos acerca del trastorno. Algunos señalan al médico H. Hoffmann como el primer autor que describe claramente a un niño con déficit de atención e hiperactividad a mediados del siglo XIX ("The Story of Fidgety Philip" 1865).

Poco después, en 1987, Bourneville describe niños inestables caracterizados por una inquietud física y psíquica exagerada, y una actitud destructiva a la que se suma un leve retraso mental.

En 1901, J. Demoor señala la presencia de niños muy lábiles comportamentalmente, que precisan moverse constantemente y que asocian una clara dificultad atencional.

Un año más tarde, el médico inglés George Still define, describe y agrupa de forma precisa los síntomas clínicos relevantes en esta patología (tres conferencias tituladas "Algunos trastornos psíquicos anormales de los niños", publicadas en The Lancet, en abril de 1902). Señala niños violentos, inquietos y molestos, revoltosos, destructivos, dispersos... Ya entonces añade la repercusión escolar como característica asociada, y la apunta incluso en niños sin déficit intelectual. Quedan sin aclarar los mecanismos etiológicos, señalando un "defecto patológico en el control moral" como causa del trastorno, pero anotando indirectamente, en algunos casos, la presencia de rasgos dismórficos como epicantus o paladar ojival. 
Esta circunstancia provocó que el trastorno comenzara a entenderse como una alteración neurológica. En esta línea, entre otras, se sitúan diversos estudios que se refieren al síndrome como "trastorno de comportamiento postencefálico" y "síndrome orgánico cerebral".

En las siguientes décadas, diversos autores evidenciaron que existía un grupo de niños que sufrían un daño cerebral y manifestaban síntomas similares a los descritos por Still. Se suceden entonces, diferentes teorías etiológicas, hasta mediados del siglo XX. Meyer en 1904 describe características clínicas similares en niños con encefalopatía traumática.

En 1914, A. Tredgold argumentó que el TDAH podría ser causado por una especie de disfunción cerebral, una encefalitis letárgica en la cual queda afectada el área del comportamiento, de ahí la consecuente hipercinesia compensatoria, explosividad en la actividad voluntaria e impulsividad.

En 1917, R. Lafora describe de nuevo las características clínicas de estos niños. Muestra niños sin déficit cognitivos ni sensoriales, nerviosos, indisciplinados, en constante actividad y disatentos.

Hohman en 1922 observa el comportamiento descrito como secuela de la encefalitis de epidémica.

Shilder en 1931 realiza una observación clara que se mantiene hasta nuestros tiempos. Refiere la presencia de la hipercinesia en pacientes con antecedente de sufrimiento perinatal, señalando de nuevo la base "orgánica" de esta patología.

En 1934, Kahn y Cohen proponen el término "Síndrome de Impulsividad Orgánica" para explicar el origen orgánico del TDAH. Estos autores proponen la disfunción troncoencefálica como origen de la labilidad psíquica de estos niños y otras patologías conductuales. 
En 1937, Bradley descubrió de forma casual los efectos terapéuticos de las anfetaminas en los niños hiperactivos.

El término «disfunción cerebral mínima» fue acuñado por Strauss y Lehtinenen 1947, y aplicado a aquellos niños con trastornos de conducta en los que no se apreciaba suficiente evidencia científica de patología cerebral (Barkley, 2006). Estos autores interpretaron la hiperactividad como un síntoma de una lesión cerebral exógena en la que se suponía que estaban interviniendo factores externos a la dotación genética del sujeto, acuñándose en consecuencia el término de "Síndrome de Strauss “.

Lauferr y Denhoff (1957) realizaron la primera denominación de síndrome hipercinético. Además describieron los síntomas y señalaron que, a pesar de que la causa de los síntomas primarios residía en deficiencias en las estructuras talámicas, otros síntomas secundarios como la tendencia al robo o a la destrucción eran producto de una interacción entre factores biológicos y sociales.

En los años 60, la consideración de la hiperactividad como una disfunción cerebral mínima supuso un cambio de visión de relevancia en su concepción. Clements (1966) definió esta disfunción cerebral mínima como un trastorno de conducta y aprendizaje que presentan niños con una inteligencia normal pero que padecen disfunciones del sistema nervioso central. Por consiguiente se estaba otorgando así un papel preponderante a los factores neurológicos como responsables del problema.

Como el concepto de disfunción cerebral mínima, no podía demostrarse de una forma experimental, la psicología y la pedagogía comprendían la hiperactividad como un trastorno conductual, que se fue concretando en etiquetas diagnósticas más específicas como trastornos de aprendizaje, trastornos de lenguaje etc. Bajo ese prisma, el síntoma considerado dominante era la excesiva actividad motora que presentaban los niños hiperactivos, en comparación a la que presentaban los niños de edad, sexo y nivel socioeconómico y cultural similares. Estas concepciones se vieron reflejadas en la 
publicación del DSM-II (American Psychiatric Association, 1968), que constituyó la primera clasificación que incluía este trastorno con el término "Reacción Hipercinética en la Infancia y en la Adolescencia". En dicho manual, la reacción hiperkinética estaba caracterizada por un exceso de actividad, de inquietud, y distractibilidad, especialmente en niños pequeños. Además se consideraba que estas conductas disminuían en la adolescencia.

En la década de los setenta, el trabajo de Virginia Douglas (1972) supuso un giro al concepto de gran interés, ella argumentó que la deficiencia básica del TDAH era la incapacidad para centrar la atención, así como en la impulsividad, y no la excesiva actividad motora. Según Douglas, en la base de estas dificultades está una escasa capacidad de autorregulación.

La dimensión cognitiva se sitúa entonces por encima de los aspectos conductuales, volviendo, de algún modo, a las concepciones iniciales de Still, que señalaban una incapacidad para adecuarse a las demandas sociales. Influyeron además de forma importante en la clasificación del DSM-III (American Psychiatric Association, 1980), que supuso un cambio de enfoque al reconocer como ejes básicos del problema la desatención y la impulsividad, dejando en un segundo plano los síntomas de hiperactividad. Esta clasificación estableció las categorías diagnósticas de "Déficit de atención con hiperactividad" y "Déficit de atención sin hiperactividad".

No obstante, el reconocimiento de las alteraciones de la atención como elementos básicos de un subtipo del trastorno, desapareció posteriormente en el DSM-III-R (American Psychiatric Association, 1987). EI TDAH fue clasificado como un trastorno de conducta perturbadora, modificándose incluso la terminología de referencia al utilizarse la denominación de "Trastorno por Déficit de Atención con Hiperactividad". Finalmente, fue con la publicación del DSM-IV y DSM-IV-TR (American Psychiatric Association, 1994, 
2000) cuando, a pesar de conservar el mismo rótulo diagnóstico general, se vuelve a contemplar el subtipo de TDAH "con predominio del déficit de atención”.

En los actuales sistemas de clasificación y diagnóstico de los trastornos mentales, el TDAH se caracteriza por la aparición de síntomas de desatención, sobreactividad e impulsividad, de modo más frecuente y grave que los que se observan habitualmente en sujetos de la misma edad.

Los criterios específicos, que se incluyen en el DSM-IV y el DSM-IV-TR para el diagnóstico del trastorno por déficit de atención con hiperactividad (TDAH) y los que aparecen en el ICD-10 (OMS, 1992) para el diagnóstico del trastorno hipercinético (THC), incluyen un listado similar de 18 síntomas de inatención, hiperactividad e impulsividad (tabla 1). También muestran su coincidencia en señalar que los síntomas se deben mantener a lo largo del tiempo y en diferentes situaciones en las que el sujeto se desenvuelve. Al mismo tiempo, los síntomas deben de producir un desajuste significativo y manifestarse en dos contextos diferentes. La duración y severidad de las conductas, su inicio temprano y su importante impacto en diferentes ambientes son aspectos claves para el diagnóstico del trastorno.

A pesar de las coincidencias señaladas, existen algunas discrepancias entre el ICD-10 y el DSM-IV. Entre otras, el ICD-10 exige la presencia de los tres síntomas esenciales para la obtención del diagnóstico de THC, señala que se deben dar al menos seis síntomas de inatención, al menos tres de hiperactividad y como mínimo uno de impulsividad. Por otra parte, el ICD-10 también considera como criterio de exclusión la presencia de otros trastornos, a excepción del trastorno de conducta, diferenciando el trastorno hipercinético con y sin trastorno de conducta. 


\section{CRITERIOS DIAGNÓSTICOS SEGÚN LA CLASIFICACIÓN DSM (CUARTA VERSIÓN)}

\section{A. Debe cumplir 6 o más de los síntomas siguientes para el déficit de atención ylo hiperactividad, síntomas que deben haber estado presentes durante más de 6 meses}

Déficit de Atención

1. No pone atención a los detalles y comete errores frecuentes por descuido

2. Tiene dificultad para mantener la atención en las tareas y los juegos

3. No parece escuchar lo que se le dice cuando se le habla directamente

4. No sigue las instrucciones, no termina las tareas en la escuela, no termina los "recados", a pesar de entenderlos

5. Dificultades para organizar sus tareas y actividades

6. Evita o rechaza realizar tareas que le demanden esfuerzo

7. Pierde sus útiles o cosas necesarias para hacer sus actividades obligatorias (lapiceros, libros...)

8. Se distrae fácilmente con estímulos irrelevantes

9. Olvidadizo en las actividades de la vida diaria

Hiperactividad-Impulsividad

1. Molesta moviendo las manos y los pies mientras está sentado

2. Se levanta del puesto en la clase o en otras situaciones donde debe estar sentado

3. Corretea, trepa... en situaciones inadecuadas

4. Dificultad para relajarse o practicar juegos donde debe permanecer quieto

5. Está continuamente en marcha como si tuviera un motor por dentro

6. Habla excesivamente

7. Contesta o actúa antes de que se terminen de formular las preguntas

8. Tiene dificultad para esperar turnos en los juegos

9. Interrumpe las conversaciones o los juegos de los demás

B. Algunos síntomas presentes antes de los 7 años

C. Síntomas presentes en dos o más lugares (escuela, casa...)

D. Clara evidencia de afectación social, académica u ocupacional

E. Exclusión previa de otros trastornos del desarrollo que puedan estar justificando la sintomatología a estudio.

Figura 1. Criterios diagnósticos según la clasificación DSM, en su cuarta versión 


\section{CLASIFICACIÓN SEGÚN LA OMS. CIE-10}

\section{F90. Trastornos hipercinéticos}

Grupo de trastornos caracterizados por su comienzo temprano (habitualmente, durante los primeros cinco años de vida), por falta de constancia en las actividades que requieren de la participación de funciones intelectuales y por una tendencia a cambiar de una actividad a otra, sin completar ninguna, junto con una actividad desorganizada, mal regulada y excesiva. Pueden hallarse asociadas otras anormalidades. Los niños hipercinéticos son a menudo imprudentes e impulsivos, propensos a los accidentes y a verse en dificultades disciplinarias, más que por una actitud desafiante deliberada por incurrir en la violación irreflexiva de normas. Sus relaciones con los adultos son a menudo socialmente desinhibidas, carentes de la reserva y la precaución normales. Son impopulares entre los demás niños, y pueden quedar socialmente aislados. Es común el deterioro intelectual, mientras los retrasos específicos del desarrollo motriz y del lenguaje son desproporcionadamente frecuentes. Entre las complicaciones secundarias se cuentan el comportamiento asocial y la baja autoestima.

Excluye: esquizofrenia, trastornos de ansiedad, generalizados del desarrollo y humor (afectivos).

\section{F90.0 Perturbación de la actividad y de la atención}

Trastorno o síndrome deficitario de la atención con hiperactividad

Trastorno hipercinético con déficit de la atención

Excluye: trastorno hipercinético asociado con trastorno de la conducta.

\section{F90.1 Trastorno hipercinético de la conducta}

Trastorno hipercinético asociado con trastorno de la conducta

\section{F90.8 Otros Trastornos hipercinéticos}

\section{F90.9 Trastorno hipercinético no especificado}

Reacción hipercinética de la niñez o de la adolescencia SAI.

Síndrome hipercinético SAI

Figura 2. Clasificación según la OMS.CIE-10 
En la actualidad, tal como se desprende de las indicaciones que aparecen en las recientes guías de la American Academy of Child and Adolescent Psychiatry (1997) y de la American Academy of Pediatrics (2001), se recomienda para el diagnóstico de un niño con TDAH realizar una evaluación comprehensiva, que incluya además de los criterios del DSM-IV o ICD-10, un examen médico minucioso, escalas de estimación conductual (realizadas por padres y profesores), evaluación psicoeducativa y observaciones en la escuela.

\section{Desarrollo histórico del TDAH}

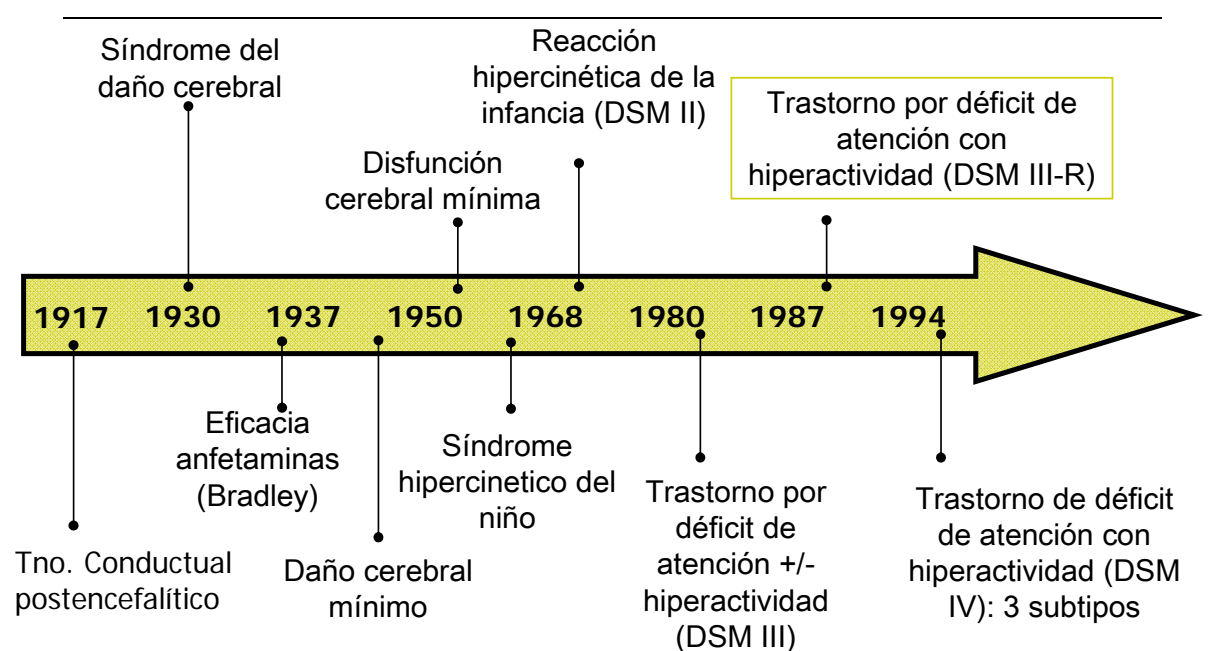

Figura 3. Diagrama cronológico del desarrollo histórico del TDAH 


\subsubsection{Desarrollo histórico del concepto}

- DSM II (1968): Reacción hipercinética de la infancia

- DSM III (1980): Trastorno de déficit de atención (TDA):

- Sin hiperactividad

- Con hiperactividad

- $\quad$ DSM III-R (1987): Trastorno por déficit de atención con hiperactividad (TDAH)

- DSM IV (1994): Trastorno de déficit atención con hiperactividad

-Tipo preferentemente déficit de atención

-Tipo preferentemente, hiperactivo/impulsivo

-Tipo combinado

- $\quad$ DSM IV- TR (2000): Trastorno de déficit atención con hiperactividad

-Tipo preferentemente déficit de atención

-Tipo preferentemente, hiperactivo/impulsivo

-Tipo combinado 


\subsection{Avances en el concepto del T.D.A.H.}

\subsubsection{Impacto y prevalencia del Trastorno}

El Trastorno de Déficit de Atención con Hiperactividad es uno de los trastornos psiquiátricos (neurobiológicos), del niño y del adolescente, más prevalentes (Barkley, 2006).

Pero, no sólo se trata de una de las alteraciones infantiles más frecuentes, sino que también de la que más interés e investigaciones ha generado en psiquiatría infantil, posiblemente por los problemas que ocasiona en el desarrollo personal, familiar y social del niño.

Se considera que el TDAH representa un problema de salud pública debido a su elevada prevalencia, que se estima, según las fuentes epidemiológicas, entre un 3 y un $7 \%$ de la población escolar en términos generales y considerando globalmente los tres subtipos (DSM-IV-TR, 2001). Esta prevalencia supondría la existencia en nuestro país de 400.000 niños y adolescentes afectados.

Prevalencia según diferencias Poblacionales-diagnósticas: No obstante, establecer con exactitud la prevalencia del TDAH es complejo pudiendo oscilar enormemente, entre un 1 y un $20 \%$. Esto se explica por varias razones:

- Por la diferencia entre los criterios diagnósticos empleados. Así pues, la utilización de criterios diagnósticos diferentes al DSM, como la Clasificación Internacional de las Enfermedades -CIE-10- o incluso dependiendo de la versión del DSM empleada, se obtienen prevalencias diferentes en una misma población; Diferentes estudios parecen reflejar que el DSM-IV-TR es más permisivo que las versiones anteriores, recogiendo mayor prevalencia en sus estudios en una 
misma muestra (Wolraich 1996; Leung, 1996; Baumgaertel, 1995; Newcorn, 1989).

- También los métodos y las fuentes de información utilizadas en los estudios generan variabilidad en las tasas de prevalencia. Aunque la mayoría de los trabajos se han realizado en escolares supuestamente sanos, algunos estudios han establecido la prevalencia del TDAH exclusivamente a través de cuestionarios. En otros estudios no se han excluido previamente otras patologías (síndromes, trastornos neurocutáneos...) que podían estar justificando un patrón de conducta similar al TDAH. También hay estudios como el de Quinn (2004) que señalan que los maestros detectan menos a las niñas que a los niños con TDAH.

- La preparación clínica de quién diagnostica los casos: En EEUU la especialización de la pediatría ha evolucionado de tal forma que los pacientes afectos, que eran periódicamente controlados por médicos de familia, se han reducido notabilísimamente en las últimas décadas, situación que no ha sido paralela en Europa. Esta última circunstancia probablemente intervenga en el diagnóstico precoz y preciso de esta patología.

\section{Prevalencia según diferencias por Sexo:}

En los niños en edad escolar, la proporción de varones que presentan este trastorno es superior a las mujeres, en una proporción de 9/1 de muestras clínicas, y de 4/1 en muestras comunitarias (APA, 1994). Esta ratio varía también según los subtipos de 4/1 para el tipo hiperactivo-impulsivo a 2/1 para el predominantemente inatento. Estas diferencias están muy condicionadas por el tipo de estudio y las características sintomáticas de las niñas, cuya hiperactividad e impulsividad es habitualmente menor. 
Según Lahey y colaboradores (1994), la proporción niños/niñas es mayor para el tipo combinado (7,3:1), seguida del tipo hiperactivo-impulsivo (4:1) y menor para el tipo inatento $(2,7: 1)$.

Más recientemente, Biederman y colaboradores (2002) presentaron la frecuencia, en porcentaje, de los subtipos de TDAH según géneros, para los que determinaron que:

- TDAH subtipo combinado: Este subtipo, se presentaba más frecuentemente en niños que en niñas ( $80 \%$ frente al $65 \%$, respectivamente)

- TDAH con predominio de déficit de atención: El subtipo inatento era más frecuente en niñas que en niños (30\% frente al $16 \%$, respectivamente)

- El TDAH subtipo hiperactivo-impulsivo: Es el menos frecuente de los tres, se encontraba tanto en las niñas (5\%) como en los niños (4\%).

En adolescentes 0 adultos, el componente de hiperactividad disminuye considerablemente; La relación entre mujeres y varones llega a igualarse o incluso a descompensarse, mostrando mayor prevalencia del TDAH en el sexo femenino. Del mismo modo, constatamos una mayor asistencia al especialista por parte de las mujeres adolescentes y adultas para recibir tratamiento, en comparación con los hombres. Esto dificulta nuevamente hacer una estimación de la prevalencia real del trastorno en ambos sexos

Por tanto, probablemente estamos ante una patología de distribución más similar entre ambos sexos que la que realmente observamos en la clínica. Los sesgos son diagnósticos, motivados por la situación clínica predominante en cada momento de estos niños, adolescentes y adultos (Anderson, 1987; Bird 1988; Szatmari 1989; Baumgaertel 1995). 
En conclusión, Las tasas de prevalencia son marcadamente dispares según los criterios diagnósticos empleados, el origen de las muestras (clínicas o poblacionales), la metodología y las edades y el sexo escogidos (Benjumea, 2006). Los rangos de prevalencia se sitúan entre el 1,9 y 14,4\% (DuPaul et al., 2001)12. El DSM-IV-TR refiere una prevalencia estimada entre el 3-7\% de la población en edad escolar. Polanczyk et al. (2007) comunicaron una prevalencia mundial del 5,29\%. En España, al igual que en otros estudios europeos, las tasas de prevalencia son similares (ver Figura 4)

\begin{tabular}{|l|c|c|}
\hline \multicolumn{2}{|c|}{ ESTUDIOS DE PREVALENCIA DEL TDAH EN ESPAÑA } \\
\hline \multicolumn{1}{|c|}{ Autores y año } & Edad (años) & Prevalencia (\%) \\
\hline Cardo et al., 2007 (Mallorca) & $6-11$ & 4,57 \\
\hline Andrés et al., 1999 (Valencia) & 10 & 3,60 \\
\hline \multirow{2}{*}{ Gómez-Beneyto et al.,1994 (Valencia) } & 8 & 14,40 \\
\cline { 2 - 3 } & 11 & 5,30 \\
\cline { 2 - 3 } & 15 & 3,00 \\
\hline Benjumea y Mojarro, 1993 (Sevilla) & $6-15$ & $4-6$ \\
\hline Farré y Narbona, 1989 (Navarra) & $5-10$ & $1-2$ \\
\hline
\end{tabular}

Figura 4. Estudios de prevalencia del TDAH en España. GPC.

Los pacientes con TDAH suponen un grupo bastante heterogéneo, que presenta una variación considerable en la intensidad de los síntomas, la edad de inicio y en la presencia de los síntomas en distintas situaciones. Los síntomas del TDAH se pueden ver afectados por factores situacionales, como el momento del día o el cansancio, y factores motivacionales, la posibilidad de supervisión, etc. (Barkley et al., 2006).

Esta situación ha llevado a algunos profesionales a cuestionar su existencia y a preguntarse cuáles son los motivos por los que cada vez más personas presentan 
síntomas de TDAH, sugiriendo que pueda ser una moda pasajera en el diagnóstico psiquiátrico.

La validez del diagnóstico del TDAH y la eficacia del tratamiento están sólidamente confirmadas por la investigación empírica. La American Medical Association (AMA) encargó un estudio que concluye que «el TDAH es uno de los trastornos mejor estudiados en medicina y los datos generales sobre su validez son más convincentes que en la mayoría de los trastornos mentales e incluso que en muchas otras enfermedades» (Goldman et al., 1998).

\subsubsection{Etiología del Trastorno de Déficit de Atención e Hiperactividad}

Al hablar de la etiología del TDAH hemos de plantear una concepción integradora de diversos estudios y factores. Estudios biológicos de TDAH ponen de manifiesto la correlación de zonas anatómico-funcionales cerebrales, estudios de familias que evidencian la heredabilidad del trastorno y estudios que hacen alusión a la importancia de los factores medioambientales. Existe una gran controversia y desconocimiento del peso de cada uno de estos factores etiológicos, así como de la compleja matriz de interacciones entre los factores psicosociales y los factores neurobiológicos. En nuestra exposición vamos a presentar una síntesis de las aportaciones que se están realizando en este campo, aunque no vamos a ahondar en ellas ya que no son objeto de nuestra investigación.

Teniendo en cuenta la heterogeneidad del grupo TDAH en cuanto a severidad de presentación, persistencia de los síntomas, comorbilidades y las diferencias en la respuesta al tratamiento, se ha hecho necesario integrar los procesos medioambientales y sociales en los modelos de explicación genéticos y neurobiológicos. 
Pese a las evidencias cada vez mayores de la influencia de factores genéticos en el TDAH, es fundamental darle un papel de relevancia al efecto mediador de los factores medioambientales. En esta línea el estudio de Kreppner, O’Connor y Rutter (2001) muestra el impacto de la experiencia temprana de deprivación severa experimentada por niños adoptados procedentes de orfanatos rumanos. En su estudio, encuentra un aumento de TDAH (y otras patologías) en función del tiempo de deprivación experimentada. Estos datos sugieren la existencia de una ruta medioambiental, una conexión entre deprivación y cambios crónicos en la neurobiología del niño.

Estudios recientes sugieren que la epigenética podría constituir el fundamento biológico que conecta la interacción entre genes y entorno. Parece ser que el remodelado epigenético se constituiría en respuesta a la activación ambiental de vías de señalización celular asociadas a la plasticidad sináptica. Las marcas epigenéticas podrían sufrir un remodelado, en respuesta a fenómenos ambientales a lo largo de todo el desarrollo. Este sería el proceso a través del cúal el entorno interacciona con el genoma para producir diferencias individuales en la expresión de rasgos específicos (Bagot, Meaney 2010).

En esta misma línea Nigg, Nikolas y Burt (2010) sostienen que existen evidencias consistentes que apuntan a una interacción del genotipo con factores psicosociales en el desarrollo del TDAH. Considerada globalmente, la magnitud de la interacción de los factores psicosociales con el genotipo es de más del doble, comparada con la interacción de los riesgos prenatales y perinatales con el genotipo.

Actualmente, se acepta que es posible la interacción de factores ambientales y genéticos de forma que la presencia de determinados genes afectaría la sensibilidad individual a ciertos factores ambientales (Lehn et al., 2007; Thapar et al., 2007).

En cuanto a la base neurobiológica del TDAH se postula que el origen del trastorno está en una disfunción de la corteza prefrontal y de sus conexiones frontoestriadas. Diversos datos apoyan este modelo etiopatogénico, entre ellos el efecto beneficioso de los 
estimulantes y los modelos animales que implican las vías dopaminérgicas de gran relevancia en el funcionamiento del lóbulo prefrontal (Shaywitz et al., 1978; Arnsten, 2006).

Los estudios de neuroimagen estructural (Resonancia magnética RM), sugieren que, en la base del trastorno, existe una disminución en el volumen de varias regiones del cerebro: áreas prefrontales, núcleo caudado y globo pálido. A nivel estructural, en la población pediátrica con TDAH se han encontrado volúmenes significativamente inferiores a nivel de la corteza prefrontal dorsolateral y regiones conectadas con ésta, como el núcleo caudado, el núcleo pálido, el giro cingulado anterior y el cerebelo (Castellanos, 2002; Seidman y colaboradores, 2005).

Estas diferencias volumétricas cerebrales se han demostrado como anomalías en el desarrollo de las estructuras corticales en los sujetos con TDAH respecto a los controles. Estos estudios sugieren que el TDAH es un trastorno de la maduración cortical más que una desviación en el desarrollo (Shaw et al., 2007).

Los estudios de neuroimagen funcional (Tomografía por emisión de fotón único SPET o Tomografía por emisión de positrones PET) han señalado una reducción en el metabolismo o en el flujo cerebral en regiones encargadas de regular la inhibición de respuestas, la planificación y la flexibilidad mental. Especialmente en adultos, se encuentran implicadas de forma consistente a la corteza prefrontal y al cingulado anterior (Bush et al., 2005; Pliszka et al., 2006).

A nivel neuroquímico, parece demostrado que en el TDAH existe un sistema defectuoso de transmisión de la dopamina y noradrenalina: receptores menos sensibles y transportadores hipereficaces que dificultan la absorción por parte de las neuronas vecinas. Esta disfunción afecta fundamentalmente a las áreas del cerebro responsables de la inhibición del comportamiento inadecuado, especialmente los lóbulos frontales y los ganglios basales, con lo que se explicarían las dificultades de autocontrol que manifiestan 
los sujetos con este trastorno. El hecho de que los fármacos dopaminérgicos (metilfenitado y dextroanfetamina) resulten efectivos para disminuir una gran variedad de síntomas, avala esta hipótesis.

A pesar de que, durante los años 90 , se han realizado muchos progresos, todavía no se ha conseguido identificar el gen o genes del TDAH, pero hay evidencias claras de que existe, en este trastorno, un componente altamente hereditario. Existe evidencia científica de la importancia de los aspectos genéticos en el TDAH. En 20 estudios independientes realizados en gemelos, se ha comprobado que la heredabilidad del TDAH es del $76 \%$ (Faraone et al., 2005). También se ha observado que los hermanos de niños con TDAH tienen el doble de riesgo de sufrir este trastorno que los niños de la población general. (Barkley Dupaul y McMurray, 1990; Biederman, Faraone, Keenan, Knee y Tsuang, 1990)

Recientes estudios genómicos muestran la complejidad genética del TDAH, que se ha asociado con marcadores en los cromosomas 4, 5, 6, 8, 11, 16 y 17 (Faraone et al., 200560; Smalley et al., 2002).

Faraone y colaboradores (2005) han identificado 7 genes que mostraban una asociación estadísticamente significativa con el TDAH. Estos genes se relacionan con los receptores DR4, DR5 y el transportador de dopamina (DAT), la enzima dopamina-hidroxilasa, el transportador $(\mathrm{DBH})$ y el receptor 1B de la serotonina (HTR1B) y el gen asociado a la proteína sinaptosómica 25 (SNAP25). Estudios anteriores, ya apuntaban la implicación de mutaciones genéticas relacionadas con la neurotransmisión dopaminérgica (Swanson y cols., 2000; Smith, Daly, Fischer, Yiannoutsos, Bauer y Barkley, 2003).

En un trabajo realizado por investigadores españoles, se ha constatado la participación de los llamados factores neurotróficos (NTF) en la susceptibilidad genética del TDAH (Ribases et al., 2008). 
En definitiva, tal y como señalan Gottesman y Gould (2003), un modelo que contemple la causalidad del TDAH necesitaría ser aquel en el que "se incluyan interactivamente al mismo tiempo, las aportaciones entre el cerebro que es una máquina compleja, los factores epigenéticos y el ambiente, dando lugar a un fenotipo particular".

Otra línea de investigaciones sobre los factores etiológicos se centra en el análisis de los posibles factores de riesgo para la presentación del TDAH. Distintos investigadores han encontrado una incidencia superior de complicaciones prenatales (sangrados, toxemia, uso de medicamentos, consumo de tabaco, consumo de drogas), perinatales (prematuridad, anoxia, parto prolongado) y postnatales (muy bajo peso, malformaciones menores, convulsiones) en las historias de niños con déficit de atención con hiperactividad comparadas con las de los niños normales (Milberger, Biederman, Faraone y Jones, 1998; Botting et al., 1997; Linnet et al., 2003).

También se ha visto en diferentes estudios la repercusión de las circunstancias ambientales desfavorables. La exposición intrauterina a sustancias como el plomo y el cinc se ha señalado como factor de riesgo para padecer TDAH (Tuthill, 1996). Los traumatismos craneoencefálicos (TCE) moderados y graves en la primera infancia, así como padecer infecciones del sistema nervioso central (SNC) se han relacionado también con un mayor riesgo de TDAH (Millichap, 2008).

A este respecto, incluso, algunos estudios apuntan la importancia de variables protectoras como la coherencia intrafamiliar o la ausencia de conflictos familiares y la dedicación del tiempo suficiente a los niños con TDAH (Niederhofer, Hackenberg y Lanzendorfer, 2002; 2004). En el lado opuesto se han publicado estudios que señalan que los problemas de relación familiar son más frecuentes en familias de niños con TDAH. No está claro si esto es una consecuencia o un factor de riesgo en sí mismo (Biederman et al. 2002). 


\subsubsection{Nuevas reflexiones hacia la comprensión de la triada sintomática: Disfunciones ejecutivas}

Desde 1990 se ha avanzado positivamente en el conocimiento y la comprensión de los trastornos de la atención; Ya no se considera que se trate de una moda diagnóstica pasajera de los EEUU. La investigación ha demostrado que cuando se utilizan criterios diagnósticos homogéneos, las tasas de incidencia del TDA son elevadas en las diversas naciones y culturas (Faraone et al., 2003; Rohde et al., 2005).

A pesar de esta mayor aceptación y reconocimiento de los Trastornos de Déficit de Atención e Hiperactividad, persiste una concepción simplista del problema incluso entre los propios profesionales de la medicina, psicología y profesorado además de la mayor parte de la sociedad. Muchas personas siguen creyendo que este síndrome es simplemente la conjunción de la "famosa" triada sintomática compuesta por Hiperactividad, Impulsividad y Desatención.

Nuevos avances científicos, fruto de investigaciones recientes constituyen una nueva forma de comprensión del TDAH; En esencia se podría resumir diciendo que: El TDAH es esencialmente un trastorno complejo del desarrollo dinámico de la autogestión inconsciente del encéfalo.

Un meta-análisis con más de 6.000 pacientes indica que la población con TDAH presenta alteraciones en distintos componentes de funciones ejecutivas, como la inhibición de respuesta, la vigilancia, la memoria de trabajo y la planificación.

En la actualidad, se considera que el TDAH es un síndrome neurobiológico, de etiología compleja, debido a un fallo en el desarrollo de los mecanismos cerebrales que regulan el autocontrol. Esta pérdida de autorregulación afecta a las funciones ejecutivas que posibilitan la integración y regulación de las funciones mentales. 
Aunque la definición de disfunción ejecutiva sigue evolucionando, la mayoría de los investigadores está de acuerdo en que se debe utilizar el término para referirse a los circuitos del encéfalo que priorizan, integran y regulan otras funciones cognitivas (Vohs y Baumeister, 2004). Estas redes neuronales de gestión actúan en un intervalo de milisegundos, de manera incosciente (no en el sentido del inconsciente dinámico descrito por Freud) en el sentido de "autorregulación automática" descrito por Fitzsimons y Bargh (2004) y Hassin et al. (2005).

La evaluación de dichas funciones ejecutivas es complicada, las pruebas neuropsicológicas dan resultados mixtos. Un metaanálisis de 83 estudios realizado por Willcut y colaboradores (2005) indicó que, en los niños y adolescentes con TDAH frente a los que no lo padecían, había un deterioro significativo de medidas neuropsicológicas en inhibición de respuesta, vigilancia, memoria de trabajo y planificación, pero estas diferencias no se encontraron de forma homogénea en los pacientes con TDAH. Por tanto, muchos pacientes con TDAH, aunque no la mayoría, tienen un deterioro significativo de las pruebas neuropsicológicas, aproximadamente el 30\%.

Esto genera una cuestión: ¿qué pasa entonces en el resto de los pacientes que tienen TDAH con pruebas neuropsicológicas normales?, ¿acaso hay TDAH con Funciones ejecutivas indemnes?

Algunos investigadores lo explican concluyendo que el deterioro de las funciones ejecutivas es un trastorno asociado que se encuentra en algunas de las personas con TDAH, aunque no en todas.

Sin embargo Barkley (1997) y Brown $(2000,2005,2006)$ proponen un punto de vista alternativo que supone dos formas de comprender la relación entre el TDAH y la función ejecutiva. Ambos modelos intentan sintetizar el conocimiento de las funciones ejecutivas como mecanismo de autorregulación del encéfalo. El modelo de Barkley no se basa en los datos de pruebas neuropsicológicas, (está más influeciado por el trabajo de 
Bronowski acerca del papel crucial del lenguaje en el desarrollo humano y por trabajos neurocientificos como los de Fuster, Damasio y Goldman-Rakic), que hacen a Barkley afirmar que el TDAH es esencialmente un deterioro del desarrollo de la función ejecutiva, principalmente de la capacidad de inhibir.

En torno a ésto, Russel Barkley $(1994,1997)$ ha logrado elaborar una explicación global al conjunto de síntomas que presenta el niño con TDAH (inatención, impulsividad e hiperactividad) en base a la existencia de fallos en la inhibición conductual, que inciden de forma negativa en la acción coordinada de las cuatro funciones neuropsicológicas que permiten al sujeto una adecuada autorregulación: Memoria de trabajo, autorregulación de la motivación y del afecto, internalización del lenguaje y procesos de análisis y síntesis. Son numerosas las investigaciones empíricas que aparecen reflejadas en literatura científica sobre el tema y que muestran cómo los niños con TDAH presentan un déficit en la autorregulación (Douglas 1989; Miranda, Presentacion y Soriano 2002; Pennington y Ozonoff, 1996; Sergeant y Van Der Meere, 1990; Tannock, 1998).

La alteración de estas funciones puede manifestarse en el niño con TDAH en una serie de dificultades como son (Orjales, 2005):

- 1. Dificultad de recuperar en su memoria aquello aprendido con anterioridad para aplicarlo a su momento actual.

- 2. Dificultad en la percepción y en el control del tiempo.

- 3. Pobres habilidades de organización de la conducta en el tiempo

- 4. Dificultad en hacer referencias a hechos del pasado o del futuro, alteraciones en la utilización de conceptos temporales. 
- 5. Dificultades en tareas que requieren cooperación, participación, tener en cuenta las consecuencias para los demás, tener presente los efectos de sus acciones en el futuro respecto a temas como la salud.

- 6. Retraso en la interiorización del lenguaje y en su utilización en el proceso de pensamiento.

- 7. Dificultad para comportarse conforme a unas reglas, ya sean impuestas, acordadas por los compañeros o cuando se le da la posibilidad de generarlas por sí mismo.

- 8. Mayor dependencia emocional del entorno, mayor dificultad para automotivarse, para analizar sus propios sentimientos y tomar las medidas necesarias para salir de estados de ánimo negativos como la ansiedad, tristeza o la frustración.

Thomas E. Brown también desarrolló un modelo sobre las capacidades cognitivas complejas que están afectadas en el TDAH. Además de las funciones ejecutivas, ya mencionadas por Barkley, Brown añade como aspectos importantes, la motivación y la regulación de las emociones. Aunque el modelo por tanto, es algo similar, para Brown hay que señalar dos diferencias importantes: "los dos describimos el TDAH como un deterioro de la función ejecutiva relacionado esencialmente con el desarrollo. Las dos diferencias principales entre nuestros modelos son las siguientes: 1) Barkley limita explícitamente su modelo de modo que se aplica sólo a las personas cuyo subtipo de TDAH es combinado, que incluye síntomas hiperactivos e impulsivos. 2) Su modelo da primacía a la inhibición conductual como función ejecutiva primordial de la que dependen el desarrollo y la función de todas las demás funciones ejecutivas.

No comparto la idea de que la inhibición conductual es de la que dependen el desarrollo de las demás funciones ejecutivas" (Brown 2009) 
La atención, para Brown, es en esencia un concepto que integra a las funciones ejecutivas del cerebro. Este autor, organiza en seis grupos las alteraciones de las funciones ejecutivas que pueden afectarse cuando fracasan los sistemas atencionales. Aunque cada grupo tenga un nombre que la "etiqueta", Brown hace hincapié en aclarar que no son cualidades aisladas, como lo son la talla, el peso o la temperatura. Cada grupo se parece más a una cesta que contiene las funciones cognitivas relacionadas que dependen e interaccionan continuamente entre sí.

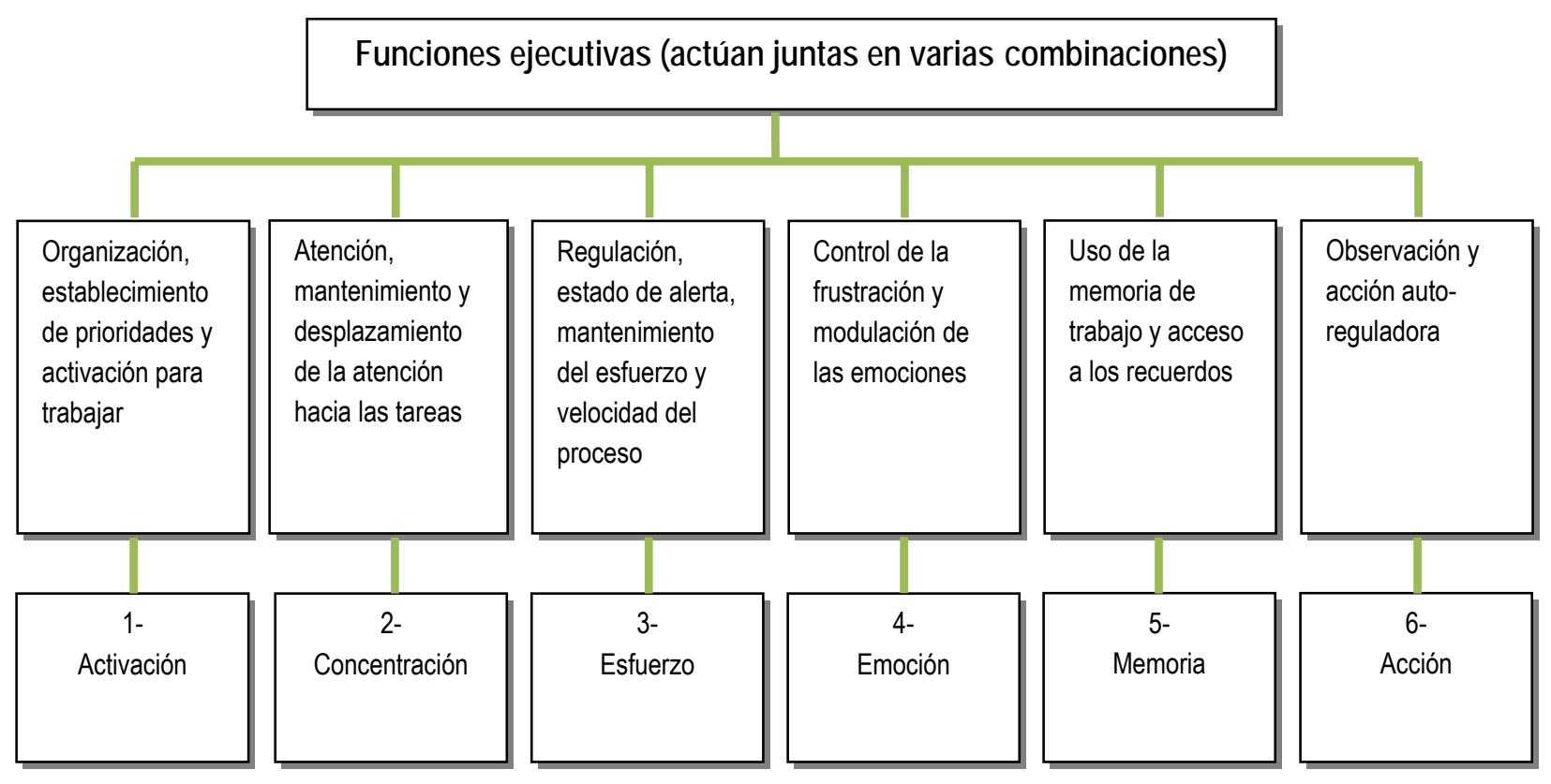

Figura 5. Alteración de las funciones ejecutivas en el síndrome de TDA. Brown 2001 C. 
- 1. Organización, establecimiento de prioridades y activación para las tareas. Los pacientes con TDAH se quejan de que tienen más dificultades que el resto de las personas para ordenar y asignar la importancia cuando tienen que enfrentarse a varias tareas. Presentan un fracaso recurrente para observar detalles críticos que lleven a tomar la decisión de cómo seleccionar la relevancia de las tareas.

- 2. Atención, mantenimiento y desplazamiento de la atención a las tareas. Ya hace más de un siglo William James (1890) describió la incapacidad para centrarse como un estado de distracción en el que la mayoría de la gente cae varias veces al día, pero en los afectados de TDAH esto se produce con mayor frecuencia e intensidad.

- 3. Regulación del estado de alerta, mantenimiento del esfuerzo y velocidad de proceso. Las personas afectas presentan con frecuencia somnolencia al realizar esfuerzo mental, dicha somnolencia se presenta a pesar de haber descansado bien y desaparece si surge algo que aumenta el interés de la tarea que están realizando. En los chicos con TDAH que describió Virginia Douglas (1999) describía que eran a la vez demasiado lentos y demasiado rápidos: sus tiempos de reacción para algunas tareas cognitivas eran muy bajos, pero en otras tareas más exigentes, tenían problemas para hacerlas más despacio y hacerlas bien. No podían regular su velocidad de procedimiento correctamente para adaptarse a las demandas del trabajo.

- 4. Control de la frustración y modulación de las emociones. Paul Wender (1987, 1995) describió como las personas con TDAH tienen una labilidad afectiva y demuestran con facilidad un estado de ánimo parecido al aburrimiento y la desmoralización, rabietas o un control insuficiente de su excitabilidad. Wender también observó como los sujetos con TDAH parecen tener una tolerancia baja a la frustración y dificultad para perseverar ante muchas tensiones a las que se 
enfrentan en su día a día, ya que tienen con facilidad sentimientos de estar "aburridos" o "estresados". Brown en sus investigaciones llega a resultados similares $(1996,2001)$.

- 5. Utilización de la memoria de trabajo y acceso a los recuerdos. Los pacientes con TDAH suelen tener buena memoria a largo plazo, pero presentan dificultades crónicas para retener la información inmediata cuando están haciendo otra cosa a la vez. El término exacto que define las dificultades de estos pacientes es el de "fallos en la memoria de trabajo", considerando como tal el retener un fragmento de la información activa cuando se trabaja con otro (por tanto no es lo mismo que la memoria a corto plazo).

- 6. Observación y autorregulación. Barkley (1997) considera el "deterioro de la capacidad de inhibición" como el problema principal de las personas con TDAH, de todas las funciones ejecutivas alteradas en el trastorno.

Juntos estos grupos constituyen el sistema de gestión cerebral ya que funcionan de una manera integrada. La mayoría de las personas con TDAH comunican dificultades crónicas importantes al menos en alguno de los aspectos de cada uno de los seis grupos, los deterioros de estos seis grupos tienden a demostrarse de forma conjunta, parecen estar clínicamente relacionados y también tienden a mejorar juntos al responder a tratamiento.

El deterioro de estas funciones ejecutivas no es exclusivo del TDAH, también se afectan en otros síndromes psiquiátricos y en etapas avanzadas del envejecimiento normal. Este deterioro de funciones puede explicar, al menos en parte, que unos diagnósticos psiquiátricos solapen síntomas con el TDAH y dé lugar a procesos comórbidos. 


\subsubsection{Factores de riesgo y pronóstico en la evolución del Trastorno de Déficit de Atención e Hiperactividad}

- Edad. En la mayor parte de los pacientes el exceso de actividad motora se reduce significativamente a medida que avanza la adolescencia, mientras que la impulsividad y la inatención tienden a mantenerse (Hart et al., 1995).

Diversos estudios de seguimiento de los síntomas a lo largo de los años (en adolescentes y adultos) presentan tasas de prevalencia dispares. Se debe a la diferencia entre los diseños metodológicos de los mismos. No obstante, en general, se puede afirmar que el $80 \%$ de los niños y niñas afectados de TDAH seguirán presentando síntomas durante la adolescencia aunque sólo alrededor de un tercio de los pacientes cumpliendo plenamente criterios de trastorno (Klein y Mannuzza 1991; Mannuzza et al., 1998; Biederman et al., 1996, 1998).

Al llegar a la edad adulta, del $30 \%$ al $65 \%$ de los pacientes presentarán el trastorno o mantendrán síntomas clínicamente significativos (Weiss et al., 1985; Biederman et al., 1996, 1998).

- Género. El pronóstico del TDAH en función del género, se evaluó en un estudio comparativo de una cohorte de 17 chicas con TDAH con una cohorte de 24 chicos con TDAH y 24 chicos control (Manuzza y Klein, 2000). Se detectaron peores puntuaciones relativas al funcionamiento académico, conductual y de funcionamiento social en las chicas frente al de los chicos. Estos resultados se invertían en la edad adulta, eran los varones los que tenían más complicaciones por mayor prevalencia de personalidad antisocial y abuso de sustancias (Manuzza y Klein, 2000).

- Nivel cognitivo. Loney et al. (1982) hallaron que el Cl era un factor predictor de trastorno de la personalidad antisocial y del abuso de alcohol. Otro estudio 
concluyó que el nivel cognitivo en la infancia, en conjunción con otros factores, es un factor predictor del pronóstico del TDAH en la edad adulta Weiss y Hechtman (1993).

- Subtipo de TDAH. Tanto la gravedad de los síntomas como que la sintomatología sea predominantemente hiperactiva-impulsivas se relacionan con el mal pronóstico del trastorno (Moffitt, 1990; Lynskey y Fergusson, 1995; Babinski et al., 1999; Merrell y Tymms, 2001)

- Psicopatología de los padres. Según un estudio realizado por Biederman (2001) los pacientes con TDAH con padres con trastorno de la personalidad antisocial tenían más ansiedad, trastorno depresivo mayor, conducta antisocial y agresividad en el seguimiento.

Los antecedentes familiares de psicopatología, y especialmente de TDAH en los padres, se asocian a un aumento del riesgo de padecer problemas psiquiátricos y emocionales de los niños en la adolescencia (August et al., 1983; Biederman et al., 1996; Fergusson et al., 1996; Fischer et al., 1993; Lambert et al., 1987105; Paternite y Loney, 1980; Taylor et al., 1996; Weiss y Hechtman, 1993).

Si además de TDAH los padres presentan problemas de conducta comórbidos, (conducta antisocial y dependencia y abuso de sustancias) también se asocian a peor pronóstico en los niños con TDAH en la adolescencia.

- Relación padres-hijos. Conflicto y/o hostilidad en la interacción paterno-filial se asocia a la conducta agresiva en la adolescencia (August et al., 1983; Biederman et al., 1996; Fergusson et al., 1996; Fischer et al., 1993; Lambert et al., 1987; Paternite y Loney, 1980; Taylor et al., 1996; Weiss y Hechtman, 1993) y en la edad adulta (Weiss y Hechtman, 1993). 
- Nivel-socioeconómico. Un bajo nivel socioeconómico parental se asocia a malos rendimientos académicos y problemas conductuales de tipo antisocial en la edad adulta del paciente TDAH (Weiss y Hechtman, 1993).

- Comorbilidad. La persistencia del TDAH se asocia con la comorbilidad con el trastorno de conducta y el trastorno de la personalidad antisocial (Biederman et al., 1996, 1998). Un peor pronóstico del TDAH se asocia a la comorbilidad con trastorno de conducta, trastorno bipolar, trastorno negativista desafiante y abuso de sustancias (Biederman et al., 2001). 


\section{CAPÍtUlO 2. ComORBiLIDAD. RELEVANCIA EN EL TRANSCURSO DEL TRASTORNO DE DÉFICIT DE ATENCIÓN E HIPERACTIVIDAD.}

\subsection{Introducción}

Comorbilidad es el término médico que se utiliza en las personas que tienen más de un trastorno. En ocasiones los investigadores utilizan este término para describir situaciones en las que ambos trastornos están presentes al mismo tiempo, por ejemplo, en un periodo de seis o doce meses. Otros consideran que, la comorbilidad es una forma más global de referirse a cualquier trastorno que se produzca a lo largo de la vida del sujeto que tiene un trastorno concreto.

La investigación ha demostrado también que los niños con TDAH presentan altos niveles de comorbilidad con otros trastornos psiquiátricos (Pliszka et al., 1999). El grupo de Kadesjo y Gillberg (2001) realizaron en Suecia un estudio que mostró que el $87 \%$ de niños que cumplían todos los criterios de TDAH tenían, por lo menos, un diagnóstico comórbido, y que el $67 \%$ cumplían los criterios para, por lo menos, dos trastornos comórbidos. Sin embargo, otro estudio realizado por Szatmari, Offord y Boyle, (1989) revela resultados más esperanzadores con tasas más bajas de comorbilidad, aunque siguen siendo altas: Un $44 \%$ de los niños con TDAH padecen al menos otro trastorno psiquiátrico, un $32 \%$ padece dos trastornos y un $11 \%$ presenta al menos tres trastornos asociados.

Varias investigaciones, apuntan que entre las comorbilidades más frecuentes se sitúan el trastorno negativista desafiante, los trastornos de aprendizaje, los trastornos por tics y los trastornos de ansiedad (Jensen et al., 1997; MTA, 1999, Barkley, 2006). 
Barkley (1981) ha sistematizado estos problemas en diferentes categorías: problemas físicos, conductuales, sociales, cognitivos, escolares y emocionales.

Existe en la actualidad, un intento de establecer subgrupos de niños en función de las comorbilidades que presentan con otros trastornos. La presencia de comorbilidades complica el proceso diagnóstico adecuado, al igual que el proceso terapéutico, dado que repercute en una evolución más desfavorable del trastorno.

En un estudio realizado con una muestra española Roselló, Amado y Bó (2000) analizaron los patrones de comorbilidad en los diferentes subtipos de TDAH:

Evaluaron la presencia asociada de trastornos externalizantes en los distintos subtipos de TDAH y encontraron diferencias significativas entre los tres subtipos en cuanto a la presencia asociada del trastorno oposicionista desafiante. En el subtipo combinado se presentaba asociado en el $44 \%$ de los casos, frente al $30 \%$ en el subtipo hiperactivoimpulsivo, y un $14 \%$ en el inatento. Por otra parte, el Trastorno disocial se presentaba en porcentajes superiores en el TDAH subtipo combinado (19\%), pero las diferencias no eran significativas respecto a los otros subtipos, el hiperactivo-impulsivo lo presentaba en un $7,7 \%$ y el inatento un $7,1 \%$.

Con respecto a los patrones de comorbilidad internalizantes (ansiedad, fobia, depresión) los resultados indicaron que los tres subtipos de TDAH muestran patrones de comorbilidad de tipo internalizante, sin que puedan establecerse diferencias significativas entre ellos; el subtipo combinado en un $38,9 \%$ de los casos, seguido del predominantemente inatento en un $32,2 \%$ y del subtipo hiperactivo impulsivo en un $30,8 \%$. 
La tabla siguiente muestra las comorbilidades más frecuentes en los niños y adolescentes con TDAH, según la GPC (2010).

\begin{tabular}{|c|c|}
\hline \multicolumn{2}{|c|}{ COMORBILIDAD CON TDAH } \\
\hline Trastorno & Tasa aproximada en niños con TDAH \\
\hline $\begin{array}{l}\text { Trastornos del aprendizaje (trastorno de la lectura, } \\
\text { del cálculo) }\end{array}$ & $\begin{array}{l}\text { Entre el } 8 \text { y el } 39 \% \text { trastorno de la lectura, del } 12 \text { al } \\
30 \% \text { trastorno del cálculo }\end{array}$ \\
\hline $\begin{array}{l}\text { Trastorno del desarrollo de la coordinación motora } \\
\text { (TDCM) / Retraso de la coordinación motora }\end{array}$ & $\begin{array}{l}\text { El } 47 \% \text { cumplen criterios de TCDM / El 52\% tienen } \\
\text { retraso en la coordinación motora }\end{array}$ \\
\hline $\begin{array}{l}\text { Trastornos del desarrollo del habla, trastornos } \\
\text { expresivos (pragmáticos) }\end{array}$ & $\begin{array}{l}\text { Hasta el } 35 \% \text { inicio tardío del habla / entre el } 10 \text { y } \\
\text { el } 54 \% \text { dificultades expresivas, principalmente } \\
\text { pragmáticas }\end{array}$ \\
\hline Trastornos generalizados de desarrollo & $\begin{array}{l}\text { Hasta el } 26 \% \text { de los niños con trastorno } \\
\text { generalizado del desarrollo (TGD) pueden } \\
\text { presentar TDAH tipo combinado }\end{array}$ \\
\hline Trastorno negativista desafiante & Entre el 40 y el $60 \%$ \\
\hline Trastorno disocial & $14,30 \%$ \\
\hline Trastorno de tics / Síndrome de Tourette & $10,90 \%$ \\
\hline Trastorno por abusos de sustancias & $\begin{array}{l}\text { En la adolescencia el riesgo es } 2-5 \text { veces mayor } \\
\text { que en controles normales, si hay comorbilidad } \\
\text { con trastorno disocial }\end{array}$ \\
\hline $\begin{array}{l}\text { Trastorno del estado de ánimo: depresión mayor y } \\
\text { trastorno bipolar }\end{array}$ & $3,8 \%$ y $2,2 \%$ respectivamente \\
\hline Trastorno de ansiedad & Entre 25 y $35 \%$ \\
\hline Trastornos del sueño & Entre el $30-60 \%$ \\
\hline
\end{tabular}

Figura 6. Tabla 3. Comorbilidad con TDAH. GPC.

Biederman, Newcorn y Sprich (1991) en un una revisión de estudios sobre la comorbilidad del TDAH, concluyen que existe una asociación considerable entre este trastorno y el trastorno de conducta, oposicionismo, trastornos afectivos, ansiedad, dificultades en el aprendizaje, síndrome Gilles de la Tourette y trastorno de la personalidad borderline. De entre ellos, los más frecuentes son los trastornos de 
conducta y oposicionismo, la ansiedad, trastornos afectivos, problemas de lenguaje y dificultades de aprendizaje. En la misma línea se sitúan los datos del reciente trabajo de Poeta y Nieto (2006) en Brasil. Además de poner de manifiesto que los factores de riesgo pre-natal y perinatal juegan un importante papel en la aparición del trastorno, los autores encontraron que, en su muestra de niños con TDAH, un $85.6 \%$ de ellos presentaba comorbilidad, siendo los trastornos comórbidos más comunes el trastorno de conducta (39.2\%) y el oposicionismo-desafiante (20.6\%).

Por otra parte, los estudios recientes parecen indicar que los patrones de comorbilidad se mantienen relativamente estables en el mismo individuo a lo largo de los años y la presencia de comorbilidad complica, lógicamente, el pronóstico y repercute en peores niveles de funcionamiento psicosocial. En base a ello, las líneas futuras de investigación pueden establecer diferentes subgrupos con factores de riesgo, cursos clínicos, factores neurobiológicos y respuestas terapéuticas diferentes.

Por tanto, realizar la evaluación completa del TDAH en niños y adolescentes significa hacer una valoración de los trastornos psiquiátricos y del aprendizaje que se pueden presentar asociados. La presencia de comorbilidad condiciona la presentación clínica, el pronóstico, el plan terapéutico y la respuesta al tratamiento. El diagnosticar a un niño de TDAH, conlleva establecer la presencia de una patología de inicio temprano, con alteraciones crónicas en las funciones cognoscitivas y conductuales cuyo buen funcionamiento es necesario para que se produzca adecuadamente la adaptación en la escuela, la familia y en la sociedad, es decir, en todos los contextos de desarrollo. 


\subsection{Clasificación conceptual de las posibles comorbilidades más prevalentes}

EI TDAH comprende el deterioro crónico de muchas funciones cognitivas. Las personas que lo padecen, tienen además dificultades en otros aspectos de su aprendizaje, la regulación emocional, el funcionamiento social o la conducta.

En la actualidad los diagnósticos psiquiátricos consisten en un conjunto de categorías, encasillamientos conceptuales que clasifican aspectos complicados del funcionamiento humano. En el DSM-IV se enumeran más de doscientas categorías diagnósticas independientes, descritas cada una de ellas como si fuera una entidad individual. En estas categorías se dividen los deterioros del funcionamiento cognitivo, emocional y conductual del ser humano. Éstas son el producto del trabajo de comités sujetos a diversas variables circunstanciales, asi como al momento histórico en el que se desarrollaron.

Bruce Pennington, en 2002, propuso un nuevo marco en el que integrar los conocimientos neurocientíficos existentes sobre los trastornos psiquiátricos. Este autor diferencia entre tres grupos de síndromes: trastornos de la motivación, trastorno de la regulación de la acción y trastornos del lenguaje y del desarrollo cognitivo.

Thomas E. Brown, en 2006, adapta estas categorías de Pennington para describir algunas de las formas en las que los síntomas de TDAH se superponen a otras categorías de trastornos psiquiátricos dando origen a comorbilidad. Las alteraciones de la función ejecutiva caracterizan la mayoría de estos diagnósticos. Estas tres agrupaciones, creadas según elementos comunes importantes, comprenden varios trastornos psiquiátricos y trastornos del aprendizaje que son frecuentes en el TDAH. Todos estos trastornos comprenden el deterioro de las funciones ejecutivas y también otras funciones específicas de este trastorno. 
Para la estructuración de nuestro estudio, nos ha parecido adecuado seguir la clasificación de Brown. Desde clasificaciones diagnósticas como la DSM-IV-TR las posibilidades comórbidas son múltiples. La sistematización de Brown, nos permite delimitar las patologías psiquiátricas que con más frecuencia se presentan conjuntamente con el Trastorno de Déficit de Atención e Hiperactividad. A continuación, en la figura 7, se muestran los tres grandes grupos diagnósticos y las diversas patologías clínicas que se engloban en ellos.

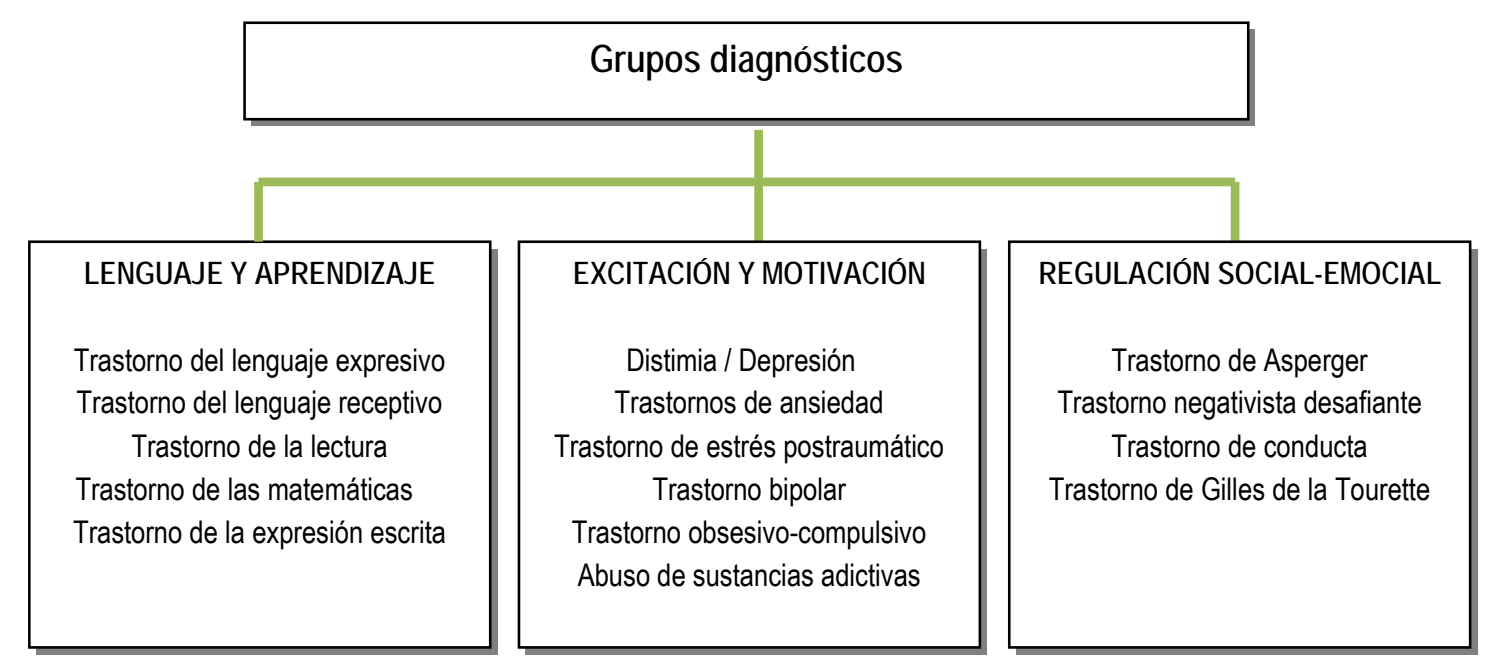

Figura 7. Alteraciones de la función ejecutiva. Agrupaciones de trastornos. T.E.Brown (2006). 


\subsection{Paso a paso por el proceso comórbido}

\subsubsection{Trastornos del lenguaje y aprendizaje}

Aprendizaje:

El TDAH y los trastornos del aprendizaje son problemas importantes de la infancia que con frecuencia aparecen juntos y persisten en la adolescencia y edad adulta. Aproximadamente el $15-40 \%$ de los pacientes con trastornos del aprendizaje cumplen criterios diagnósticos de TDAH (Willcutt y Pennington, 2000) son estudios con muestras comunitarias. En muestras clínicas hasta el $70 \%$ de los niños con TDAH pueden tener un trastorno del aprendizaje (Mayes y Calhoun, 2006). Aproximadamente el $4 \%$ de la población infantil tiene TDAH y trastornos del aprendizaje comorbidos (Pastor y Reuben, 2008).

Para Barkley (1982), del 60 al $80 \%$ de los niños con TDAH manifiestan dificultades académicas, fruto de los déficits de atención, la impulsividad, otros elementos psicopatológicos asociados, la calidad de los refuerzos ambientales y la propia capacidad de desarrollar mecanismos compensadores. Derivado de esas dificultades de atención, memoria y control ejecutivo manifiestan menor rendimiento escolar con peores calificaciones y mayor porcentaje de casos que deben recibir apoyo en las aulas de educación especial.

El bajo rendimiento académico de los niños TDAH está asociado, principalmente, a las dificultades específicas en el aprendizaje de la lectura, la escritura, las matemáticas y la solución de problemas. Se puede apreciar una prevalencia de dificultades lectoras que oscila entre un $15 \%$ y un $50 \%$ (August y Ganfinkel, 1990), en matemáticas entre un $24 \%$ y un $60 \%$ (Semrud-Clikerman y cols., 1992) y en deletreo entre un $24 \%$ y $60 \%$ (Barkley, 1998). Estudios recientes señalan que alrededor del $70 \%$ de niños TDAH presentan alguna dificultad de aprendizaje (Mayes, Calhoum y Crowell, 2000). 
En lo relacionado a Trastorno de la Lectura (T. del Aprendizaje):

Sally Shaywitz en 2003 describió que "el primer descubrimiento que hace un niño en su camino a la lectura es darse cuenta de que las palabras habladas tienen partes, pequeñas piezas de sonido...ha desarrollado entonces la conciencia fonémica...la capacidad de identificar, apreciar y manipular los sonidos". Shaywitz evidenció, que el 70$80 \%$ de los niños aprenden a traducir el código de las letras escritas a sonidos hablados sin gran dificultad, pero el $20-30 \%$ restante tienen dificultades persistentes de aprendizaje, en mayor o menor grado, para convertir las combinaciones de letras en palabras habladas. Esta dificultad para procesar los fonemas (y no la tendencia a la inversión de las letras y los números) es el principal componente de la dislexia (o trastorno de la lectura). La dislexia se asocia a deterioros específicos de la función cerebral. Este mismo autor, en 2002, comparo las imágenes funcionales de resonancia magnética de los cerebros de niños con dislexia y de lectores sanos, detectando alteración del funcionamiento en los circuitos específicos del hemisferio izquierdo que han resultado ser fundamentales para la lectura.

El $40 \%$ de los niños con TDAH también presentan un trastorno de la lectura asociado (cumpliendo los criterios diagnósticos del manual DSM-IV). El principal vínculo es la presencia o no en el paciente con TDAH de déficit de atención (no si presenta hiperactividad o impulsividad) (Willcutt y Pennington, 2000). El estrecho vínculo entre la falta de atención y el deterioro de la adquisición de las habilidades lectoras se detecta en estudios tanto longitudinales como transversales (Carroll et al., 2005; Dally, 2006; McGee et al., 2002; Rabiner y Coie, 2000).

En la lectura, las dificultades pueden aparecer fundamentalmente en la adquisición de una velocidad lectora adecuada, debido a las exigencias de atención que conlleva la adquisición de esta habilidad. Las dificultades de atención, junto a las propias de la escasa memoria de trabajo que presentan estos alumnos, pueden conllevar también 
problemas en la comprensión de textos escritos sobre todo si existen párrafos largos, frases que no inician con el sujeto o si se trata de textos expositivos que exigen integrar la información. Miranda, García y Jara (2001) encuentran una posible interacción entre los déficits cognitivos esenciales de los diferentes subtipos del TDAH y las habilidades cognitivas implicadas en la lectura (atención selectiva en el subtipo impulsivo e inhibición en el subtipo combinado), encontrando ejecuciones diferentes en exactitud, velocidad y comprensión lectora. Los sujetos TDAH subtipo inatento, manifestaban más lentitud en el procesamiento de palabras, y mayor deficiencia en comprensión lectora que los sujetos TDAH subtipo combinado. También manifestaban dificultad en la velocidad de lectura de textos, aunque en este aspecto las diferencias no eran tan elevadas.

La superposición entre las dificultades de lectura y el TDAH o los síntomas de TDAH persiste hasta la adolescencia y la edad adulta (Bierderman et al., 2005; Ghelani et al., 2004; Goldston et al., 2007).

En lo relacionado a Trastorno de las Matemáticas (T. del Aprendizaje):

En 1994 Geary describió dos tipos distintos en niños con discapacidad para las matemáticas, el primero implica dificultad para representar los datos aritméticos o para recuperarlos de la memoria a largo plazo (dificultad para recordar datos aritméticos básicos como 5+9=14), el segundo que presenta dificultades para ejecutar los procedimientos aritméticos, como al llevar o calcular una suma compleja o al ejecutar recuentos para solucionar problemas de sumas sencillas.

El deterioro de la lectura como el de las matemáticas, los trastornos del aprendizaje, son habilidades cognitivas deficitarias que se sabe son hereditarias pero se desconocen los mecanismos cerebrales implicados.

La numeración y el cálculo exigen importantes niveles de atención y control para mantener la información numérica. La dificultad para acceder de forma rápida y precisa al 
nombre de los números y al establecimiento de la correspondencia uno a uno provoca un embotellamiento en la memoria de trabajo que impide manejar la información de forma fluida. La adquisición de automatismos del cálculo que dependen de procedimientos de repetición de asociaciones $(2+2=4)$, exige vigilancia e implicación activa por parte de procedimientos del niño, ya que debe mantener simultáneamente en la memoria todos los términos de la igualdad y cuando la capacidad es limitada se producen pérdidas de información. Además, es frecuente en muchos niños TDAH que desarrollen estrategias inmaduras de conteo. La impulsividad les puede llevar, además, a cambiar signos, modificar la secuencia de las operaciones, etc.

La solución de problemas exige grandes recursos atencionales, de memoria de trabajo y habilidades de planificación, organización y estrategias de comprensión que son deficitarias en niños TDAH. Por ello, señalan Miranda y García (2003), "no es extraño que estos niños respondan al problema sin leerlo con detenimiento o incluso si lo leen, debido a fallos en su repertorio estratégico, no pueden recordar lo que se les pregunta, confunden datos relevantes, o no pueden diferenciar entre la información que aporta el texto y la información que se desconoce y que hay que encontrar. Además las dificultades en el sistema ejecutivo impiden la aplicación de una estrategia organizada para la resolución del problema".

Los estudios actuales sobre el tema apuntan a la existencia del solapamiento del déficit de atención con el funcionamiento ejecutivo. En este sentido, en un estudio realizado por Miranda, Meliá, Marco, Roselló y Mulas (2006) con 78 niños de 6 a 13 años, de los cuales 33 presentaban TDAH, 15 presentaban dificultades de matemáticas (DAM), 15 presentaban TDAH y DAM y 15 niños control. Se les administraron pruebas dirigidas a evaluar procesos cognitivos y conocimiento matemático aplicado. Los resultados muestran que los tres grupos con problemas mostraron déficit de atención y de memoria de trabajo. Cabe destacar que el grupo con DAM presentaba déficit específico en el 
recuerdo de la información temporovisoespacial, en cambio el grupo TDAH mostró un déficit específico en el control inhibitorio.

La superposición entre TDAH y trastorno de las matemáticas, es importante, con estimaciones que varían entre el 10-60\% (Barkley, 1990; Semrud-Clikeman et al., 1992; Shalev et al., 2005). La superposición entre el TDAH y la discalculia es menos frecuente (11\%) cuando se excluyen los casos de TDAH que presentan trastorno de la lectura comórbido (Monteaux et al., 2005). Es preciso destacar, que todas las estimaciones disponibles proceden de muestras derivadas a consulta y no de muestras epidemiológicas, y por tanto pueden estar aumentadas artificialmente por sesgos de evaluación (Berkson, 1946).

\section{Lenguaje:}

El Trastorno de la Expresión Escrita no está reconocido y diferenciado como tal. Ello hace que la evaluación de la frecuencia con la que se asocia al TDAH sea difícil de determinar. Muchos niños con TDAH tienen una mala ortografía y una caligrafía descuidada, irregular y con frecuencia ilegible (Barkley, 1990). La escritura manuscrita exige la puesta en marcha de habilidades viso-espaciales, motricidad fina y coordinación ojo-mano. "Casi la mitad de los escolares TDAH poseen escasas capacidades de motricidad fina, de forma que son frecuentes manifestaciones disgráficas como letras irregulares, tachones, interlineado y márgenes ondulantes, soldaduras, etc" (Miranda y cols., 2001). Las composiciones escritas de estos niños TDAH son de peor calidad, con textos más cortos, utilizan un vocabulario pobre y omiten los componentes fundamentales de la historia.

En lo referente a los Trastornos de la Comunicación, un estudio comparó niños con TDAH frente a niños con trastorno de lectura, con el objeto de evaluar si presentaban dificultades en la comunicación. Determinó que los niños con TDAH hablan más alto, no modulan el volumen de la voz, y hablan durante mucho más tiempo de un tirón. No se encontró que los niños con trastorno de lectura tuvieran dificultades del habla. Se piensa 
que la falta de pausas y el habla continua se debe a la falta de planificación de la salida verbal inmediatamente posterior (Kircher et al., 2004). Las cortas pausas del habla de los niños con TDAH parecen demasiado rápidas para permitir el pensamiento, la organización y la planificación de la información, y también son demasiado cortas para permitir que los demás participen de la conversación.

Se puede afirmar que los niños con TDAH parecen tener más problemas en el desarrollo del lenguaje que los niños normales, observándose dificultades tanto en los aspectos de forma como de contenido del lenguaje.

Investigaciones recientes realizadas por Ygual, Miranda y Cervera (2000) han encontrado que en los niños con TDAH se evidencian ejecuciones significativamente inferiores en la producción verbal con procesos de simplificación del habla importantes.

Los hallazgos asimismo indican que los niños con TDAH poseen un nivel inferior de conocimientos semánticos que los niños del grupo control, con peores resultados en el establecimiento de relaciones analógicas, peor vocabulario comprensivo y dificultad en definir palabras conocidas. En cuanto a la fluidez verbal, se aprecian tendencias a circunloquios y uso de palabras inespecíficas (p. ej., "trasto", "esa cosa"...) al igual que en habilidades narrativas, donde se observan relatos de historias más cortas, con menor información, más desestructuradas y menos coherentes (Tannock et al., 1993, 1995; Oram et al., 1999).

Es de destacar que el rendimiento inferior en todos estos aspectos está muy mediado por las exigencias propias de las tareas presentadas. Éstas precisan, por parte del niño, la puesta en marcha de mecanismos cognitivos que en el TDAH están afectados como la atención auditiva, memoria de trabajo, procesamiento simultáneo de la información, control inhibitorio, etc. 


\subsubsection{Trastornos de la regulación de la excitación-motivación}

\section{Trastorno Depresivo:}

Los síntomas de TDAH son prevalentes en pacientes con Trastorno de Depresión Mayor (TDM) y viceversa. Esto se ha demostrado en estudios de niños derivados a la consulta (Biederman, 2004; Biederman y cols., 1995), muestras de pacientes ingresados (Alessi y Magen, 1998), estudios poblacionales (Angold y cols, 1999; K.D.Chang y cols., 2000) y consultas de atención primaria (Brusch y cols., 2002).

Las tasas acerca de la prevalencia con la que coexisen TDAH Y TDM varían de unos estudios a otros, ya sean muestras clínicas o poblacionales. No obstante los datos son homogéneos al indicar que ambos síndromes coexisten con frecuencia.

Para autores como Spencer Biederman y Wilens (1999), el TDAH coexiste con la depresión en porcentajes superiores al 30\%. Para algunos autores como Borden (1987), las dificultades que experimentan los niños hiperactivos pueden ocasionar una acumulación de frustraciones que precipiten síntomas depresivos. Mientras el niño con desarrollo normal cada vez es más exacto en la evaluación de sus actuaciones y hace más atribuciones internas, los niños hiperactivos muestran más atribuciones externas sobre los resultados positivos y negativos y ejercen un escaso control personal sobre los acontecimientos. Suelen tener un bajo nivel de expectativas y un bajo autoconcepto debido a sus frecuentes fracasos, de manera que obtienen puntuaciones más altas en depresión infantil. Son los pacientes TDAH subtipo combinado los que parecen tener más probabilidad de padecer síntomas depresivos (Carlson et al., 2005), posiblemente por padecer mayor deterioro funcional a nivel de relación social recibiendo más actitudes de rechazo. A pesar de que no existen estudios concluyentes, con cierta frecuencia se ha encontrado que los niños que poseen sintomatología depresiva suelen tener padres con ese problema, de forma que la interacción familiar parece jugar un importante papel en el desarrollo de estos síntomas en casos de niños con TDAH. 
Al parecer, las tasas de comorbilidad parecen variar según el sexo a lo largo de toda la vida y demuestran un aumento de la frecuencia de comorbilidad en adultos frente a adolescentes y niños. Otro estudio realizado por Biederman sobre pacientes derivados a la consulta (2004) encontró que el $11 \%$ de las niñas tenía TDM comórbido, frente al $72 \%$ de las mujeres adultas que padecían TDAH y TDM. En los varones las tasas fueron más comparables con $21 \%$ de niños y un $35 \%$ de adultos que tenían ambos diagnósticos.

Según las consideraciones más actuales, Brown (2010) habla de considerar los síntomas de depresión y de TDAH como un continuo de intensidad desde un subsíndrome hasta un trastorno. Se establecería diagnóstico sindrómico cuando la intensidad y la frecuencia de los síntomas llegasen a un determinado "nivel". Esto tiene relevancia ya que diversos estudios han detectado en los pacientes TDAH subsíndromes o síntomas subliminales que también tienen relevancia. Así pues, muchos datos indican que los síntomas subliminales producen deterioro (Lewinsohn et al., 2000), tienen implicaciones genéticas (Lewinsohn et al., 2003) y son estables hasta la edad adulta (Pezawas et al., 2003). Todos los niveles de gravedad de TDAH, pueden aparecer simultáneamente con diversos niveles de depresión y viceversa.

\section{Trastorno Bipolar:}

El TDAH y el Trastorno Bipolar (TB) comparten muchos síntomas (Giedd, 2000; Kent y Craddock, 2003; Milberger et al., 1995) como actividad psicomotriz, distraibilidad, conducta desinhibida, impulsiva e intrusiva. Sin embargo, mientras el TDAH es un trastorno crónico del desarrollo, el TB es un trastorno episódico.

Los síntomas transversales del TDAH y la manía son prácticamente indistinguibles (Carlson, 1990; Gield, 2000). 


\section{SUPERPOSICIÓN DE SÍNTOMAS ENTRE LA MANÍA Y EL TDAH}

\begin{tabular}{|c|c|}
\hline Criterios de Manía & Criterios de TDAH \\
\hline Estado de ánimo elevado y expansivo & $\begin{array}{l}\text { (Aunque no forma parte de los criterios del TDAH, } \\
\text { el texto describe "el payaso de la clase", la } \\
\text { búsqueda de atención y la conducta tonta en niños } \\
\text { con TDAH, y esto se debe distinguir de la conducta } \\
\text { tonta que se produce como consecuencia de una } \\
\text { alegría verdadera) }\end{array}$ \\
\hline Estado de ánimo irritable & $\begin{array}{l}\text { Características asociadas: baja tolerancia a la } \\
\text { frustración, rabietas }\end{array}$ \\
\hline $\begin{array}{l}\text { Aumento de la actividad dirigida a los objetivos o } \\
\text { agitación psicomotora }\end{array}$ & $\begin{array}{l}\text { Con frecuencia corre por ahí, con frecuencia deja } \\
\text { su asiento, con frecuencia está "en marcha", } \\
\text { impulsado por un motor }\end{array}$ \\
\hline $\begin{array}{l}\text { Más hablador de lo habitual, presión para seguir } \\
\text { hablando }\end{array}$ & Con frecuencia habla mucho \\
\hline Distraibilidad & Con frecuencia se distrae por estímulos externos \\
\hline $\begin{array}{l}\text { Participación excesiva en actividades con elevado } \\
\text { potencial de consecuencias dolorosas }\end{array}$ & $\begin{array}{l}\text { Participación en actividades con elevado potencial } \\
\text { de consecuencias dolorosas por falta de previsión }\end{array}$ \\
\hline $\begin{array}{l}\text { Disminución de la necesidad de sueño (es decir, } \\
\text { no duerme mucho y no se siente cansado) }\end{array}$ & $\begin{array}{l}\text { (Con frecuencia tiene problemas para acostarse } \\
\text { por la noche y se levanta pronto, aunque } \\
\text { habitualmente hay datos de que necesita sueño } \\
\text { porque está gruñón e irritable al día siguiente o se } \\
\text { despierta tarde cuando tiene oportunidad. }\end{array}$ \\
\hline Autoestima exagerada o grandiosidad & $\begin{array}{l}\text { (No forma parte de la sintomatología del TDAH, } \\
\text { aunque los niños con TDAH con frecuencia } \\
\text { fanfarronean, niegan que tengan problemas o no } \\
\text { aprecian el peligro, por lo que se podría inferir una } \\
\text { autoestima exagerada) }\end{array}$ \\
\hline $\begin{array}{l}\text { Fuga de ideas } 0 \text { experiencias subjetivas de } \\
\text { pensamientos aceleradas }\end{array}$ & $\begin{array}{l}\text { (Se produce un trastorno del lenguaje pragmático, } \\
\text { con los consiguientes problemas para el } \\
\text { mantenimiento de los temas, en hasta el } 40 \% \text { de } \\
\text { los niños con TDAH. Se debe distinguir de la } \\
\text { verdadera fuga de ideas. Es probable que la } \\
\text { capacidad metacognitiva de pensar sobre los } \\
\text { propios pensamientos y su velocidad varíe con la } \\
\text { edad) }\end{array}$ \\
\hline $\begin{array}{l}\text { Estos síntomas deben representar un cambio } \\
\text { diferenciado del desempeño de funciones }\end{array}$ & $\begin{array}{l}\text { Estos síntomas deben ser crónicos, y deben } \\
\text { haber empezado antes de los siete años }\end{array}$ \\
\hline
\end{tabular}

Figura 8. Superposición de síntomas entre la manía y el TDAH 
Existe mucha controversia a la hora de definir los síntomas que se consideran diagnósticos en edades infantiles (Harrington y Myatt 2003) y esto da lugar a diferentes tasas de diagnóstico y evoluciones (Dubicka y cols., 2007; Jairam y cols., 2004; Meyer y cols., 2004).

La frecuencia del TDAH en pacientes con trastorno bipolar parece depender de la edad de la población de estudio. Las tasas de niños prepuberales varía entre el $70-90 \%$ (Biederman y cols., 1996a; Findling y cols., 2001; Geller y cols., 2000) y hay un claro predominio masculino según los resultados de estos tres estudios. En el caso de inicio de TB de inicio en adolescentes las tasas de TDAH son menores y más variables. Kutcher et al., 1998 encontraron que el 11\% de su muestra de adolescentes con TB I tenía TDAH comorbido. Evidentemente estas tasas aumentan si se incluyen en el estudio los pacitentes con TB II.

Las tasas de TDAH en pacientes con TB también son variables. En dos muestras de niños con TDAH, Biederman y colaboradores (1996), identificaron que el 11 y el $20 \%$ tenían TB. Cuatro años después del estudio original se aplicó a un total del $21 \%$ de los jóvenes un diagnóstico a lo largo de la vida de TB (Biederman y cols., 2004).

Parece existir consenso en afirmar que la presencia de antecedentes y síntomas de la combinación de trastorno bipolar y de déficit de atención e hiperactividad genera mayor deterioro que padecer alguno de los dos aisladamente. La evolución, sin una intervención eficaz, es a menudo abuso de sustancias, conducta antisocial, depresión, historia laboral inadecuada y relaciones tormentosas. 


\section{Trastorno de Ansiedad:}

Hay muchos tipos de trastornos de ansiedad:

- La ansiedad de separación se presenta cuando el niño sufre una ansiedad excesiva cuando se separa o espera separarse del hogar o de las personas a las que está unido.

- Las fobias específicas afectan al sujeto haciéndole mostrar un gran temor cuando se enfrentan a alguna situación concreta.

- La fobia social, o trastorno de ansiedad social, es un miedo intenso, persistente y exagerado a sufrir situaciones embarazosas cuando el sujeto interacciona o participa con otras personas.

- Las crisis de ansiedad se caracterizan por episodios breves y recurrentes de miedo intenso que aparecen bruscamente cuando no hay un peligro real y no se espera que lo haya.

- El trastorno de ansiedad generalizada es un patrón más amplio y persistente de preocupación y miedo crónicos ante la expectativa de que algo malo pueda suceder.

EI TDAH y los Trastornos de Ansiedad son los problemas psiquiátricos más prevalentes en la infancia y en la adolescencia (Anderson y cols., 1987; Bird y cols., 1988; Yoo y cols., 2005). Además a menudo ambos trastornos aparecen juntos en la misma persona, el TDAH y los T. Ansiedad aparecen juntos en el $25-33 \%$ de los pacientes en muestras epidemiológicas y clínicas (Bierderman y cols., 1991b; Jensen y cols., 2001). Como es lógico se encuentran mayores tasas de comorbilidad en las muestras clínicas (Berkson, 1946). Es posible que el $30-40 \%$ de los niños con TDAH que acuden a consulta cumplan criterios para uno o más trastornos de ansiedad. 
La siguiente tabla muestra una revisión de los resultados de recientes estudios a este respecto.

\begin{tabular}{|c|c|}
\hline \multicolumn{2}{|c|}{$\begin{array}{l}\text { PREVALENCIA DEL TDAH Y DE TRASTORNOS DE ANSIEDAD (ANS) } \\
\text { COMÓRBIDOS EN ESTUDIOS CLÍNICOS }\end{array}$} \\
\hline Estudio & Comorbilidad \\
\hline ANS & ANS con TDAH (\%) \\
\hline Last et al., 1987 & $20-27$ \\
\hline Last et al., 1992 & $17-18$ \\
\hline \multirow{2}{*}{ Strauss et al., 1988} & 35 (<12 años) \\
\hline & 9 ( $\geq 12$ años) \\
\hline TDAH & TDAH con ANS (\%) \\
\hline Biederman et al., 1991b & $30^{a}$ \\
\hline Biederman et al., 1999 & $34^{\mathrm{b}}$ \\
\hline Byun et al., 2006 & 33 \\
\hline Jensen et al., 1993 & 27 \\
\hline \multirow{2}{*}{ Lahey et al., 1987} & $43(\mathrm{TDA} / \mathrm{-H})$ \\
\hline & $10(T D A /+H)$ \\
\hline Livingston et al., 1990 & 40 (ANS/ estado de ánimo) \\
\hline Munir et al., 1987 & 27 \\
\hline Pliszka, 1989 & 28 \\
\hline Riesgo de ANS ylo depresión & TDAH + ANS \\
\hline Keller et al., 1992 & $16^{\mathrm{b}}$ \\
\hline McCellan et al., 1990 & $32^{\mathrm{a}}$ \\
\hline \multicolumn{2}{|l|}{ Otros } \\
\hline \multirow{2}{*}{ Woolston et al., 1989} & $38^{\mathrm{a}}$ \\
\hline & $23^{c}$ \\
\hline \multicolumn{2}{|c|}{$\begin{array}{l}\text { Nota: ANS/estado de ánimo = trastornos de ansiedad y/o del estado de ánimo; TDA/+H = trastorno de } \\
\text { déficit de atención con hiperactividad; TDA/-H = trastorno de déficit de atención sin hiperactividad; } \\
\text { TDAH+ANS = trastorno de déficit de atención con hiperactividad y trastornos de ansiedad comórbidos. } \\
\text { a Niños de ambos sexos con ANS que también tenían TDAH. } \\
\text { b Niñas con TDAH que también tenían uno o más ANS; estudio restringido a niñas. } \\
\text { c Niños de ambos sexos con TDAH que también tenían ANS }\end{array}$} \\
\hline
\end{tabular}

Figura 9. Prevalencia del TDAH y de trastornos de ansiedad (ANS) comórbidos en estudios clínicos. Brown (2010).

Por otro lado, tal como señalan Miranda, Amado y Jarque (2001), las manifestaciones de ansiedad pueden ser frecuentes y se concretan en "dificultades por separarse de los padres, evitación de situaciones sociales y excesiva preocupación por acontecimientos específicos". 
Desde un punto de vista clínico, hay una diferencia importante que poseen los niños con TDAH que asocian trastornos de ansiedad, y es que estos niños son "aprensivos" y se preocupan, en contraste con los no ansiosos, de su rendimiento en las diversas áreas académicas, atléticas, sociales y de conducta.

\section{Trastorno Obsesivo Compulsivo:}

EI TOC es según la DSM-IV-TR (American Psychiatric Association, 2000) el trastorno en niños, adolescentes o adultos que tienen pensamientos perturbadores recurrentes (obsesiones) y/o conductas repetitivas crónicas que se ven abocados a realizar (compulsiones) para evitar una marcada ansiedad generadora de importante deterioro en la actividad diaria del individuo. El contenido específico de las obsesiones y de las compulsiones es muy variable. Algunos factores sintomáticos frecuentes son comprobar, buscar la simetría y el orden, limpiar, lavar y acumular objetos. EI TOC habitualmente se inicia al final de la adolescencia o al comienzo de la edad adulta, aunque muchos casos realmente comienzan en la infancia alrededor de los 10 años. Tanto en niños como adultos se trata de un trastorno de curso episódico, aunque aproximadamente el $10 \%$ de los casos tiene un deterioro progresivo.

Recientes publicaciones aportan datos de que algunas formas de TOC de inicio temprano están asociadas genéticamente al TDAH. Geller y cols., (2007a, 2007b) encontraron que familiares en primer grado de niños con TDAH tenían tasas mayores de lo esperado de TOC, y que familiares de primer grado de niños con TOC tenían tasas mayores de lo esperado de TDAH. La mejor interpretación a este hecho puede ser que exista un subtipo de TOC pediátrico relacionado con TDAH comórbido.

Se ha observado que el TOC es comórbido con muchos trastornos psiquiátricos, como síndrome de Tourette, trastornos de ánimo, de ansiedad y de conducta perturbadora 
(Geller y cols., 1996), este estudio no evaluaba el TDAH. En otros estudios que sí evaluaban el TDAH, los porcentajes de los que cumplían criterios para el diagnóstico de TDAH variaron, pero la variabilidad se puede achacar a diferencias metodológicas. Toro y cols., 1992 encontraron una superposición del 6\% entre TOC y TDAH, mientras que otros investigadores encontraron superposiciones del 10\% (Swedo y cols., 1989), el 16\% (Hanna, 1995) y el 32\% (Geller et al., 1996).

\section{Abuso de Tóxicos:}

Diversas revisiones independientes, encontraron datos convergentes que indican que la presencia conjunta de TDAH y Trastorno por Consumo de Tóxicos es mayor de lo esperado por azar y es bidireccional, habiéndose descrito en muestras de adolescentes y adultos consumidores de sustancias, como en pacientes diagnosticados de TDAH durante el desarrollo (Wilens 1998, 2002, 2004; Wilens y cols., 1995; Faraone y cols., 2007; Levin y Kleber 1995; Levin y cols., 1999; Schubiner y cols., 1995; Bukstein y cols., 1989; Weinberg y Glantz 1999; Weinberg y cols., 1998).

Estudios prospectivos de niños con TDAH han aportado datos de que, el grupo con trastorno disocial o con trastorno bipolar comórbido con el TDAH, tiene mayor riesgo de padecer trastornos por consumo de sustancias y morbilidad grave (Biederman y cols., 1997; Lambert y cols., 1997; Lynskey y Fergusson 1995; Mannuzza y cols., 1993; Weiss y cols., 1985).

La bibliografía médica disponible muestra que los hijos adolescentes o adultos de padres con trastornos por consumo de sustancias también tienen aumento de riesgo, no sólo de Trastornos por Consumo de Sustancia, sino también de conductas agresivas y antisociales (Chassin y cols., 1991; Mathew y cols., 1993; Moss y cols., 1995; Nunes y cols., 1998; Sher y cols., 1991; Tarter y Edwards, 1988). 
Marshal, Molina y Pelhman (2003) evaluaron la relación de los niños TDAH con compañías "desadaptativas" como factor de riesgo para los Trastornos por Consumo de Sustancias en la adolescencia. Los resultados mostraron que es más probable que los niños con TDAH se relacionen con pares "desadaptativos" y como resultado consuman más sustancias. En definitiva, los adolescentes con TDAH son más vulnerables a las influencias sociales negativas y éstas son un factor de riesgo para el consumo de sustancias.

En lo referente a la presencia de Trastornos por Consumo de Sustancias en los antecedentes familiares, diversos estudios han detectado que la presencia de trastornos psicológicos y abuso de sustancias es más frecuente en los padres de niños con TDAH y TOD. En este sentido, Chronis, Lahey, Pelma, Kipp, Baumann y Lee (2003) evaluaron a madres de 98 niños con TDAH entre 3 y 7 años y 116 de la misma edad sin TDAH. Los resultados indican que el TDAH del niño estaba asociado a un incremento de síntomas de TDAH en los padres en relación con el grupo de niños sin TDAH. También se observó que la presencia de TDAH y TOD en el niño estaba asociada con trastornos del humor, ansiedad y dependencia a la cocaína en la madre y desórdenes conductuales de los padres en la infancia. También revelaron que los padres tenían más problemas con la bebida. 


\subsubsection{Trastornos de la regulación social-emocional}

Entre los problemas más importantes que presentan los niños TDAH (principalmente aquellos del subtipo combinado), se encuentra la dificultad de establecer de forma adecuada relaciones sociales con sus compañeros: escasas habilidades de comunicación, bajo control en situaciones de conflicto, escasa tolerancia a la frustración e incumplimiento de normas en juegos de grupo. Este estilo de interacción molesto, lógicamente, provoca el rechazo del grupo de iguales.

Investigaciones como la llevada a cabo por Gentschel y Mclaughin, (2000) señalan que, en el niño con TDAH, se observa una escasa comprensión de los indicadores relacionales (que son claves para seguir las interacciones sociales, conocer y seguir las reglas que las regulan) y alto nivel de egocentrismo en las interacciones con los demás. Otro de los aspectos, que dificulta la interacción social, es su baja competencia social y las escasas habilidades para hacer y mantener amistades. Todo ello ocasiona que sus compañeros de juego sean con frecuencia más pequeños.

Se podría afirmar que los niños con TDAH conocen las acciones apropiadas pero fracasan en llevarlas a cabo. En un estudio reciente llevado a cabo, en colegios de Castellón, por García, Presentación, Siegenthaler y Miranda (2006), se evidenció la gravedad de la problemática social que presentan estos niños en el colegio. Son rechazados por sus compañeros principalmente por sus problemas de conducta y por sus características de personalidad. También se pudo observar como estos niños no perciben de manera adecuada su situación social, lo que les lleva a seguir manifestando conductas sociales incompetentes.

Otro aspecto importante, a tener en cuenta respecto a las dificultades sociales de los niños con TDAH, es que éstas se mantienen a lo largo del tiempo, de manera que entre un 50 y un $80 \%$ de los niños con TDAH siguen presentando problemas de relación con sus iguales al llegar a la adolescencia (Barkley, 1990). 


\section{Trastornos del Espectro Autista. Síndrome de Asperger:}

Los Trastornos del Espectro Autista incluyen, no sólo el Autismo, sino también otras diversas variedades de trastornos desintegrativos, Trastornos Generalizados del Desarrollo No Especificados (TGD NE) y Síndorme de Asperger, todas ellas se caracterizan por problemas graves en la triada de: comunicación recíproca, interacción social recíproca y capacidad de modificar el repertorio conductual.

Muchos pacientes con TDAH tienen problemas significativos en las interacciones sociales que, habitualmente, se deben al deterioro de las funciones ejecutivas asociadas al TDAH y no a los deterioros más específicos de los Trastornos del Espectro Autista. Sin embargo, algunos pacientes con TDAH, también pueden cumplir los criterios para el diagnóstico de un Trastorno del Espectro Autista, y un grupo mucho mayor tiene rasgos significativos sin cumplir por completo los criterios del manual DSM-IV.

Hasta hace poco, no se reconocía el TDAH en pacientes con Trastornos del Espectro Autista. Recientemente, esta concepción excluyente de ambos diagnósticos está modificándose, por la necesidad de abordar ambos síndromes por separado cuando conviven en el mismo paciente.

La investigación ha demostrado que, el $58 \%$ de los pacientes diagnosticados de Autismo (C. Gillberg, 1983) y el 74-85\% de los diagnosticados de síndrome de Asperger, tienden a cumplir también los criterios diagnósticos de TDAH (Goldstein y Schwebach, 2004; Yoshida y Uchiyama, 2004).

Capacidades de autogestión y autoregulación, necesarias en la interacción social, se encuentran entre las funciones ejecutivas que están alteradas en los pacientes con TDAH (p.ej. alerta para observar los detalles de la interacción en curso; capacidad para centrarse en la situación inmediata sin distraerse excesivamente; centrar la atención cuando sea necesario por la dinámica cambiante de la interacción; capacidad de 
mantener en la mente lo que se está diciendo y haciendo en la situación actual; capacidad de utilizar y recordar recuerdos importantes de expectativas previas; capacidad para inhibir las respuestas excesivamente impulsivas; capacidad de modular adecuadamente la expresión de la emoción) (Brown, 2005).

Algunos niños, adolescentes y adultos tienen dificultades en sus interacciones sociales que son mucho más graves que las que se tienen en general con personas de la misma edad con TDAH. Tienen no solo deterioro de las capacidades de autogestión general asociadas al TDAH, sino deterioros crónicos y graves de las capacidades específicas necesarias para manejar la interacción social recíproca, llevar a cabo una comunicación recíproca (verbal o no verbal) y adaptar la conducta a los requisitos de la situación interpersonal actual.

Dado que, como criterio de exclusión en nuestro trabajo, se ha considerado el padecer un Trastorno del Espectro Autista diferente del síndrome de Asperger, centraremos la expoción en este último, que sí ha sido incluido en nuestro estudio:

No se ha documentado claramente que el déficit de la comunicación social básica del Síndrome de Asperger, sea menos grave que en el trastorno Autista. Posiblemente la principal diferencia, entre el trastorno Autista y el síndrome de Asperger, es que el Cl suele ser menor en el primero y la dificultad de aprendizaje mayor (por la baja capacidad intelectual), contribuyendo ésto a la impresión global de padecer un trastorno más grave.

Según las clasificaciones DSM-IV y CIE 10, el Síndrome de Asperger se diagnostica con los mismos criterios generales que el trastorno Autista, pero la diferencia importante es que el desarrollo del lenguaje, en los primeros tres años, debe haber sido normal (no es necesario que haya problemas de la comunicación recíprocos).

Sin embargo, según Brown (2010): "Hay acuerdo generalizado en que estos casos no existen en la vida real o son tan infrecuentes como para que la entidad diagnóstica sea 
casi irrelevante desde el punto de vista clínico (Leekam et al., 2000); además los criterios diagnósticos pueden estar tan alejados de los que describió el Dr. Asperger que los individuos que descubrió no los cumplen (Miller y Ozonoff, 1997). Si se aplicaran de forma estricta los criterios de Síndrome de Asperger de la clasificación DSM-IV o CIE, se esperaría que menos del $2 \%$ de todos los pacientes con trastornos del espectro autista los cumplirían (Leekam et al., 2000). En la práctica, y en muchos estudios de investigación, se utilizan en su lugar los criterios de síndrome de Asperger publicados por I.C. Gillberg y Gillberg (1989) y elaborados por C. Gillberg (1991), sobre la base de las descripciones iniciales de casos de Hans Asperger (1984). El síndrome de Asperger en ocasiones se denomina autismo de alto funcionamiento. Sin embargo, este término lleva a error porque no es el autismo el que es de alto funcionamiento. El término más adecuado, si se llega a utilizar, sería pacientes con alto funcionamiento o con inteligencia normal) con autismo".

Estudios de resultados a largo plazo indican que al final de la adolescencia y en la edad adulta, muchos pacientes con Síndrome de Asperger tienen deterioros de las funciones sociales y laborales, a pesar de tener una inteligencia media o mayor que la media, mucho mayor que la mayoría de las personas con autismo (Howlin y cols., 2004).

\section{Tics y trastorno de Gilles de la Tourette:}

Los tics son movimientos motores o vocales súbitos, sin finalidad, repetitivos y estereotipados, que se pueden caracterizar por su localización anatómica, su número, su frecuencia, su intensidad y su complejidad (Leckman, 2003).

La forma extrema de la presentación de los tics, con episodios más graves y con presencia tanto de tics motores como vocales, recibe el nombre de síndrome Gilles de la Tourette, ya que en 1885 Gilles de la Tourette describió a nueve pacientes con tics 
motores y fónicos, y usó el caso de la marquesa de Dampierre para ejemplificar los síntomas del síndrome que pronto llevaría su nombre. Gilles, también describió, cómo estos casos eran de inicio precoz (infantil), persistentes a lo largo de la vida y evolución con mejorías y empeoramientos. Desde entonces, se han conformado estas características, en numerosas series clínicas de todo el mundo (Lin y cols., 2002; Staley y cols., 1997).

Es frecuente que el síndrome se presente asociado a otros trastornos psiquiátricos, especialmente Trastorno Obsesivo Compulsivo (TOC) y Trastorno de Déficit de Atención e Hiperactividad (TDAH). No obstante existen publicaciones diversas de asociación del síndrome a Trastornos del Ánimo (Robertson y cols., 2002), Trastornos de Ansiedad distintos al TOC (Coffey et al., 2000), Trastornos Generalizados del Desarrollo (BaronCohen y cols., 1999) y Dificultades del Aprendizaje (Kerbeshian y Burd, 1992).

Estudios comunitarios indican que los tics afectan del 4 al $24 \%$ de los niños en edad escolar (Gadow et al., 2002; Snider et al., 2002), y la estimación media es que aproximadamente el 10\% de los niños tienen tics (Robertson, 2003).

Entre el $70-90 \%$ de los niños y adolescentes derivados a consulta, que presentan el síndrome de Tourette, presentan de forma comórbida TDAH (Coffey y cols., 2000; Robertson y cols., 2002; Spencer y cols., 2001a; Sukhodolsky y cols., 2003). La frecuencia de comorbilidad de síndrome de Gilles de la Tourette y TDAH es algo menor en muestras comunitarias.

En lo referente a los Trastornos de Tics Crónicos, las características clínicas de los tics (como la evolución con exacerbaciones y remisiones, el inicio precoz y la variabilidad de los tics ante la observación clínica) hacen muy difícil establecer las relaciones entre los tics, el TDAH y el tratamiento con psicoestimulantes. Existe controversia sobre el beneficio o perjuicio de los psicoestimulantes en niños con tics (Castellanos, 1999; Kurlan, 2003). Como los síntomas del TDAH suelen manifestarse de forma más temprana 
que los tics, resulta difícil, en los casos tratados con psicoestimulantes, saber si su presencia, se ha desencadenado de forma independiente o por influencia farmacológica. No obstante, los estudios más recientes están resultando a favor de confirmar que el metilfenidato es un fármaco seguro y eficaz en la mayoría de los niños TDAH con tics comóbidos (Gadow y cols., 1995; Tourette’s Síndrome Study Group, 2002).

La asociación genética del TDAH con el Guilles de la Tourette aún se conoce mal, a pesar de las altas tasas de comorbilidad.

\section{Trastornos del Comportamiento:}

Los problemas de conducta suponen la mayor parte de la comorbilidad que presentan los niños con trastorno de déficit de atención e hiperactividad (TDAH) subtipo combinado.

El Manual Diagnóstico y Estadístico de los Trastornos Mentales, en su texto revisado (DSM-IV-TR), define como característica esencial del Trastorno Oposicionista o negativista Desafiante (TOD): “Un patrón recurrente de comportamiento negativista, desafiante, desobediente y hostil, dirigido a las figuras de autoridad, que persiste por lo menos durante 6 meses". Además, durante ese tiempo es frecuente la aparición de cuatro o más de los siguientes síntomas: "accesos de cólera, discusiones con adultos, desafiar activamente o negarse a cumplir las demandas o normas de los adultos, llevar a cabo deliberadamente actos que molestarán a otras personas, acusar a otros de sus propios errores o problemas de comportamiento, ser quisquilloso o sentirse fácilmente molestado por otros, mostrarse iracundo y resentido o ser reconroso o vengativo". Dichos comportamientos han de aparecer "con mayor frecuencia de lo que correspondería a la edad y nivel de desarrollo y deben causar un déficit significativo en el funcionamiento social, académico o laboral". Mientras la clasificación DSM-IV considera como distintos diagnósticos el Trastorno de Déficit de Atención e Hiperactividad (TDAH) y los Trastornos 
de Conducta, la clasificación CIE-10 se aparta de esta línea e insiste en la formulación de una entidad diagnóstica única, Trastorno de Conducta Hipercinética, para describir a los niños con sintomatología mixta. La clasificación DSM, permite así, identificar un grupo más extenso que los criterios de clasificación CIE (Tripp y cols., 1999).

Desde los años ochenta ha habido mucha controversia sobre si el TDAH, el Trastorno Disocial y el Trastorno Oposicionista Desafiante. La duda planteada es si se trata de enfermedades psiquiátricas distintas, o por el contrario, representan diversas manifestaciones de un fenómeno general. La valoración cuidadosa de los criterios diagnósticos del TDAH, el Trastorno Oposicionista Desafiante y el Trastorno Disocial indica que hay muy poca superposición entre los síntomas que se utilizan para definir estos trastornos. Pero, la frecuente aparición conjunta de falta de atención, impulsividad, hiperactividad, negativismo y agresividad, en los pacientes, indica que estos dominios sintomáticos están muy relacionados entre sí. Es muy difícil individualizarlos tanto en la teoría como en la práctica clínica. Diversos datos indican que es posible distinguir los síntomas de TDAH de los de la agresividad utilizado diversas medidas descriptivas, psicosociales, relacionadas con el desarrollo y de laboratorio. Uno de estos instrumentos es la escala IOWA Conners rating scale, que tiene una subescala de agresividad (Loney y Milich, 1982).

Diferentes estudios epidemiológicos (Maughan et al., 2004; Szatmari et al., 1989a; Faraone y Biederman, 1997; Greenhill, 1998) muestran que los trastornos de conducta, el Trastorno Oposicionista Desafiante (TOD) y el Trastorno Disocial (TD), están presentes en un $40-70 \%$ de los niños TDAH. La coexistencia o comorbilidad del TDAH/TOD se traduce desde una edad muy temprana en conductas perturbadoras: muestran niveles más elevados de conductas motoras y de impulsividad, presentan continuamente rabietas, son desobedientes y reaccionan de forma desmedida cuando no consiguen lo que quieren. Esta relación es bidireccional ya que en los niños con TND y TD de estos mismos estudios se muestra que el 40-60\% tienen también TDAH. 
En algunas muestras epidemiológicas también se han identificado la diferenciación entre TDAH y TD (Maughan et al., 2004; Moffitt., 1990). En estos estudios los niños con TDAH se caracterizaban por un patrón persistente de problemas desarrollados con el desarrollo y deterioros cognitivos, mientras que los niños con TD se caracterizaban con más frecuencia por un nivel socioeconómico y adversidad psicosocial, como aumento de los problemas familiares. Lo que es importante, datos de estudios tanto epidemiológicos como clínicos (Schanchar y Tannock., 1993; Szatmari et al., 1989a) indican que los niños con TDAH y TD comórbidos tenían los factores de riesgo y los rasgos asociados característicos de ambos trastornos. Estos hallazgos son compatibles con la hipótesis de que el TD puede depender más de factores ambientales que el TDAH, aunque los hallazgos no excluyen las contribuciones genéticas ni neurobiológicas a la patogenia del TD, además de la participación de mecanismos psicosociales en el TDAH (Biederman et al., $\left.1995^{a}, 1995 b\right)$.

Los niños que tienen TDAH con TD tienen los factores de riesgo y los rasgos asociados de ambos trastornos (Maughan et al., 2004; Moffitt 1990), y eso indica que el TD comórbido va a conferir peor evolución a los niños con TDAH y, a su vez, el TDAH comórbido contribuye a un aumento del riesgo de mala evolución en niños con TD (Kuhne et al., 1997). El estudio Multimodal Treament Study of Chlidren with ADHD (MTA) emite datos de que los padres pueden distinguir con fiabilidad entre las conductas asociadas al TDAH, el TND y el TD, y que el grupo comórbido tiene más deterioro (Jennsen et al., 2001).

Los datos clínicos indican que los niños con TDAH del subtipo combinado, particularmente los que tienen síntomas graves y persistentes del TDAH, tienen mayor riesgo de aparición de formas de conducta, como TND y TD. Además, en niños con TDAH, los que tienen agresividad de inicio temprano tienen el mayor riesgo. Cuando no hay factores de riesgo específicos de Trastornos de Conducta, la probabilidad de aparición de Trastorno de Conducta es baja, aún cuando sí haya TDAH. Sin embargo, 
cuando están presentes los factores de riesgo y los signos de alarma clínicos tempranos de Trastorno de Conducta, la presencia simultánea de TDAH puede acelerar la aparición de la agresividad y la progresión hasta un trastorno comportamental completamente desarrollado.

Estudios actuales, sugieren que los trastornos de conducta comórbidos tan frecuentes en los niños con TDAH pueden tener una base genética. En este sentido los estudios de genética molecular muestran que existe una asociación entre el gen DRD4 y TDAH con trastornos de conducta comórbido (Holmes y cols., 2002; Kirley y cols., 2004).

Por otra parte, los hallazgos de uno de los principales estudios genéticos del TDAH encontraron que el TDAH y Trastorno Disocial son síndromes diferentes desde el punto de vista genético (Smalley et al., 2000). Los estudios de familias también ponen de manifiesto la posible existencia de un origen genético distinto para el TDAH con Trastorno de Conducta comórbido, incluso como una variante más severa del TDAH y con peor pronóstico (Faraone y Biederman, 1998). Se observó que la presencia, en los familiares de primer grado de los niños con TDAH, de trastornos psiquiátricos (de ansiedad, como depresión, TND y TD) estaba aumentada en estos pedigrís. Además, el riesgo de Trastornos Antisociales en familiares de niños con TDAH y TOD fue mayor que en los de los niños únicamente con TDAH, aunque fue menor que en los niños con TDAH y TD comórbido (Biederman 1992a, 1992 b).

Otros investigadores llegan a proponer que el TDAH con Trastornos de conducta asociados es una variante con más carga genética y que justificaría una categoría diagnóstica separada en la línea de lo que establece la ICD-10 (Thapar, Harringon y McGuffin, 2001).

La comorbilidad con trastornos del comportamiento condiciona el pronóstico, los niños con TDAH y Trastorno Oposicionista tienen mayor riesgo de desarrollar en la adolescencia y en la edad adulta conductas antisociales, abuso de sustancias, de sufrir 
accidentes de tráfico y en general peor pronóstico que los niños con TDAH sin trastorno de conducta asociado (Molina y Pelhman, 2003).

En algunos casos el paciente con TDAH y Trastorno de Conducta comórbido (TD, TND o agresividad) también se presentan asociados síntomas de interiorización (del tipo ansiosos, depresivos, etc...). Varios estudios han documentado esta comorbilidad en niños que padecían TDAH y TND o TD y a su vez presentan un aumento de riesgo para padecer trastornos depresivos o ansiosos (Busch y cols., 2002; Willcutt y cols., 1999).

En la muestra del estudio MTA, dos tercios de los niños de ambos sexos con TDAH y trastorno de ansiedad también tenían TD (March et al., 2000). En la muestras de este mismo estudio (MTA), Jennsen y cols, (2001) encontraron que los niños con TND o TD y un trastorno de ansiedad comórbido tenían las mayores tasas de deterioro. Esta interacción indica que los niños que tienen TDAH con trastornos de exteriorización y de interiorización comórbidos tienen mayor deterioro y no menor, y merecen una atención especial.

No está aún establecido de forma clara si existe relación entre padecer TDAH, abusar de sustancias en la adolescencia o edad adulta y haber tenido comorbidamente trastorno de conducta en la infancia. Flory y colaboradores (2003) encontraron una relación, entre el riesgo de abusar de marihuana y drogas duras, si se padecía TDAH y TD comórbido frente a los que tenían TDAH sin TD. Sin embargo no se asociaba a abusar y depender de alcohol en una muestra diferente de adolescentes (Molina et al., 2002).

En estos aspectos, relativos al riesgo de futuro consumo de tóxicos, encontramos controversia entre los diversos estudios. Algunos estudios no han encontrado aumento del consumo de sustancias en la adolescencia en los pacientes TDAH (Weiss y Hetchman, 1993; Loney et al., 1981). Otros, por el contrario, han demostrado que hay un aumento del riesgo de consumo de sustancias en adolescentes TDAH y adultos seguidos desde la infancia (BarKley y cols., 1991; Klein y Mannuzza, 1991; Mannuzza y cols., 
1993). Es imporante señalar que esta evolución se produjo principalmente en pacientes que también tenían personalidad antisocial o TD (Barkley y cols., 1990a ; McDonald y Achenbach, 1996), pero los adolescentes con TDAH a los que se siguió tuvieron aumento del consumo de sustancias incluso cuando se excluyó a los pacientes con TD comórbido (Flory y cols., 2003). 


\section{TítULO III. TRABAJO EMPIRICO}

\section{CAPÍTULO 1. EXPOSICIÓN DEL TRABAJO EMPÍRICO}

\subsection{Justificación e Hipótesis}

En las consultas de Salud Mental infanto-juvenil la mayor dificultad, a la hora de hacer un diagnóstico certero del TDAH, es la interferencia frecuente que en la sintomatología suponen los procesos psicopatológicos acompañantes. La publicación del estudio sueco de Kadesjo y Gillberg (2001) supuso una revolución en este aspecto porque identificó que el $87 \%$ de los niños que cumplían todos los criterios de TDAH tenían, al menos, un diagnóstico comórbido, y que el $67 \%$ cumplían los criterios para, por lo menos, dos trastornos comórbidos. A su vez, otros estudios han tratado de establecer las frecuencias de presentación de las diversas comorbilidades más habituales (Jensen y cols., 1997; MTA 1999; Barkley, 2006)

Hemos considerado interesante, acometer el análisis de los parámetros relacionados con la comorbilidad de niños con TDAH de nuestro país. Nos parece interesante constatar si los estudios realizados en otras culturas, fundamentalmente la americana, que es la que domina en presencia la literatura científica, son o no extrapolables a nuestro contexto.

Por tanto, dada la frecuencia y relevancia de la comorbilidad en la presentación clínica, pronóstico, plan terapéutico y la respuesta al tratamiento, hemos querido evaluar en la población de estudio cómo afecta la psicopatología acompañante al niño y adolescente con TDAH. 
Nuestra hipótesis de partida es la siguiente:

En nuestra población de pacientes TDAH, existe una elevada prevalencia de comorbilidad psiquiátrica asociada. Determinadas variables sociodemográficas y clínicas de las que destacamos el sexo, la edad, el subtipo de TDAH y la agresividad, pueden estar directamente relacionadas con el riesgo de padecer o no comorbilidad psiquiátrica en general, y enfermedades psiquiátricas concretas en particular. El paciente con Trastorno de Déficit de Atención e hiperactividad que asocie comorbilidad, puede comportarse de forma diferente frente a la necesidad y uso del tratamiento farmacológico respecto a los que tienen TDAH como único diagnóstico.

\subsection{Objetivos de la Investigación}

La investigación que a continuación se expone, intenta profundizar en el estudio de la comorbilidad psiquiátrica en el niño y adolescente con TDAH, planteándose específicamente cinco objetivos (ver cuadro de la figura 10).

- En el primer objetivo: se trata de analizar aspectos relevantes de la historia personal, familiar y de desarrollo del paciente. Para ello se analizan: antecedentes familiares, antecedentes personales, historia académica y características de la enfermedad que padecen. Apoyándonos en la revisión de la bibliografía sobre el tema, se plantea la existencia de diferencias relevantes en diversos aspectos del paciente TDAH.

- En el segundo objetivo: partiendo de las altas tasas de prevalencia de la comorbilidad psiquiátrica en los pacientes TDAH (Kadesjo y Gillberg, 2001; Jensen y cols., 1997; MTA 1999; Barkley, 2006), se trata de predecir en la población de estudio la frecuencia con la que encontraremos enfermedades 
psiquiátricas coexistentes con el TDAH, y la influencia del sexo, grupo de edad, subtipo y presencia o no de agresividad.

- En el tercer objetivo: nos proponemos desgranar dentro del proceso comórbido las morbilidades psiquiátricas más frecuentes que se van a asociar en los pacientes con Trastorno de Déficit de Atención e Hiperactividad y la influencia en ellas de las variables subtipo, agresividad,

- Como cuarto objetivo se trata de describir si interfiere, padecer comorbilidad psiquiátrica, para el cumplimiento de la prescripción facultativa y precisar más tempranamente tratamiento farmacológico.

- Por último, en el quinto objetivo: se ha tratado de relacionar las variables, que han mostrado en el estudio ser más relevantes, y elaborar árboles de decisión que puedan ser útiles, para la detección precoz de la comorbilidad en el paciente TDAH, en la práctica clínica. 


\section{OBJETIVOS DEL ESTUDIO}

\section{Objetivo General}

Profundizar en el estudio de la comorbilidad psiquiátrica en el niño y adolescente con TDAH.

\section{Objetivo Específicos}

$1^{\circ}$ ) Determinar las características clínico-epidemiológicas de los niños y adolescentes con TDAH: prevalencia de los diferentes subtipos de TDAH; prevalencia de las formas leves-moderadas-severas; antecedentes familiares psiquiátricos; antecedentes personales de psicopatología; Capacidad intelectual; historia académica.

$2^{\circ}$ ) Evaluar la presencia de comorbilidad psiquiátrica de los niños y adolescentes con TDAH de la muestra y la influencia de las variables sexo, grupo de edad, subtipo, agresividad.

$3^{0}$ ) Evaluar los tipos de comorbilidad más prevalentes en los niños y adolescentes TDAH y la influencia de las variables subtipo y agresividad.

$4^{\circ}$ ) Analizar la relevancia de la comorbilidad en el mejor o peor cumplimiento y según la edad de inicio de la medicación.

$5^{\circ}$ ) Elaborar, relacionando entre sí las variables más relevantes del estudio, árboles de decisión que permitan la detección precoz de la comorbilidad en el paciente TDAH.

Figura 10. Objetivos del estudio

\subsection{Material y Método}

\subsubsection{Sujetos de estudio}

Para los pacientes de nuestro estudio se ha diseñado un PROTOCOLO DE INVESTIGACIÓN SOBRE TDAH y COMORBILIDAD que se inició en Diciembre de 2009.

Se trata de un Estudio retrospectivo, de 4 años de evolución, en el que han participado un total de 201 pacientes diagnosticados de TDAH y seleccionados de forma aleatoria. 
De la muestra se han dividido dos grupos, el grupo que tienen diagnosticada otra u otras enfermedades psiquiátricas comórbidas que constituye el grupo de casos y el grupo de los qué cumplen criterios diagnósticos de TDAH sin otra patología psiquiátrica acompañante que constituyen el grupo de controles.

En lo referente a los criterios de inclusión y exclusión a continuación pasamos a describirlos:

El grupo de pacientes TDAH casos está formado por pacientes pertenecientes al área de Salud Mental Infanto-juvenil que comprende la ciudad de León y provincia (excluyendo la zona de El Bierzo que en sí misma constituye otro área asistencial), con niños de ambos sexos, con edades comprendidas entre 5 y 18 años. Todos los niños tenían un diagnóstico confirmado de trastorno por déficit de atención con hiperactividad (TDAH), subtipo combinado o inatento, según los criterios establecidos en el DSM-IV-TR.

A su vez se valoró que cumpliesen criterios diagnósticos según la clasificación DSM-IVTR de uno o varios de los siguientes trastornos a estudio: T. del Lenguaje, $T$. de Aprendizaje, T. de Ansiedad, T. Depresivo, T. Obsesivo Compulsivo, T. por Consumo de Tóxicos, Síndrome de Asperger, T. oposicionista desafiante, T. de Conducta y/o T. de Tics.

El grupo de casos también, por tanto, está formado por pacientes de las edades comprendidas entre 5 y 18 años, diagnosticados de TDAH según criterios DSM-IV y del área de Salud Mental Infanto-juvenil de León. Estos pacientes presentan exclusivamente el diagnóstico psiquiátrico de TDAH y no otros.

En lo referente a la edad de los niños de la muestra, se excluyeron los mayores de edad y los niños en edad preescolar. Se excluyeron también aquellos casos en los que el $\mathrm{Cl}$ era inferior a 70 (es decir, con retraso mental leve, moderado o grave). Tampoco se consideraron aptos para entrar en el estudio, pacientes diagnosticados de Trastorno 
Generalizado del desarrollo (a excepción del síndrome de Asperger). Otro criterio de exclusión fue padecer enfermedades somáticas que interfieran en el manejo de datos como la epilepsia u otras enfermedades neurológicas, alteraciones endocrinológicas, cromosomopatía.

\section{Criterios de Inclusión y de Exclusión}

\section{Criterios de Inclusión}

Pacientes con un diagnóstico confirmado de Trastorno por Déficit de Atención con Hiperactividad (TDAH), subtipo combinado o inatento, según los criterios establecidos en el DSM-IV-TR.

Acudir a consulta del área de Salud Mental Infanto-juvenil que comprende la ciudad de León y provincia (excluyendo la zona de El Bierzo que en sí misma constituye otro área asistencial).

\section{Criterios de Exclusión}

No cumplir uno de los criterios de inclusión.

Tener menos de 5 años o ser mayor de 19.

Tener el $\mathrm{Cl}$ inferior a 70 (es decir, con retraso mental leve, moderado o grave).

Padecer un TGD (trastorno de espectro autista), a excepción del síndrome de Asperger.

Padecer enfermedades somáticas que interfieran en el manejo de datos como la epilepsia u otras enfermedades neurológicas, alteraciones endocrinológicas, cromosomopatías...

Figura 11. Criterios de inclusión/exclusión del estudio 


\subsubsection{Variables analizadas e Instrumentos de evaluación}

En el Protocolo Clínico diseñado para la recogida de datos se han incluido las siguientes variables:

- Edad, subdividida en dos grupos (el de niños cuya edad es de 5 a 12 años y el de preadolescentes y adolescentes de edades comprendidas de 13 a 18 años): variable cualitativa.

- Género: variable cualitativa.

- Subtipo de Trastorno de Déficit de Atención e Hiperactividad (TDAH): según DSM IV-TR: subtipo inatento frente al subtipo combinado. Variable cualitativa.

- Antecedentes personales: Variable cualitativa.

- Antecedentes familiares: Variable cualitativa.

- Cociente intelectual, subdividido en border-line, bajo, medio, alto y sobredotación: variable cualitativa.

- Nivel educativo: Curso en el que se encuentra el paciente en el momento de la recogida de datos. Variable cualitativa.

- Número de ingresos: variable cuantitativa.

- Relación paterno-filial: variable cualitativa subdividida de la siguiente manera.

- Buena.

- Regular.

- Mala. 
- Relación escolar: variable cualitativa subdividida de la siguiente manera.

- Buena.

- Regular.

- Mala.

- Relación con iguales: variable cualitativa subdividida de de la siguiente manera.

- Buena.

- Regular.

- Mala.

- Rendimientos académicos: variable cualitativa subdividida de la siguiente manera.

- Muy buenos (nota media de notable o sobresaliente)

- Buenos (nota media de bien o suficiente)

- Medios (suspende menos de 2 asignaturas a final de curso)

- Malos (suspende 2 o más asignaturas a final de curso)

- Fracaso escolar (suspende 2 o más asignaturas a final de curso y ya había repetido uno o más cursos en su historia escolar)

- Nivel socio-económico: variable cualitativa estratificada de la siguiente manera.

- Alto

- $\quad$ Medio

- Bajo 
- Gravedad del TDAH: Subdividida en leve, moderada o grave en función del deterioro funcional que le genera al paciente según lo que cabría esperar para niños o adolescentes de su misma edad. Variable cualitativa.

- Presencia de conductas agresivas: para considerarlo relevante éstas conductas deben ser desadaptativas por su intensidad o frecuencia en relación a sus iguales. Variable cualitativa.

- $\quad$ Sí presenta

- $\quad$ No presenta

- Edad de inicio del tratamiento: en función de si se ha iniciado antes de los 13 años o a partir de esa edad. Variable cualitativa:

- Precoz

- Tardío

- Cumplimiento: Variable cualitativa. Según conste en la historia la mayor o frecuencia de olvidos o abandonos de tratamiento comunicada por el paciente o por los padres. Subdividido en

- Bueno

- Malo ó dudoso

- Respuesta al tratamiento: Variable cualitativa, subdividida en

- Completa

- Parcial

- Nula 
- Presencia de comorbilidad psiquiátrica: Variable cualitativa subdividida en

- Presente

- Ausente

- En caso de comorbilidad psiquiátrica presente, tipo de trastorno o trastornos psiquiátricos que padece según los criterios DSM-IV-TR. Variable cualitativa:

- Lenguaje y aprendizaje

Trastorno del lenguaje

Trastorno del aprendizaje

- Excitación y motivación

\author{
Distimia/depresión \\ Trastorno de ansiedad \\ Trastorno bipolar \\ TOC
}

Abuso de tóxicos

- Regulación social-emocional

Trastorno de Asperger

TOD

TC

T. Tics incluido Guilles de la Tourette. 


\section{Instrumentos de evaluación:}

La información acerca de los síntomas del comportamiento se puede obtener mediante varios métodos, que incluyen: Preguntas abiertas, preguntas específicas, entrevistas semiestructuradas, cuestionarios y escalas (AAP, 2000).

Una revisión técnica realizada por la Agency for Health Care Policy and Research (AHCPR) (Technical Review n.3, 1999) ha evaluado la fiabilidad y validez de los instrumentos de cribado y evaluación del TDAH para el diagnóstico de éste. Del informe se extrae que los cuestionarios de amplio espectro no permiten distinguir adecuadamente a los pacientes psiquiátricos (AAP, 2000). No obstante, las escalas de cribado aportan información de utilidad a pesar de no ser diagnósticas en sí mismas. Por ello, tras realizar un análisis de la bibliografía sobre el tema, se incluyeron cuestiones sobre aspectos que pueden influir de algún modo en el TDAH y son útiles para complementar la exploración del niño con TDAH y otros diagnósticos de comorbilidad psiquiátrica.

Para nuestro estudio hemos utilizado:

- 1. Protocolo Clínico de recogida de datos heteroaplicado. Con el fin de poder obtener datos relevantes, del niño con TDAH, confeccionamos una entrevista de diagnóstico estructurada que permite obtener información de los padres sobre una serie de información en relación al trastorno.

Las preguntas de la entrevista se agrupan en las siguientes áreas de interés: datos sociodemográficos, antecedentes de psicopatología familiar y personal, relaciones familiares, escolares y sociales, historia académica, diagnóstico, gravedad de los síntomas y edad de inicio del tratamiento del TDAH, cumplimiento de la prescripción facultativa, presencia de sintomatología acompañante constitutiva de diagnóstico (esto ha sido explicado más detalladamente en la exposición de las variables que hemos realizado previamente). 
- 2. Escala SNAP-IV (según los autores Swanson, Nolan y Pelham, 2003) es una escala de cribado y evaluación de los síntomas de TDAH. Sensible a los cambios de tratamiento. Consta de 18 items, tipo Likert, de 4 grados. Está dividida en dos subescalas: Inatención e Hiperactividad/Impulsividad, y una puntuación total. Las preguntas indagan acerca de las características del comportamiento del niño con TDAH y se pregunta por la frecuencia de aparición de la misma desde un valor 0 (no, o no del todo) hasta un valor 3 (sí, mucho). En cada hoja se pueden recoger hasta 4 evaluaciones, lo que permite directamente registrar un seguimiento de la sintomatología de cada paciente a lo largo del tiempo. Se aplicaron las dos versiones (padres y maestros).

- 3. Escala CEDI: CEDI-I: cuestionario de depresión infantil para niños de 5 a 10 años de edad. (Rodriguez-Sacristán y Carzone. Modificado de Beck). Consta de 16 ítems cada uno formado por tres frases colocadas en orden de gravedad de la respuesta. Es heteroaplicado y la información se obtiene de los padres o cuidadores del niño. La puntuación directa se obtiene sumando los valores señalados, en cada una de las frases marcadas por los padres o cuidadores, en el que las puntuación de 0 a 6 se consideran normales, de 7 a 12 niños/as con depresión ligera, de 12 a 17 niños/as con depresión moderada y más de 17 niños/as con depresión severa. Aunque no debe utilizarse como método diagnóstico, es ampliamente utilizado en la valoración de eficacia terapeútica por su sensibilidad al cambio.

En la misma línea, se utiliza el CEDI-II, para pacientes entre 11 y 16 años. Es similar al anterior en cuanto a número de preguntas y forma de puntuarlas, salvo que, en este caso, es autoaplicada, es el propio paciente el que elige entre las opciones la que más define cómo siente sus síntomas. 
- 4. Escala STAIC: Cuestionario de ansiedad estado-rasgo. (Spielberger y cols., 1970; adaptación castellana, 1977). Se trata de un cuestionario autoaplicado que mide dos modalidades independientes de la ansiedad del niño-adolescente: ansiedad como estado y ansiedad como rasgo. La primera es una condición emocional transitoria, que se caracteriza por sentimientos subjetivos de tensión y aprensión, así como por hiperactividad del sistema nervioso autónomo; Puede variar con el tiempo y fluctuar de la intensidad. La segunda se caracteriza por propensión ansiosa relativamente estable. El cuestionario consta de 20 items, puede se administrado individual o colectivamente y no tiene tiempo limitado. La duración aproximada es de 15 minutos. La puntuación en las dos escalas puede variar desde un mínimo de 0 puntos a un máximo de 60. Los sujetos se evalúan en una escala que va de 0 a 3 en cada elemento. Las puntuaciones directas se trasforman en centiles y decatipos. Las notas altas son indicativas de elevada ansiedad en la modalidad correspondiente.

- 5. Escala de Yale-Brown: Cuestionario de detección del trastorno obsesivo síntomas obsesivo-compulsivo (Goodman, Rasmussen, Riddle, Price y Rapoport 1986; adaptación castellana de J.L. Pedreira). Se trata de un cuestionario heteroaplicado que mide en un primer lugar obsesiones (a través de cinco ítems) y en segundo lugar conductas compulsivas (a través de cinco ítems). En ambas se explora tiempo ocupado, interferencia, malestar asociado, resistencia, y grado de control. La puntuación en las dos escalas puede variar desde un mínimo de 0 puntos a un máximo de 24 puntos, siendo los rangos: $\leq 10$ para síntomas leves, 11-23 para síntomas moderados $\mathrm{y} \geq 24$ para síntomas severos.

- 6. Escala de Young: Cuestionario de detección síntomas de trastorno bipolar (Young RC y cols., 1978. Adaptada de J. Diez Atienza). Es un instrumento de cuantificación de síntomas que consta de 11 items, con 5 opciones en cada uno, que reflejan grados crecientes de intensidad sintomática. La selección de los 
items es empírica, y se basa en una selección de los síntomas considerados como nucleares de la fase maniaca del trastorno bipolar. El rango total de la escala es de $0-60$ puntos. No hay puntos de corte establecidos ni tampoco estratificación por niveles de severidad, y podemos encontrar distintos criterios en la bibliografía. Para definir niveles de severidad, pueden ser orientativa la categorización de Pope HG (2000), quien establece tres niveles $(<10,10-19,>19)$ que corresponden a hipomanía, manía leve y manía moderada-severa. La Escala de Manía de Young es actualmente el instrumento más utilizado por clínicos e investigadores en este ámbito, con una probada validez para evaluar la gravedad / intensidad sintomática y la respuesta al tratamiento. La fiabilidad interobservadores de la escala en su conjunto es muy alta (0.93) y la de los items es algo más heterogénea (0.66-0.92). En nuestro medio, el no disponer de una versión adaptada y validada representa una limitación importante.

- 7. Cuestionario de cribaje para síndrome de Asperger y otros autismos de alto funcionamiento (ASSQ). (Ehlers, S. y cols., 1999). Se administra a chicos de 7 a 16 años de edad. El cuestionario presenta 27 ítems que se puntúan escogiendo entre las opciones No (normalidad), Algo (indica algún nivel de alteración) y Sí (define una alteración), asociadas a los valores numéricos de 0, 1 y 2 respectivamente. La puntuación total va de 0 a 54. Los ítems se refieren a la interacción social, problemas de comunicación, conductas restrictivas y repetitivas, torpeza motora y diferentes tipos de posibles tics. Se entrevista a padres y maestros y se pide que completen los ítems. En una primera aproximación puede afirmarse que una puntuación de 19 dada por maestros o una puntuación de 22 dada por los padres indicaría riesgo elevado de padecer un síndrome de Asperger.

- 8. En la mayoría de los pacientes de estudio hemos podido disponer de pruebas de inteligencia y neuropsicológicas, especialmente WISC-IV (de David 
Weschler, 2005) y CARAS (percepción de diferencias) (Thurstone y Yela. Narbona, 1985), que han sido aplicadas frecuentemente por los profesionales de los Equipos de Orientación Educativa de los centros escolares.

\subsubsection{Procedimiento}

De los pacientes que acuden a la consulta de Salud Mental Infanto-Juvenil se seleccionó, aleatoriamente, a pacientes que cumplían criterios diagnósticos, según la DSM-IV, para ser diagnosticado de Trastorno de déficit de atención e hiperactividad. De entre ellos, se evalúo quién había sido diagnosticado, en los últimos cuatro años, de algún otro u otros diagnósticos psiquiáticos y contaba con pruebas de cribaje realizadas ante la sospecha diágnostica para la posterior confirmación en sucesivas revisiones clínicas. Sólo se incluyeron en el estudio los pacientes que contaban con las pruebas de cribaje propias del/los diagnóstico/s que se les había confirmado. Una vez incluidos en el proyecto, y tras acudir el paciente a su revisión ordinaria, se cumplimentaba el Protocolo Clínico de recogida de datos.

\subsubsection{Análisis Estadístico}

Se han realizado análisis estadísticos descriptivos e inferenciales. De cada variable observada se ha realizado una estadística descriptiva obteniéndose su distribución de frecuencias.

Realizaremos un descripción general de la muestra y otra, más detallada para el grupo de pacientes que han presentado comorbilidad psiquiátrica. Dentro del grupo de pacientes que padecen comorbilidad, hay que reseñar que se han realizado subgrupos para 
describir las frecuencias con que se presentan las diversas patologías psiquiátricas que con más frecuencia se asocian al TDAH.

Adicionalmente, para presentar los resultados, se han realizado gráficas donde ha sido necesario.

Para estudiar las relaciones entre las variables cualitativas, se han empleado pruebas de chi-cuadrado de Pearson o el test exacto de Fisher en el caso de que el número de celdas, con valores esperados menores de 5 , sea mayor de un $20 \%$. Aquellos valores de $p<0,05$ han sido considerados estadísticamente significativos.

Para realizar las comparaciones entre los grupos en variables cualitativo que pueden estar interaccionando entre ellas, usamos estudios de riesgo del tipo Odds Ratio.

Todos estos análisis se han realizado en el paquete estadístico SPSS versión 19.

Para el último objetivo, que evaluaba la capacidad predictiva de un conjunto de variables de mayor significación estadística respecto a la variable objetivo y establecer árboles de decisión clínica, se ha utilizado el paquete estadístico WEKA (Waikato Environment for Knowledge Analysis) que contiene una colección de herramientas de visualización y algoritmos para análisis de datos y modelado predictivo. 


\section{CAPÍTULO 2. RESULTADOS}

Para exponer de la forma más explicativa el análisis de los resultados de nuestra investigación los vamos a plantear en dos partes:

a) Una primera descripción general, descriptiva de la muestra sugestiva de estudio.

b) Una segunda por objetivos, según los cinco planteados anteriormente y con estudios estadísticos tanto descriptivos como inferenciales.

Comenzamos a continuación por los resultados obtenidos relacionados con la descripción muestral.

\subsection{Descripción socio-demográfica de la muestra}

Se hizo una selección aleatoria de 201 pacientes, los cuales se dividieron en dos grupos:

1. El grupo de casos: Pacientes con diagnóstico de TDAH y comorbilidad psiquiátrica asociada (uno o más diagnósticos psiquiátricos además del de TDAH).

2. El grupo de controles: Pacientes con diagnóstico de TDAH.

\subsubsection{Grupo de Casos}

El grupo de casos está formado por 135 pacientes, del área de León, que acuden a consulta de Salud Mental Infanto- juvenil. Con edades comprendidas entre 5 y 18 años. Diagnostico confirmado de TDAH subtipo combinado o inatento y otro $u$ otros diagnósticos psiquiátricos (según cumplimiento de los criterios establecidos en la DSM- 
IV-TR). De éstos, el $25 \%$ tenían un diagnóstico del subtipo inatento y el $75 \%$ eran del subtipo combinado.

\subsubsection{Grupo de Controles}

El grupo de controles incluía 66 pacientes del mismo rango de edades, que son seleccionados también en consulta de Salud Mental Infanto-juvenil, del mismo área asistencial, pero en este caso sólo estaban diagnosticados de TDAH. De ellos el 45\% son del subtipo inatento frente al $54 \%$ combinado. La distribución por sexo y demás características se expone en la tabla siguiente:

\section{VARIABLES SOCIODEMOGRÁFICAS DE LA MUESTRA}

\begin{tabular}{|c|c|c|}
\hline & $\begin{array}{c}\text { Grupo de TDHA + C } \\
(\mathrm{N}=135)\end{array}$ & $\begin{array}{l}\text { Grupo Control } \\
\qquad(\mathrm{N}=66)\end{array}$ \\
\hline \multicolumn{3}{|l|}{ Edad niños } \\
\hline De 5 a 12 años (\%) & 55,56 & 53,03 \\
\hline De 13 a 18 años (\%) & 44,44 & 46,97 \\
\hline \multicolumn{3}{|l|}{ Sexo } \\
\hline Masculino (\%) & \begin{tabular}{|l|}
77,78 \\
\end{tabular} & 84,85 \\
\hline Femenino (\%) & 22,22 & 15,15 \\
\hline \multicolumn{3}{|l|}{ Procedencia } \\
\hline Área asistencial de León (\%) & 100 & 100 \\
\hline \multicolumn{3}{|l|}{ Subtipo TDAH } \\
\hline Inatento (\%) & 25,19 & 45,45 \\
\hline Combinado (\%) & 74,81 & 54,55 \\
\hline \multicolumn{3}{|l|}{ Nivel Socioeconómico } \\
\hline Alto (\%) & 2,22 & 10,61 \\
\hline Medio (\%) & 75,56 & 87,88 \\
\hline Bajo (\%) & 22,22 & 1,51 \\
\hline
\end{tabular}

Figura 12. Variables sociodemográficas de la muestra 


\subsection{Resultados por objetivos planteados en nuestro estudio}

\subsubsection{Determinar las características clínico-epidemiológicas de los niños y adolescentes} con TDAH

- Antecedentes familiares psiquiátricos

- Antecedentes personales de psicopatología

- Capacidad intelectual

- Historial académico

- Historia de sus habilidades sociales

- Prevalencia de los diferentes subtipos de TDAH

- Prevalencia de las formas leves-moderadas-severas

Se analizaron los antecedentes familiares encontrados, según la entrevista clínica a los padres de los pacientes, en los parientes de primer grado: abuelos, padres, tíos, hermanos y primos carnales de los niños-adolescentes del grupo de casos y del grupo control. Se registró el tipo de trastorno padecido y se agrupó en función de que pudiera incluirse entre los trastornos de aprendizaje (TLA), de excitación-motivación (TEM) o del tipo social-emocional (TSE).

Se determinaron, en los sujetos de la muestra y dentro de los tres grandes grupos descritos de los procesos comórbidos (TLA; TEM; TSE), los trastornos comórbidos concretos del que se había diagnosticado a cada niño o adolescente de nuestro estudio. 


\begin{tabular}{|l|c|c|c|c|}
\hline \multirow{2}{*}{ Antecedentes familiares } & \multicolumn{2}{|c|}{ ANTECEDENTES FAMILIARES } \\
\cline { 2 - 5 } & $\mathbf{N}$ & $\%$ & $\mathbf{2}$ & Controles \\
\hline No & 18 & 13,33 & 15 & 22,73 \\
\hline N/C & 1 & 0,74 & 0 & 0 \\
\hline Sí & 166 & 85,93 & 51 & 77,23 \\
\hline Sólo TA & 3 & 2,22 & 0 & 0 \\
\hline Sólo TE & 37 & 27,41 & 24 & 36,36 \\
\hline Sólo TS & 6 & 4,44 & 2 & 3,03 \\
\hline Varios & 70 & 51,86 & 25 & 37,88 \\
\hline TA + TE & 0 & 0 & 0 & 0 \\
\hline TA + TS & 0 & 0 & 0 & 0 \\
\hline TE + TS & 62 & 45,93 & 23 & 34,85 \\
\hline TA + TE + TS & 8 & 5,93 & 2 & 3,03 \\
\hline
\end{tabular}

Figura 13. Historia psicopatológica familiar

El grupo de casos y el de controles tenían ambos altas frecuencias de antecedentes familiares con psicopatología constitutiva de trastorno.

En lo referente a los antecedentes personales psiquiátricos, se evaluaron los niñosadolescentes que, previo a acudir a consulta, ya habían precisado recibir ayuda de otro psicólogo clínico o psiquiatra en consulta de salud mental. Se obtuvieron los resultados que se representan en siguiente tabla:

\begin{tabular}{|l|c|c|c|c|}
\hline \multicolumn{3}{|c|}{ ANTECEDENTES PERSONALES } \\
\hline \multirow{3}{*}{ Antecedentes personales } & \multicolumn{2}{|c|}{ TDHA + C } & \multicolumn{2}{c|}{ Controles } \\
\cline { 2 - 5 } & N & $\%$ & N & $\%$ \\
\hline Sí & 85 & 62,96 & 11 & 16,67 \\
\hline No & 50 & 37,04 & 55 & 83,33 \\
\hline
\end{tabular}

Figura 14. Antecedentes personales psiquiátricos 
Los resultados ponen de manifiesto la baja proporción en que los controles tienen historia psicopatológica previa, frente a los casos.

La historia académica, en la que, como variables de estudio, hemos analizado los datos acerca de la capacidad intelectual de los pacientes y los rendimientos académicos medios.

\begin{tabular}{|c|c|c|c|c|c|}
\hline & & HIS & ADÉMIC & & \\
\hline & & & & & \\
\hline C.I. & & $N$ & $\%$ & $N$ & $\%$ \\
\hline Sobredotació & & 5 & 3,70 & 1 & 1,52 \\
\hline Alto & & 9 & 6,67 & 7 & 10,61 \\
\hline Medio & & 62 & 45,93 & 36 & 54,55 \\
\hline Bajo & & 13 & 9,63 & 5 & 7,58 \\
\hline Border-line & & 15 & 11,11 & 8 & 4,55 \\
\hline $\mathrm{NC}$ & & 31 & 22,26 & 14 & 21,21 \\
\hline Rendimiento & Académicos & $\mathbf{N}$ & $\%$ & $\mathrm{~N}$ & $\%$ \\
\hline Muy buenos & & 2 & 1,48 & 7 & 10,61 \\
\hline Buenos & & 11 & 8,15 & 17 & 25,76 \\
\hline Medios & & 35 & 25,93 & 23 & 34,85 \\
\hline Malos & & 56 & 41,48 & 10 & 15,15 \\
\hline Fracaso & & 31 & 22,96 & 9 & 13,64 \\
\hline Nivel Acadér & ico & Grupo de & $(\mathrm{N}=135$ & Grup & $\mathrm{V}=66$ ) \\
\hline & $1^{0}(\%)$ & 3,70 & & 7,58 & \\
\hline & $2^{0}(\%)$ & 2,96 & & 3,03 & \\
\hline EPO $/ \%$ & $3^{\circ}(\%)$ & 9,63 & 1880 & 7,58 & 5000 \\
\hline EFU (\%) & $4^{0}(\%)$ & 11,85 & 48,89 & 12,12 & 50,00 \\
\hline & $5^{\circ}(\%)$ & 8,15 & & 7,58 & \\
\hline & $6^{0}(\%)$ & 12,59 & & 12,12 & \\
\hline & $1^{0}(\%)$ & 16,30 & & 7,58 & \\
\hline ESO $/ \%$ & $2^{\circ}(\%)$ & 13,33 & 4503 & 9,09 & 3939 \\
\hline EउU (\%) & $3^{\circ}(\%)$ & 9,63 & 45,90 & 15,15 & 39,09 \\
\hline & $4^{0}(\%)$ & 5,93 & & 7,58 & \\
\hline Rochillor (0/) & $1^{0}(\%)$ & 0,00 & 071 & 0,00 & 55 \\
\hline sacniner (\%) & $2^{0}(\%)$ & 0,74 & 0,14 & 4,55 & 4,00 \\
\hline FP (\%) & & 4,44 & 4,44 & 6,06 & 6,06 \\
\hline
\end{tabular}

Figura 15. Historia académica 
Como se puede observar en los resultados, la proporción de pacientes con fracaso escolar y malos rendimientos es mayor en los niños y adolescentes que tienen un TDAH con comorbilidad psiquiátrica añadida, frente al grupo control que presenta resultados académicos mejores.

En lo referente a las habilidades sociales en las diferentes áreas se analizó la capacidad de los pacientes de ambos grupos de establecer relaciones saludables tanto con sus padres, como con sus profesores y con sus iguales. Se muestra a continuación la relación de datos obtenidos.

\begin{tabular}{|l|c|c|c|c|}
\hline \multicolumn{4}{|c|}{ RELACIONES SOCIALES } \\
\hline & \multicolumn{2}{|c|}{ TDHA + C } & \multicolumn{2}{c|}{ Controles } \\
\hline Paterno-Filial & N & $\%$ & N & $\%$ \\
\hline Buena & 33 & 24,44 & 42 & 63,64 \\
\hline Regular & 53 & 39,26 & 20 & 30,30 \\
\hline Mala & 49 & 36,30 & 4 & 6,06 \\
\hline Profesores & $\mathbf{N}$ & $\%$ & $\mathbf{N}$ & $\%$ \\
\hline Buena & 48 & 35,56 & 51 & 77,27 \\
\hline Regular & 47 & 34,81 & 15 & 22,73 \\
\hline Mala & 40 & 29,63 & 0 & 0 \\
\hline Iguales & $\mathbf{N}$ & $\%$ & $\mathbf{N}$ & $\%$ \\
\hline Buena & 47 & 34,81 & 57 & 86,36 \\
\hline Regular & 47 & 34,81 & 8 & 12,12 \\
\hline Mala & 41 & 30,38 & 1 & 1,52 \\
\hline
\end{tabular}

Figura 16. Relaciones sociales

Por último, se analizó la gravedad de los síntomas del TDAH presentados por los pacientes de los dos grupos de estudio y los que, por tener una clínica que hacía difícil el manejo ambulatorio, habían precisado ingreso en Unidad de Psiquiatría para controlar los síntomas. 


\begin{tabular}{|l|c|c|c|c|}
\hline \multicolumn{2}{|c|}{ GRAVEDAD DE LOS SÍNTOMAS E INGRESOS } \\
\hline \multicolumn{2}{|c|}{ TDHA + C } & \multicolumn{2}{c|}{ Controles } \\
\hline Gravedad TDAH & N & $\%$ & N & $\%$ \\
\hline Leve & 4 & 2,96 & 10 & 15,15 \\
\hline Moderado & 57 & 54,81 & 40 & 60,61 \\
\hline Grave & 57 & 42,22 & 16 & 24,24 \\
\hline Ingresos & $\mathbf{N}$ & $\%$ & $\mathbf{N}$ & $\%$ \\
\hline Sí & 4 & 2,96 & 0 & 0,00 \\
\hline No & 131 & 97,04 & 66 & 100,00 \\
\hline
\end{tabular}

Figura 17. Gravedad de los síntomas y necesidad de ingreso psiquiátrico

Se observa que la presencia de síntomas más graves es más frecuente en el grupo de casos, al igual que el hecho de ser diagnosticados de un TDAH leve es poco probable en el grupo que presenta comorbilidad asociada. 


\subsubsection{Evaluar la presencia de comorbilidad psiquiátrica de los niños y adolescentes con} TDAH de la muestra y la influencia de las variables sexo, grupo de edad, subtipo, agresividad.

Se determinaron, en los sujetos de la muestra y dentro de los tres grandes grupos descritos de los procesos comórbidos, Trastornos del Lenguaje-Aprendizaje (TLA), Trastornos de la Excitación-Motivación (TEM) y Trastornos lo Social-Emocional (TSE), la frecuencia de presentación en los niños o adolescentes de nuestro estudio. Mientras 93, de los niños y adolescentes estudiados, presentaban comorbilidad englobable dentro de uno de los tres grandes grupos (a cada uno de los grupos le hemos asignado diferente color), en 62 de nuestros pacientes, encontramos patologías que hemos clasificado en más de uno de los tres grupos (representados en la figura con un único color).

\section{COMORBILIDAD}

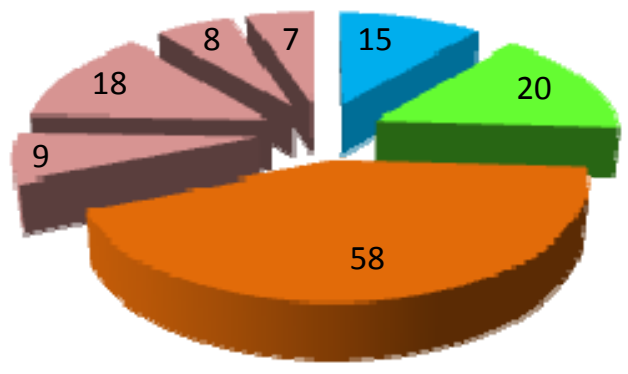

- T. LENGUAJE-APRENDIZAJE(LA)

T. EXCITACIÓNMOTIVACIÓN(EM)

- T. SOCIAL-EMOCIONAL(SE)

- LA+EM

$\mathrm{EM}+\mathrm{SE}$

$\mathrm{SE}+\mathrm{LA}$

LA+EM+SE

Figura 18. Patologías de los pacientes de estudio 
A continuación, en lo relativo a los tres grandes grupos de comorbilidad, para los pacientes que tan sólo padecen enfermedades englobadas en uno de los tres, pormenorizamos la frecuencia con la que aparecen.

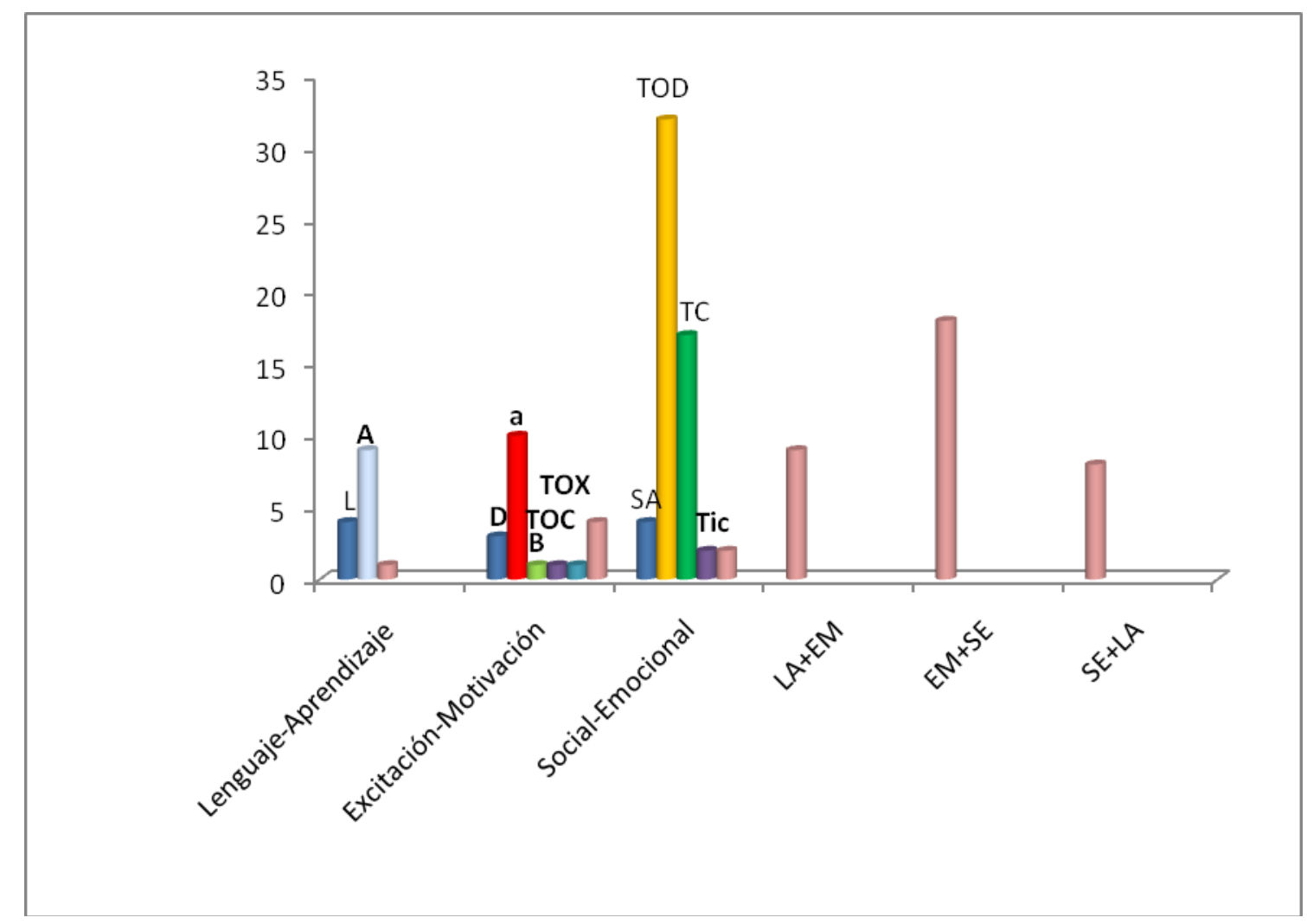

Figura 19. L: trastornos del lenguaje/ A: trastornos del aprendizaje/ D: depresión/a: ansiedad/ B: trastorno bipolar/TOC: trastorno obsesivo-compulsivo/ TOX: trastornos de consumo de tóxicos/SA: Asperger/ TOD: trastorno oposicionista desafiante/TC: trastorno de conducta/ Tic: trastorno de tics/ barras rosas: más de 1 diagnóstico comórbido.

Tras exponer los hallazgos obtenidos relativos a los aspectos más descriptivos pasamos ya a elaborar la parte más relevante de nuestro estudio. Nos centramos en las variables objetivo y la comorbilidad, y valoramos cómo aparecían afectadas en el análisis de nuestra muestra, con respecto a las variables de edad, sexo, subtipo y agresividad.

Se realizaron análisis de regresión lineal para comparar los dos grupos, TDAH con comorbilidad y TDAH sin morbilidad, teniendo en cuenta que las variables de estudio son 
cualitativas en los cuatro casos. En los casos en que la prueba de la Chi-cuadrado nos ha dado resultados de significación estadística, para tener una mejor visualización de los datos, hemos representado también las correspondientes tablas de contingencia y la estimación del riesgo. (Ver tablas de las figuras 19 a 26).

\section{Grupo de edad}

\section{COMORBILIDAD Y EDAD. PRUEBAS DE CHI-CUADRADO}

\begin{tabular}{|c|c|c|c|c|c|}
\hline & Valor & gl & $\begin{array}{l}\text { Sig. asintótica } \\
\text { (bilateral) }\end{array}$ & $\begin{array}{l}\text { Sig. exacta } \\
\text { (bilateral) }\end{array}$ & $\begin{array}{l}\text { Sig. exacta } \\
\text { (unilateral) }\end{array}$ \\
\hline $\begin{array}{l}\text { Chi-cuadrado de } \\
\text { Pearson }\end{array}$ & ,114 (a) & 1 & ,736 & & \\
\hline $\begin{array}{l}\text { Corrección por } \\
\text { continuidad (b) }\end{array}$ &, 035 & 1 & ,852 & & \\
\hline $\begin{array}{l}\text { Razón de } \\
\text { verosimilitudes }\end{array}$ & ,114 & 1 & ,736 & & \\
\hline $\begin{array}{l}\text { Estadístico exacto de } \\
\text { Fisher }\end{array}$ & & & & ,764 & ,425 \\
\hline N de casos válidos & 201 & & & & \\
\hline
\end{tabular}

Figura 20. Comorbilidad y Edad. Pruebas de Chi-Cuadrado 


\section{Género}

\begin{tabular}{|c|c|c|c|c|c|}
\hline \multicolumn{6}{|c|}{ COMORBILIDAD Y SEXO. PRUEBAS DE CHI-CUADRADO } \\
\hline & Valor & gl & $\begin{array}{l}\text { Sig. asintótica } \\
\text { (bilateral) }\end{array}$ & $\begin{array}{c}\text { Sig. exacta } \\
\text { (bilateral) }\end{array}$ & $\begin{array}{l}\text { Sig. exacta } \\
\text { (unilateral) }\end{array}$ \\
\hline $\begin{array}{l}\text { Chi-cuadrado de } \\
\text { Pearson }\end{array}$ & $1,390(a)$ & 1 & ,238 & & \\
\hline $\begin{array}{l}\text { Corrección por } \\
\text { continuidad (b) }\end{array}$ & ,982 & 1 & ,322 & & \\
\hline $\begin{array}{l}\text { Razón de } \\
\text { verosimilitudes }\end{array}$ & 1,442 & 1 & ,230 & & \\
\hline $\begin{array}{l}\text { Estadístico exacto de } \\
\text { Fisher }\end{array}$ & & & & ,265 &, 161 \\
\hline N de casos válidos & 201 & & & & \\
\hline
\end{tabular}

Figura 21. Comorbilidad y Sexo. Pruebas de Chi-Cuadrado

La edad y la comorbilidad no muestran asociación de significacióne estadística según los datos obtenidos $(p=0.736)$. El sexo y la comorbilidad tampoco parecen estar relacionados en nuestro estudio $(p=0.238)$.

\section{Subtipo de TDAH}

\section{TABLA DE CONTINGENCIA. SUBTIPO Y COMORBILIDAD}

\begin{tabular}{|c|c|c|c|c|c|}
\hline & \multicolumn{2}{|c|}{ Comorbilidad } & \multirow{2}{*}{ Total } \\
\hline & & & Si & No & \\
\hline \multirow{6}{*}{$\begin{array}{l}\text { SUBTIPO } \\
\text { DE TDAH }\end{array}$} & \multirow{3}{*}{ Combinado } & Recuento & 101 & 36 & 137 \\
\hline & & $\%$ dentro de SUBTIPO DE TDAH & $73,7 \%$ & $26,3 \%$ & $100,0 \%$ \\
\hline & & \% dentro de COMORBILIDAD & $74,8 \%$ & $54,5 \%$ & $68,2 \%$ \\
\hline & \multirow{3}{*}{ Inatento } & Recuento & 34 & 30 & 64 \\
\hline & & $\%$ dentro de SUBTIPO DE TDAH & $53,1 \%$ & $46,9 \%$ & $100,0 \%$ \\
\hline & & $\%$ dentro de COMORBILIDAD & $25,2 \%$ & $45,5 \%$ & $31,8 \%$ \\
\hline \multirow{3}{*}{\multicolumn{2}{|c|}{ Total }} & Recuento & 135 & 66 & 201 \\
\hline & & \% dentro de SUBTIPO DE TDAH & $67,2 \%$ & $32,8 \%$ & $100,0 \%$ \\
\hline & & $\%$ dentro de COMORBILIDAD & $100,0 \%$ & $100,0 \%$ & $100,0 \%$ \\
\hline
\end{tabular}

Figura 22. Tabla de contingencia. Subtipo y Comorbilidad 


\section{SUBPTIPO Y COMORBILIDAD. PRUEBAS DE CHI-CUADRADO}

\begin{tabular}{|l|c|c|c|c|c|}
\hline & Valor & gl & $\begin{array}{c}\text { Sig. asintótica } \\
\text { (bilateral) }\end{array}$ & $\begin{array}{c}\text { Sig. exacta } \\
\text { (bilateral) }\end{array}$ & $\begin{array}{c}\text { Sig. exacta } \\
\text { (unilateral) }\end{array}$ \\
\hline $\begin{array}{l}\text { Chi-cuadrado de } \\
\text { Pearson }\end{array}$ & $8,392(a)$ & 1 &, 004 & & \\
\hline $\begin{array}{l}\text { Corrección por } \\
\text { continuidad (b) }\end{array}$ & 7,484 & 1 &, 006 & & \\
\hline $\begin{array}{l}\text { Razón de } \\
\text { verosimilitudes }\end{array}$ & 8,190 & 1 &, 004 &, 006 &, 003 \\
\hline $\begin{array}{l}\text { Estadístico exacto de } \\
\text { Fisher }\end{array}$ & & & & & \\
\hline N de casos válidos & 201 & & & & \\
\hline (a) casilas (0,0\%) tienen & & & & & \\
\hline
\end{tabular}

(a) 0 casillas $(0,0 \%)$ tienen una frecuencia esperada inferior a 5. La frecuencia mínima esperada es 21,01.

(b) Calculado sólo para una tabla de 2x2.

Figura 23. Subtipo y Comorbilidad. Pruebas de Chi-Cuadrado

\section{ESTIMACIÓN DEL RIESGO. SUBTIPO Y COMORBILIDAD}

\begin{tabular}{|l|c|c|c|}
\hline & \multicolumn{2}{|l|}{ Valor } & \multicolumn{2}{|l|}{ Intervalo de confianza al 95\% } \\
\cline { 3 - 4 } & & Inferior & Superior \\
\hline $\begin{array}{l}\text { Razón de las ventajas para SUBTIPO DE TDAH } \\
\text { (COMBINADO / INATENTO) }\end{array}$ & 2,475 & 1,330 & 4,607 \\
\hline Para la cohorte COMORBILIDAD = SI & 1,388 & 1,080 & 1,783 \\
\hline Para la cohorte COMORBILIDAD = NO &, 561 &, 382 &, 822 \\
\hline N de casos válidos & 201 & & \\
\hline
\end{tabular}

Figura 24. Estimación del riesgo. Subtipo y Comorbilidad

Los resultados obtenidos, ponen de manifiesto que el padecer un Trastorno de déficit de atención e hiperactividad de predominio inatento, no se comporta de la misma forma frente al riesgo de padecer otras enfermedades comórbidas como el Trastorno de déficit de atención e hiperactividad de subtipo combinado. Existen diferencias significativas 
entre los dos grupos de pacientes en cuanto a presentar comorbilidad psiquiátrica asociada $(p=0.04)$.

En cuanto a la estimación del riesgo reflejada en la figura 24, podemos ver la fuerza de asociación existente entre ambas variables, que viene determinada por la OR (2,475 para combinado/inatento) , y que indica que los pacientes con TDAH subtipo combinado tienen un riesgo 2,4 veces el de los TDAH de predominio inatento para tener comorbilidad. Ver gráfico de barras a continuación.

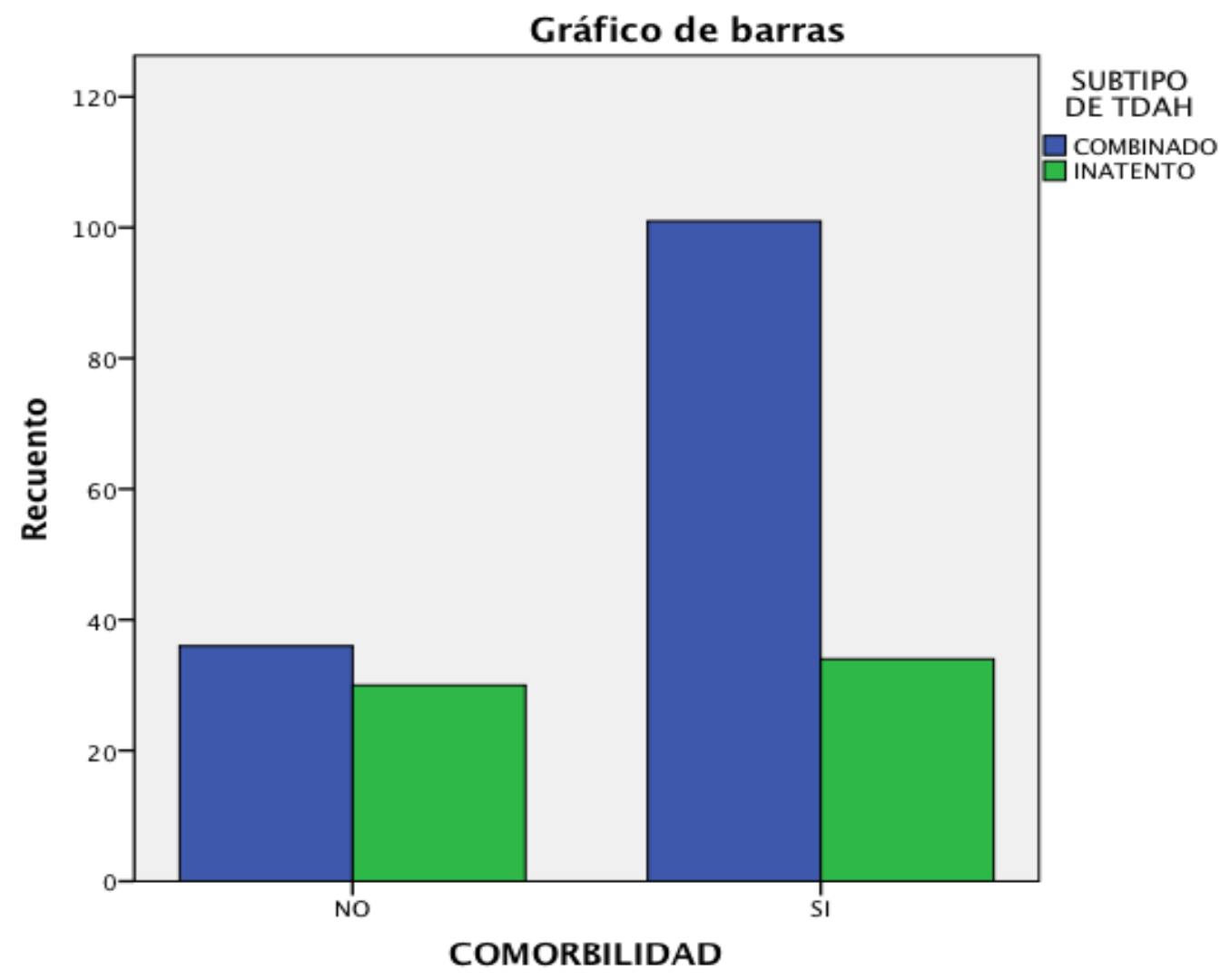

Figura 25. Gráfico de barras 


\section{$\underline{\text { Agresividad }}$}

\begin{tabular}{|c|c|c|c|c|c|}
\hline & & & \multicolumn{2}{|c|}{ Comorbilidad } & \multirow{2}{*}{ Total } \\
\hline & & & $\mathrm{Si}$ & No & \\
\hline \multirow{6}{*}{ Con Agresividad } & \multirow{3}{*}{ Si } & Recuento & 71 & 3 & 74 \\
\hline & & $\%$ dentro de CON AGRESIVIDAD & $95,9 \%$ & $4,1 \%$ & $100,0 \%$ \\
\hline & & $\%$ dentro de COMORBILIDAD & $52,6 \%$ & $4,5 \%$ & $36,8 \%$ \\
\hline & \multirow{3}{*}{ No } & Recuento & 64 & 63 & 127 \\
\hline & & $\%$ dentro de CON AGRESIVIDAD & $50,4 \%$ & $49,6 \%$ & $100,0 \%$ \\
\hline & & $\%$ dentro de COMORBILIDAD & $47,4 \%$ & $95,5 \%$ & $63,2 \%$ \\
\hline \multirow{3}{*}{\multicolumn{2}{|c|}{ Total }} & Recuento & 135 & 66 & 201 \\
\hline & & $\%$ dentro de CON AGRESIVIDAD & $67,2 \%$ & $32,8 \%$ & $100,0 \%$ \\
\hline & & \% dentro de COMORBILIDAD & $100,0 \%$ & $100,0 \%$ & $100,0 \%$ \\
\hline
\end{tabular}

Figura 26. Tabla de contingencia. Comorbilidad y Agresividad

\section{COMORBILIDAD Y AGRESIVIDAD. PRUEBAS DE CHI-CUADRADO}

\begin{tabular}{|c|c|c|c|c|c|}
\hline & Valor & gl & $\begin{array}{l}\text { Sig. asintótica } \\
\text { (bilateral) }\end{array}$ & $\begin{array}{l}\text { Sig. exacta } \\
\text { (bilateral) }\end{array}$ & $\begin{array}{l}\text { Sig. exacta } \\
\text { (unilateral) }\end{array}$ \\
\hline $\begin{array}{l}\text { Chi-cuadrado de } \\
\text { Pearson }\end{array}$ & $43,992(a)$ & 1 & ,000 & & \\
\hline $\begin{array}{l}\text { Corrección por } \\
\text { continuidad (b) }\end{array}$ & 41,951 & 1 & ,000 & & \\
\hline $\begin{array}{l}\text { Razón de } \\
\text { verosimilitudes }\end{array}$ & 53,309 & 1 & ,000 & & \\
\hline $\begin{array}{l}\text { Estadístico exacto de } \\
\text { Fisher }\end{array}$ & & & &, 000 &, 000 \\
\hline N de casos válidos & 201 & & & & \\
\hline
\end{tabular}

Figura 27. Comorbilidad y Agresividad. Pruebas de Chi-Cuadrado 


\section{ESTIMACIÓN DEL RIESGO. COMORBILIDAD Y AGRESIVIDAD}

\begin{tabular}{|l|c|c|c|}
\hline & \multirow{2}{*}{ Valor } & \multicolumn{2}{|l|}{ Intervalo de confianza al 95\% } \\
\cline { 3 - 4 } & & Inferior & Superior \\
\hline $\begin{array}{l}\text { Razón de las ventajas para SUBTIPO DE TDAH } \\
\text { (COMBINADO I INATENTO) }\end{array}$ & 23,297 & 6,972 & 77,851 \\
\hline Para la cohorte COMORBILIDAD = SI & 1,904 & 1,592 & 2,277 \\
\hline Para la cohorte COMORBILIDAD = NO &, 082 &, 027 &, 251 \\
\hline N de casos válidos & 201 & & \\
\hline
\end{tabular}

Figura 28. Estimación del riesgo. Comorbilidad y Agresividad

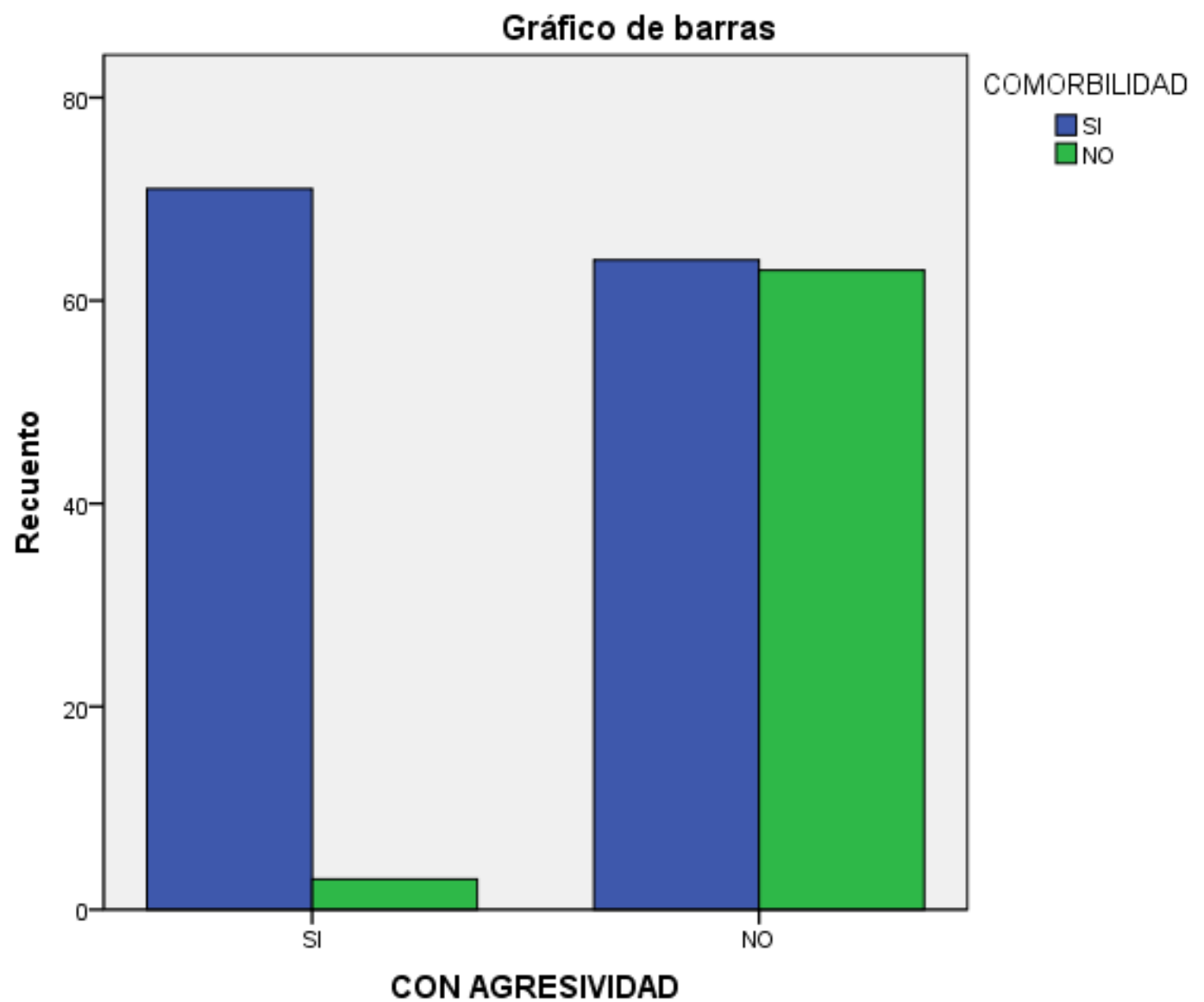

Figura 29. Gráfico de barras 
Los resultados obtenidos, ponen de manifiesto que para los niños/adolescentes que padecen agresividad como síntoma clínico relevante, frente a los que no la tienen, existen diferencias significativas en cuanto a presentar comorbilidad psiquiátrica asociada $(p=0.00)$ a favor de los primeros.

En cuanto a la estimación del riesgo reflejada en la tabla de la figura 26, podemos ver la fuerza de asociación existente entre ambas variables, determinada nuevamente por la OR (Razón de ventajas de 23,297 para agresivos/no agresivos). Los pacientes con agresividad como síntoma clínico relevante tienen un riesgo, 23 veces mayor que el de los no agresivos, para tener comorbilidad.

Por tanto, en función de estos resultados, podemos afirmar que las variables sexo y edad no parecen estar afectando a padecer o no comorbilidad en los sujetos de estudio, ya que no se obtienen resultados estadísticamente significativos. Sin embargo, para las variables subtipo de TDAH y agresividad sí obtenemos diferencias relevantes estadísticamente. Es en estas dos últimas en las que nos vamos a centrar para elaborar el tercer objetivo. 


\subsubsection{Evaluar los tipos de comorbilidad más prevalentes en los pacientes TDAH y la} influencia de las variables subtipo y agresividad.

En este tercer objetivo, vamos a intentar profundizar más en los tipos de comorbilidad más frecuentes y cuáles parecen afectarse, de las dos variables más destacadas de nuestro estudio subtipo y agresividad.

Desglosamos, a continuación, la frecuencia de presentación de las diferentes enfermedades psiquiátricas comórbidas objeto de nuestro estudio. La representación, nuevamente la agrupamos bajo los tres epígrafes de TLA, TEM y TSE. (Ver figura 29).

\section{FRECUENCIA DE LOS TIPOS DE COMORBILIDAD}

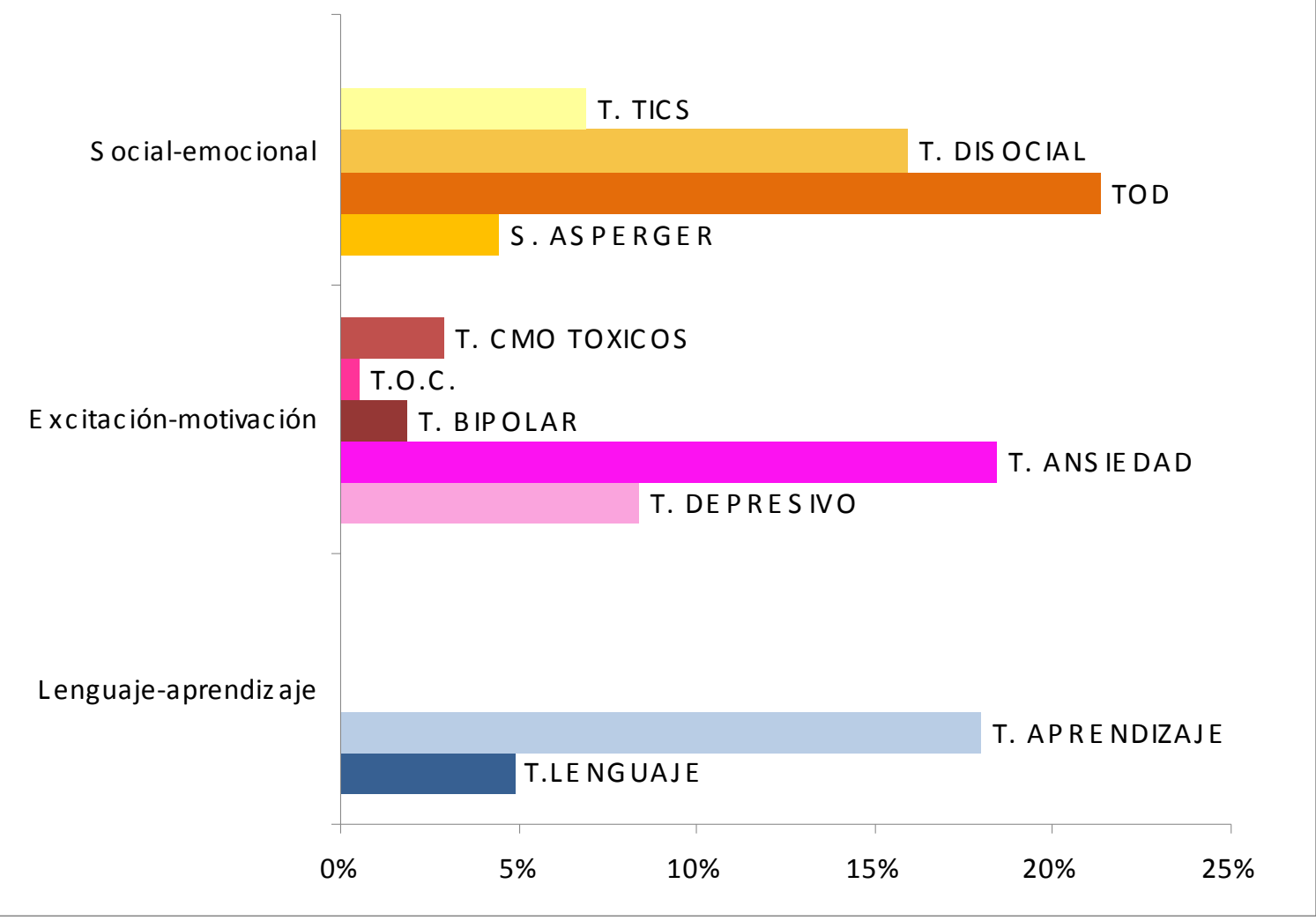

Figura 30. Frecuencia de los tipos de comorbilidad 


\section{Lenguaje-aprendizaje}

- Trastornos del Lenguaje

- Subtipo:

\begin{tabular}{|c|c|c|c|c|c|}
\hline \multicolumn{6}{|c|}{ SUBTIPO. PRUEBAS DE CHI-CUADRADO } \\
\hline & Valor & gl & $\begin{array}{l}\text { Sig. asintótica } \\
\text { (bilateral) }\end{array}$ & $\begin{array}{l}\text { Sig. exacta } \\
\text { (bilateral) }\end{array}$ & $\begin{array}{l}\text { Sig. exacta } \\
\text { (unilateral) }\end{array}$ \\
\hline $\begin{array}{l}\text { Chi-cuadrado de } \\
\text { Pearson }\end{array}$ &, $737(\mathrm{a})$ & 1 &, 391 & & \\
\hline $\begin{array}{l}\text { Corrección por } \\
\text { continuidad (b) }\end{array}$ & ,269 & 1 & ,604 & & \\
\hline $\begin{array}{l}\text { Razón de } \\
\text { verosimilitudes }\end{array}$ & ,738 & 1 & ,390 & & \\
\hline $\begin{array}{l}\text { Estadístico exacto de } \\
\text { Fisher }\end{array}$ & & & &, 503 & ,302 \\
\hline $\mathrm{N}$ de casos válidos & 76 & & & & \\
\hline
\end{tabular}

Figura 31. Subtipo. Pruebas de Chi-Cuadrado

\section{- Agresividad:}

\begin{tabular}{|c|c|c|c|c|c|}
\hline \multicolumn{6}{|c|}{ AGRESIVIDAD. PRUEBAS DE CHI-CUADRADO } \\
\hline & Valor & gl & $\begin{array}{l}\text { Sig. asintótica } \\
\text { (bilateral) }\end{array}$ & $\begin{array}{l}\text { Sig. exacta } \\
\text { (bilateral) }\end{array}$ & $\begin{array}{l}\text { Sig. exacta } \\
\text { (unilateral) }\end{array}$ \\
\hline $\begin{array}{l}\text { Chi-cuadrado de } \\
\text { Pearson }\end{array}$ &, $518(a)$ & 1 & ,472 & & \\
\hline $\begin{array}{l}\text { Corrección por } \\
\text { continuidad (b) }\end{array}$ &, 000 & 1 & 1,000 & & \\
\hline $\begin{array}{l}\text { Razón de } \\
\text { verosimilitudes }\end{array}$ & ,432 & 1 &, 511 & & \\
\hline $\begin{array}{l}\text { Estadístico exacto de } \\
\text { Fisher }\end{array}$ & & & & ,438 & ,438 \\
\hline N de casos válidos & 76 & & & & \\
\hline
\end{tabular}

Figura 32. Agresividad. Pruebas de Chi-Cuadrado 
Los trastornos del lenguaje no muestran asociación estadísticamente significativa ni con el subtipo ni con la agresividad ( $p=0.503$ y $p=0,438$ respectivamente).

\section{- Trastornos del Aprendizaje}

\section{- Subtipo:}

\begin{tabular}{|c|c|c|c|c|c|}
\hline \multicolumn{6}{|c|}{ SUBTIPO. PRUEBAS DE CHI-CUADRADO } \\
\hline & Valor & gl & $\begin{array}{l}\text { Sig. asintótica } \\
\text { (bilateral) }\end{array}$ & $\begin{array}{c}\text { Sig. exacta } \\
\text { (bilateral) }\end{array}$ & $\begin{array}{l}\text { Sig. exacta } \\
\text { (unilateral) }\end{array}$ \\
\hline $\begin{array}{l}\text { Chi-cuadrado de } \\
\text { Pearson }\end{array}$ & , 106 (a) & 1 & ,745 & & \\
\hline $\begin{array}{l}\text { Corrección por } \\
\text { continuidad (b) }\end{array}$ &, 011 & 1 & ,915 & & \\
\hline $\begin{array}{l}\text { Razón de } \\
\text { verosimilitudes }\end{array}$ &, 106 & 1 & ,745 & & \\
\hline $\begin{array}{l}\text { Estadístico exacto de } \\
\text { Fisher }\end{array}$ & & & & ,828 & ,459 \\
\hline $\mathrm{N}$ de casos válidos & 97 & & & & \\
\hline
\end{tabular}

Figura 33. Subtipo. Pruebas de Chi-Cuadrado

\section{- Agresividad:}

\begin{tabular}{|c|c|c|c|c|c|}
\hline \multicolumn{6}{|c|}{ AGRESIVIDAD. PRUEBAS DE CHI-CUADRADO } \\
\hline & Valor & gl & \begin{tabular}{|l} 
Sig. asintótica \\
(bilateral)
\end{tabular} & $\begin{array}{c}\text { Sig. exacta } \\
\text { (bilateral) }\end{array}$ & $\begin{array}{l}\text { Sig. exacta } \\
\text { (unilateral) }\end{array}$ \\
\hline $\begin{array}{l}\text { Chi-cuadrado de } \\
\text { Pearson }\end{array}$ & $7,420(a)$ & 1 & ,006 & & \\
\hline $\begin{array}{l}\text { Corrección por } \\
\text { continuidad (b) }\end{array}$ & 5,598 & 1 & 018 & & \\
\hline $\begin{array}{l}\text { Razón de } \\
\text { verosimilitudes }\end{array}$ & 6,849 & 1 & ,009 & & \\
\hline $\begin{array}{l}\text { Estadístico exacto de } \\
\text { Fisher }\end{array}$ & & & & 011 & 011 \\
\hline N de casos válidos & 97 & & & & \\
\hline \multicolumn{6}{|c|}{ (a) 1 casillas $(25,0 \%)$ tienen una frecuencia esperada inferior a 5 . La frecuencia mínima esperada es 3,20. } \\
\hline (b) Calculado sólo para & abla de $2 x^{2}$ & & & & \\
\hline
\end{tabular}

Figura 34. Agresividad. Pruebas de Chi-Cuadrado 
Para los Trastornos del Aprendizaje, según los resultados obtenidos, mientras el padecer un TDAH inatento o combinado no muestra relación estadísticamente significativa con tener un trastorno del aprendizaje $(p=0,745)$, la agresividad sí muestra relación estadística con presentar problemas de aprendizaje relevantes $(p=0,011)$.

\section{Excitación-Motivación}

- Trastorno Depresivo

\section{- Subtipo:}

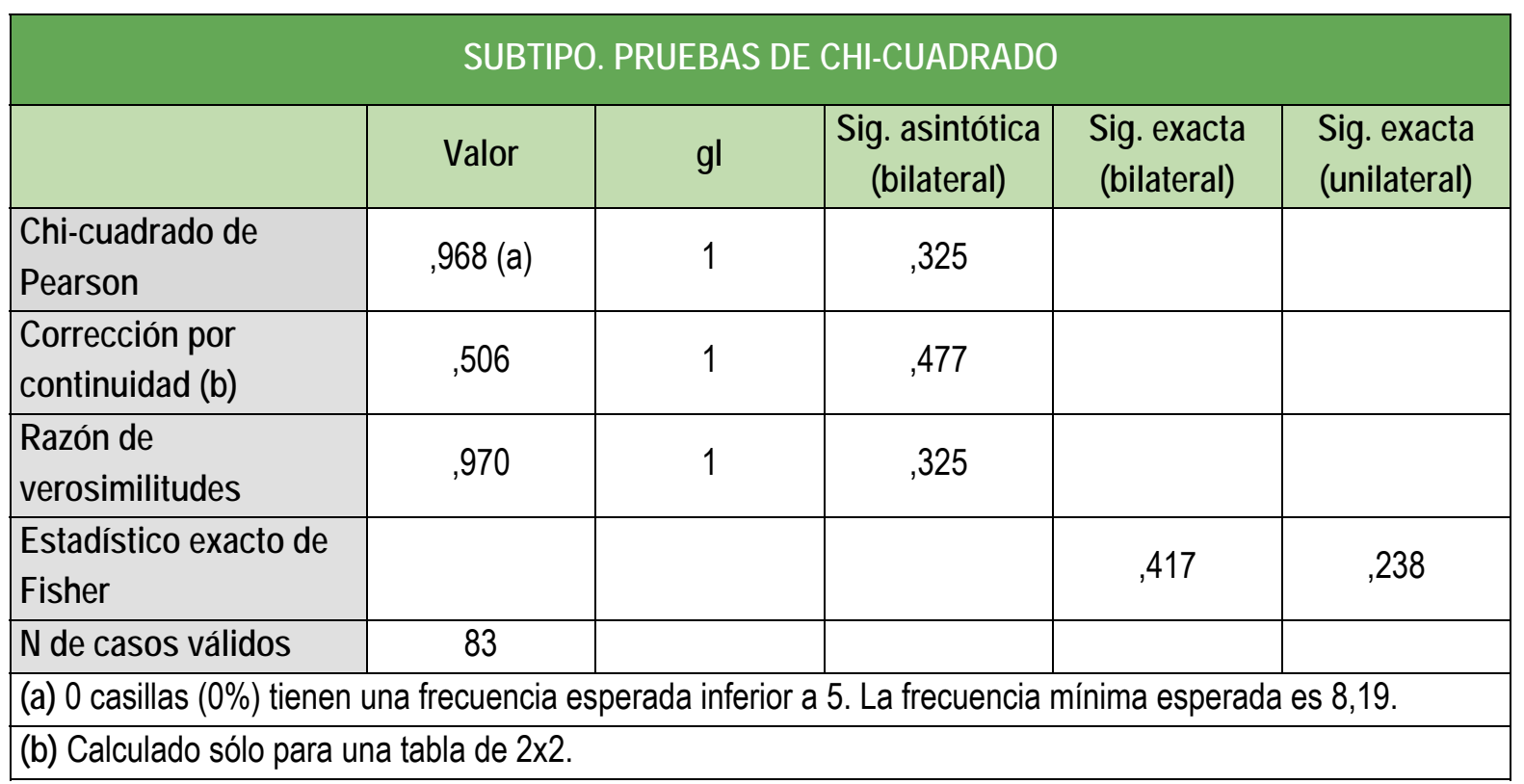

Figura 35. Subtipo. Pruebas de Chi-Cuadrado 
- Agresividad:

\begin{tabular}{|c|c|c|c|c|c|}
\hline \multicolumn{6}{|c|}{ AGRESIVIDAD. PRUEBAS DE CHI-CUADRADO } \\
\hline & Valor & gl & $\begin{array}{l}\text { Sig. asintótica } \\
\text { (bilateral) }\end{array}$ & $\begin{array}{l}\text { Sig. exacta } \\
\text { (bilateral) }\end{array}$ & $\begin{array}{l}\text { Sig. exacta } \\
\text { (unilateral) }\end{array}$ \\
\hline $\begin{array}{l}\text { Chi-cuadrado de } \\
\text { Pearson }\end{array}$ & $9,597(a)$ & 1 &, 002 & & \\
\hline $\begin{array}{l}\text { Corrección por } \\
\text { continuidad (b) }\end{array}$ & 6,954 & 1 &, 008 & & \\
\hline $\begin{array}{l}\text { Razón de } \\
\text { verosimilitudes }\end{array}$ & 7,628 & 1 &, 006 & & \\
\hline $\begin{array}{l}\text { Estadístico exacto de } \\
\text { Fisher }\end{array}$ & & & &, 008 &, 008 \\
\hline N de casos válidos & 83 & & & & \\
\hline
\end{tabular}

Figura 36. Agresividad. Pruebas de Chi-Cuadrado

\section{TABLA DE CONTINGENCIA. CON AGRESIVIDAD - TRASTORNO DEPRESIVO}

\begin{tabular}{|c|c|c|c|c|c|}
\hline & & & Trastorn & epresivo & Tatol $>$ \\
\hline & & & Si & No & \\
\hline & & Recuento & 5 & 3 & 8 \\
\hline & $\mathrm{Si}$ & $\%$ dentro de CON AGRESIVIDAD & $62,5 \%$ & $37,5 \%$ & $100,0 \%$ \\
\hline Can Aaracividad & $\mathrm{SI}$ & $\begin{array}{l}\text { \% dentro de TRASTORNO } \\
\text { DEPRESIVO }\end{array}$ & $29,4 \%$ & $4,5 \%$ & $9,6 \%$ \\
\hline Con Agresividaa & & Recuento & 12 & 63 & 75 \\
\hline & No & $\%$ dentro de CON AGRESIVIDAD & $16,0 \%$ & $84,0 \%$ & $100,0 \%$ \\
\hline & INO & $\begin{array}{l}\text { \% dentro de TRASTORNO } \\
\text { DEPRESIVO }\end{array}$ & $70,6 \%$ & $95,5 \%$ & $90,4 \%$ \\
\hline & & Recuento & 17 & 66 & 83 \\
\hline Total & & $\%$ dentro de CON AGRESIVIDAD & $20,5 \%$ & $79,5 \%$ & $100,0 \%$ \\
\hline Tulal & & $\begin{array}{l}\text { \% dentro de TRASTORNO } \\
\text { DEPRESIVO }\end{array}$ & $100,0 \%$ & $100,0 \%$ & $100,0 \%$ \\
\hline
\end{tabular}

Figura 37. Tabla de contingencia. Con Agresividad -Trastorno Depresivo 


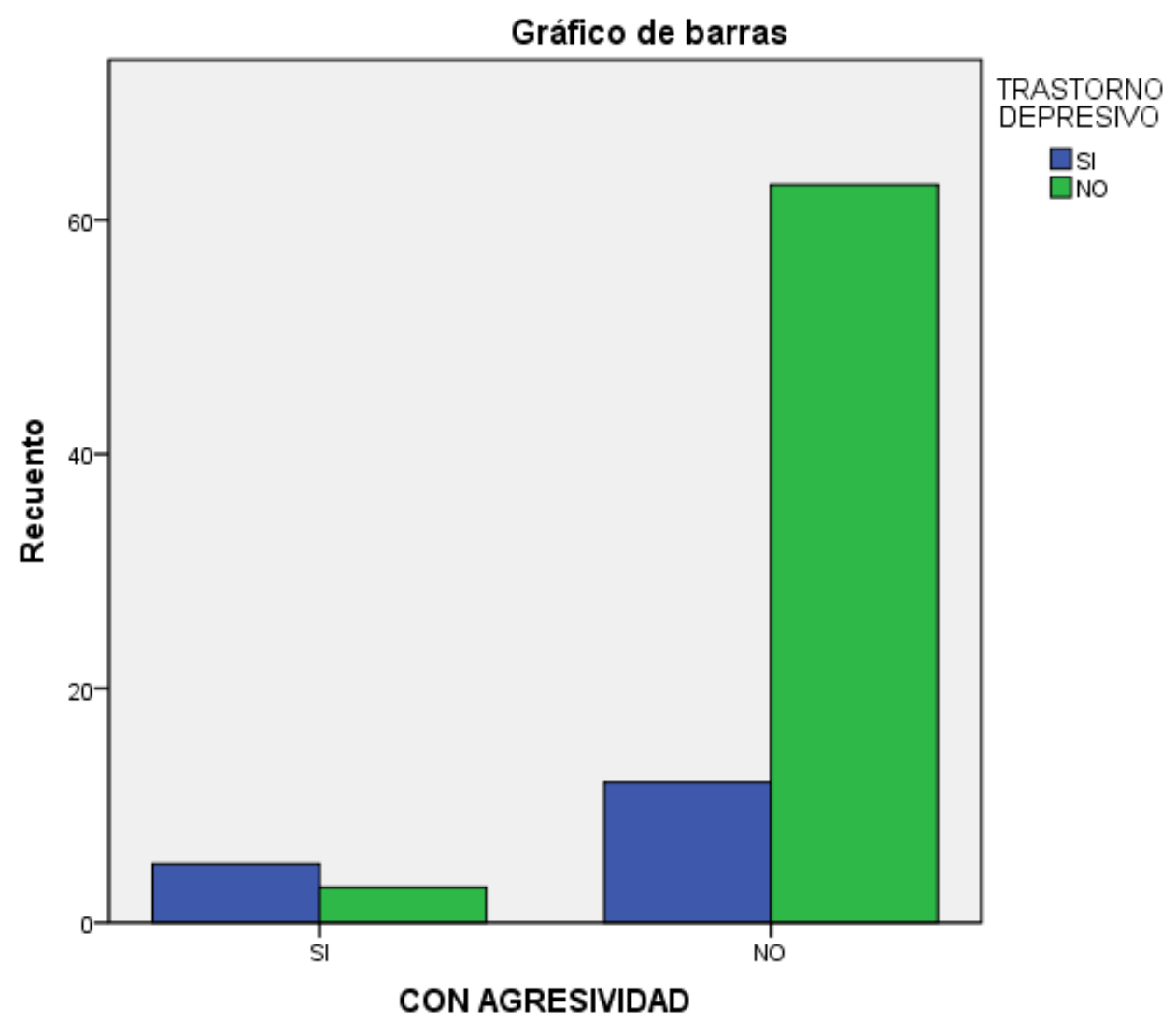

Figura 38. Gráfico de barras

En relación a los Trastornos Depresivos, mientras que el subtipo de TDAH no muestra relación estadística con padecer asociados Trastornos Depresivos $(p=0.32)$, la presencia de agresividad, como síntoma clínicamente significativo, en el paciente TDAH, muestra asociarse estadísticamente de forma significativa a la depresión $(p=0.008)$. 


\section{- Trastorno Bipolar}

\section{- Subtipo:}

\begin{tabular}{|c|c|c|c|c|c|}
\hline \multicolumn{6}{|c|}{ SUBTIPO. PRUEBAS DE CHI-CUADRADO } \\
\hline & Valor & gl & $\begin{array}{l}\text { Sig. asintótica } \\
\text { (bilateral) }\end{array}$ & $\begin{array}{c}\text { Sig. exacta } \\
\text { (bilateral) }\end{array}$ & $\begin{array}{l}\text { Sig. exacta } \\
\text { (unilateral) }\end{array}$ \\
\hline $\begin{array}{l}\text { Chi-cuadrado de } \\
\text { Pearson }\end{array}$ & $3,182(a)$ & 1 &, 074 & & \\
\hline $\begin{array}{l}\text { Corrección por } \\
\text { continuidad (b) }\end{array}$ & 1,596 & 1 & ,206 & & \\
\hline $\begin{array}{l}\text { Razón de } \\
\text { verosimilitudes }\end{array}$ & 4,658 & 1 &, 031 & & \\
\hline $\begin{array}{l}\text { Estadístico exacto de } \\
\text { Fisher }\end{array}$ & & & &, 130 &, 100 \\
\hline $\mathrm{N}$ de casos válidos & 70 & & & & \\
\hline \multicolumn{6}{|c|}{ (a) 2 casillas (50,0\%) tienen una frecuencia esperada inferior a 5. La frecuencia mínima esperada es 1,71. } \\
\hline (b) Calculado sólo para & abla de $2 \times 2$ & & & & \\
\hline
\end{tabular}

Figura 39. Subtipo. Pruebas de Chi-Cuadrado

\section{- Agresividad:}

\begin{tabular}{|c|c|c|c|c|c|}
\hline \multicolumn{6}{|c|}{ AGRESIVIDAD. PRUEBAS DE CHI-CUADRADO } \\
\hline & Valor & gl & $\begin{array}{l}\text { Sig. asintótica } \\
\text { (bilateral) }\end{array}$ & $\begin{array}{c}\text { Sig. exacta } \\
\text { (bilateral) }\end{array}$ & $\begin{array}{l}\text { Sig. exacta } \\
\text { (unilateral) }\end{array}$ \\
\hline $\begin{array}{l}\text { Chi-cuadrado de } \\
\text { Pearson }\end{array}$ & $11,748(a)$ & 1 &, 001 & & \\
\hline $\begin{array}{l}\text { Corrección por } \\
\text { continuidad (b) }\end{array}$ & 5,895 & 1 &, 015 & & \\
\hline $\begin{array}{l}\text { Razón de } \\
\text { verosimilitudes }\end{array}$ & 6,072 & 1 & ,014 & & \\
\hline $\begin{array}{l}\text { Estadístico exacto de } \\
\text { Fisher }\end{array}$ & & & &, 023 &, 023 \\
\hline $\mathrm{N}$ de casos válidos & 70 & & & & \\
\hline \multicolumn{6}{|c|}{ (a) 3 casillas $(75,0 \%)$ tienen una frecuencia esperada inferior a 5. La frecuencia mínima esperada es 0,29. } \\
\hline
\end{tabular}

Figura 40. Agresividad. Pruebas de Chi-Cuadrado 


\begin{tabular}{|c|c|c|c|c|c|}
\hline \multicolumn{6}{|c|}{ TABLA DE CONTINGENCIA. CON AGRESIVIDAD - TRASTORNO BIPOLAR } \\
\hline & & & \multicolumn{2}{|c|}{ Trastorno Bipolar } & \multirow{3}{*}{$\begin{array}{c}\text { Total } \\
5\end{array}$} \\
\hline & & & Si & No & \\
\hline \multirow{6}{*}{ Con Agresividad } & \multirow{3}{*}{ Si } & Recuento & 2 & 3 & \\
\hline & & $\%$ dentro de CON AGRESIVIDAD & $40,0 \%$ & $60,0 \%$ & $100,0 \%$ \\
\hline & & $\begin{array}{l}\text { \% dentro de TRASTORNO } \\
\text { BIPOLAR }\end{array}$ & $50,0 \%$ & $4,5 \%$ & $7,1 \%$ \\
\hline & \multirow{3}{*}{ No } & Recuento & 2 & 63 & 65 \\
\hline & & $\%$ dentro de CON AGRESIVIDAD & $3,1 \%$ & $96,9 \%$ & $100,0 \%$ \\
\hline & & $\begin{array}{l}\text { \% dentro de TRASTORNO } \\
\text { BIPOLAR }\end{array}$ & $50,0 \%$ & $95,5 \%$ & $92,9 \%$ \\
\hline \multirow{3}{*}{\multicolumn{2}{|c|}{ Total }} & Recuento & 4 & 66 & 70 \\
\hline & & $\%$ dentro de CON AGRESIVIDAD & $5,7 \%$ & $94,3 \%$ & $100,0 \%$ \\
\hline & & $\begin{array}{l}\text { \% dentro de TRASTORNO } \\
\text { BIPOLAR }\end{array}$ & $100,0 \%$ & $100,0 \%$ & $100,0 \%$ \\
\hline
\end{tabular}

Figura 41. Tabla de contingencia. Con Agresividad -Trastorno Bipolar

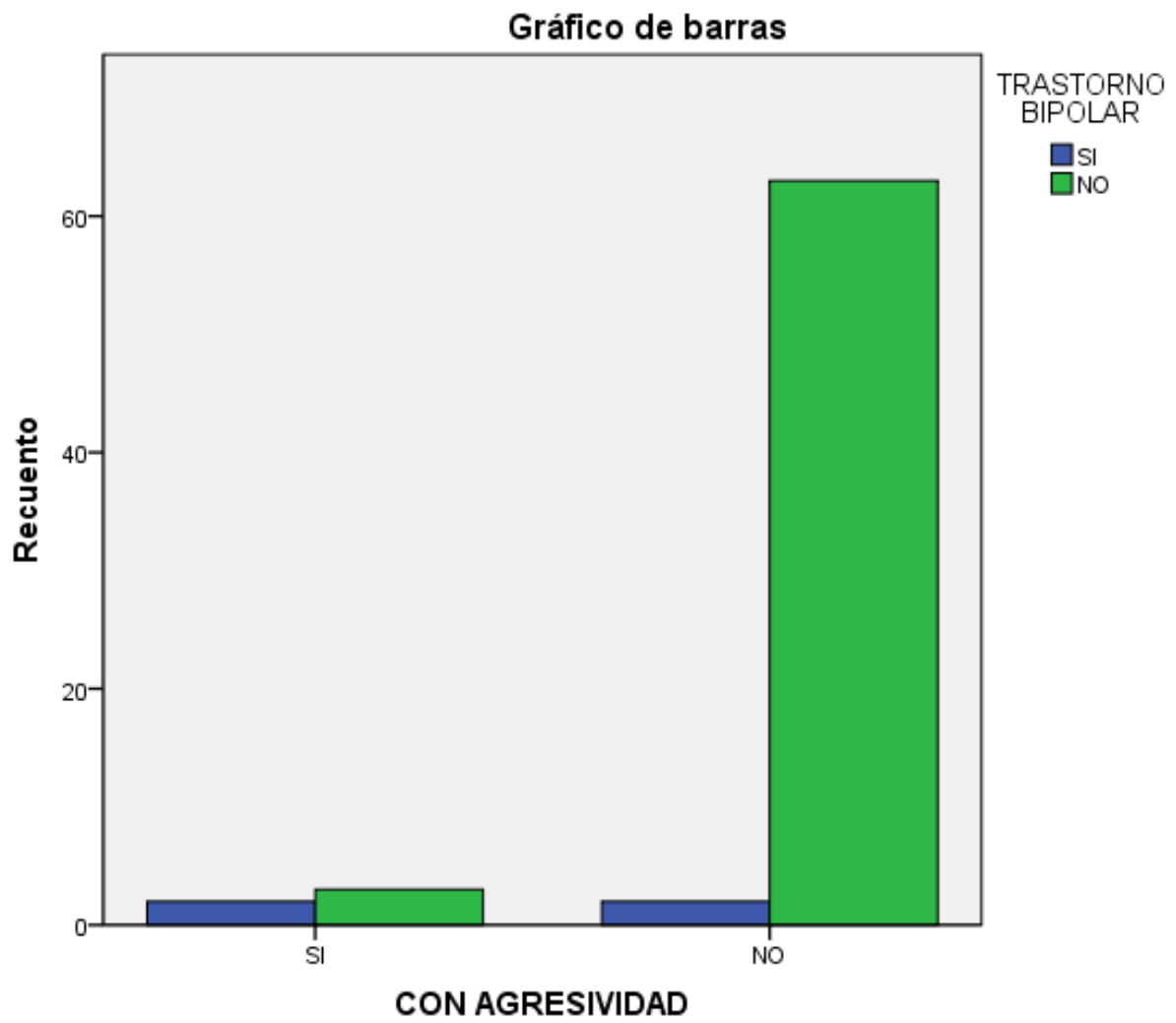

Figura 42. Gráfico de barras 
De forma similar a lo observado para los trastornos de ánimo depresivo, el subtipo de TDAH no parece relacionarse estadísticamente con padecer asociado el Trastorno Bipolar $(p=0.130)$, la presencia de agresividad entre los síntomas clínicamente significativos en el paciente TDAH muestra asociarse estadísticamente de forma significativa a la manía $(p=0.023)$.

- Trastornos de Ansiedad

- Subtipo:

\begin{tabular}{|c|c|c|c|c|c|}
\hline \multicolumn{6}{|c|}{ SUBTIPO. PRUEBAS DE CHI-CUADRADO } \\
\hline & Valor & gl & $\begin{array}{l}\text { Sig. asintótica } \\
\text { (bilateral) }\end{array}$ & $\begin{array}{l}\text { Sig. exacta } \\
\text { (bilateral) }\end{array}$ & $\begin{array}{l}\text { Sig. exacta } \\
\text { (unilateral) }\end{array}$ \\
\hline $\begin{array}{l}\text { Chi-cuadrado de } \\
\text { Pearson }\end{array}$ & ,047 (a) & 1 & ,829 & & \\
\hline $\begin{array}{l}\text { Corrección por } \\
\text { continuidad (b) }\end{array}$ &, 000 & 1 & ,992 & & \\
\hline $\begin{array}{l}\text { Razón de } \\
\text { verosimilitudes }\end{array}$ &, 047 & 1 & ,828 & & \\
\hline $\begin{array}{l}\text { Estadístico exacto de } \\
\text { Fisher }\end{array}$ & & & & 840 & ,497 \\
\hline N de casos válidos & 103 & & & & \\
\hline
\end{tabular}

Figura 43. Subtipo. Pruebas de Chi-Cuadrado 
- Agresividad:

\begin{tabular}{|c|c|c|c|c|c|}
\hline \multicolumn{6}{|c|}{ AGRESIVIDAD. PRUEBAS DE CHI-CUADRADO } \\
\hline & Valor & gl & $\begin{array}{l}\text { Sig. asintótica } \\
\text { (bilateral) }\end{array}$ & $\begin{array}{l}\text { Sig. exacta } \\
\text { (bilateral) }\end{array}$ & $\begin{array}{l}\text { Sig. exacta } \\
\text { (unilateral) }\end{array}$ \\
\hline $\begin{array}{l}\text { Chi-cuadrado de } \\
\text { Pearson }\end{array}$ & $7,247(a)$ & 1 &, 007 & & \\
\hline $\begin{array}{l}\text { Corrección por } \\
\text { continuidad (b) }\end{array}$ & 5,568 & 1 &, 018 & & \\
\hline $\begin{array}{l}\text { Razón de } \\
\text { verosimilitudes }\end{array}$ & 6,950 & 1 &, 008 & & \\
\hline $\begin{array}{l}\text { Estadístico exacto de } \\
\text { Fisher }\end{array}$ & & & &, 016 & ,010 \\
\hline N de casos válidos & 103 & & & & \\
\hline
\end{tabular}

Figura 44. Agresividad. Pruebas de Chi-Cuadrado

\section{TABLA DE CONTINGENCIA. CON AGRESIVIDAD - TRASTORNO DE ANSIEDAD}

\begin{tabular}{|c|c|c|c|c|c|}
\hline & & & \multicolumn{2}{|c|}{ Trastorno de Ansiedad } & \multirow{2}{*}{ Total } \\
\hline & & & Si & No & \\
\hline \multirow{6}{*}{ Con Agresividad } & \multirow{3}{*}{$\mathrm{Si}$} & Recuento & 8 & 3 & 11 \\
\hline & & $\%$ dentro de CON AGRESIVIDAD & $72,7 \%$ & $27,3 \%$ & $100,0 \%$ \\
\hline & & $\begin{array}{l}\text { \% dentro de TRASTORNO DE } \\
\text { ANSIEDAD }\end{array}$ & $21,6 \%$ & $4,5 \%$ & $10,7 \%$ \\
\hline & \multirow{3}{*}{ No } & Recuento & 29 & 63 & 92 \\
\hline & & $\%$ dentro de CON AGRESIVIDAD & $31,5 \%$ & $68,5 \%$ & $100,0 \%$ \\
\hline & & $\begin{array}{l}\text { \% dentro de TRASTORNO DE } \\
\text { ANSIEDAD }\end{array}$ & $78,4 \%$ & $95,5 \%$ & $89,3 \%$ \\
\hline \multirow{3}{*}{\multicolumn{2}{|c|}{ Total }} & Recuento & 37 & 66 & 103 \\
\hline & & $\%$ dentro de CON AGRESIVIDAD & $35,9 \%$ & $64,1 \%$ & $100,0 \%$ \\
\hline & & $\begin{array}{l}\text { \% dentro de TRASTORNO DE } \\
\text { ANSIEDAD }\end{array}$ & $100,0 \%$ & $100,0 \%$ & $100,0 \%$ \\
\hline
\end{tabular}

Figura 45. Tabla de contingencia. Con Agresividad -Trastorno de Ansiedad 


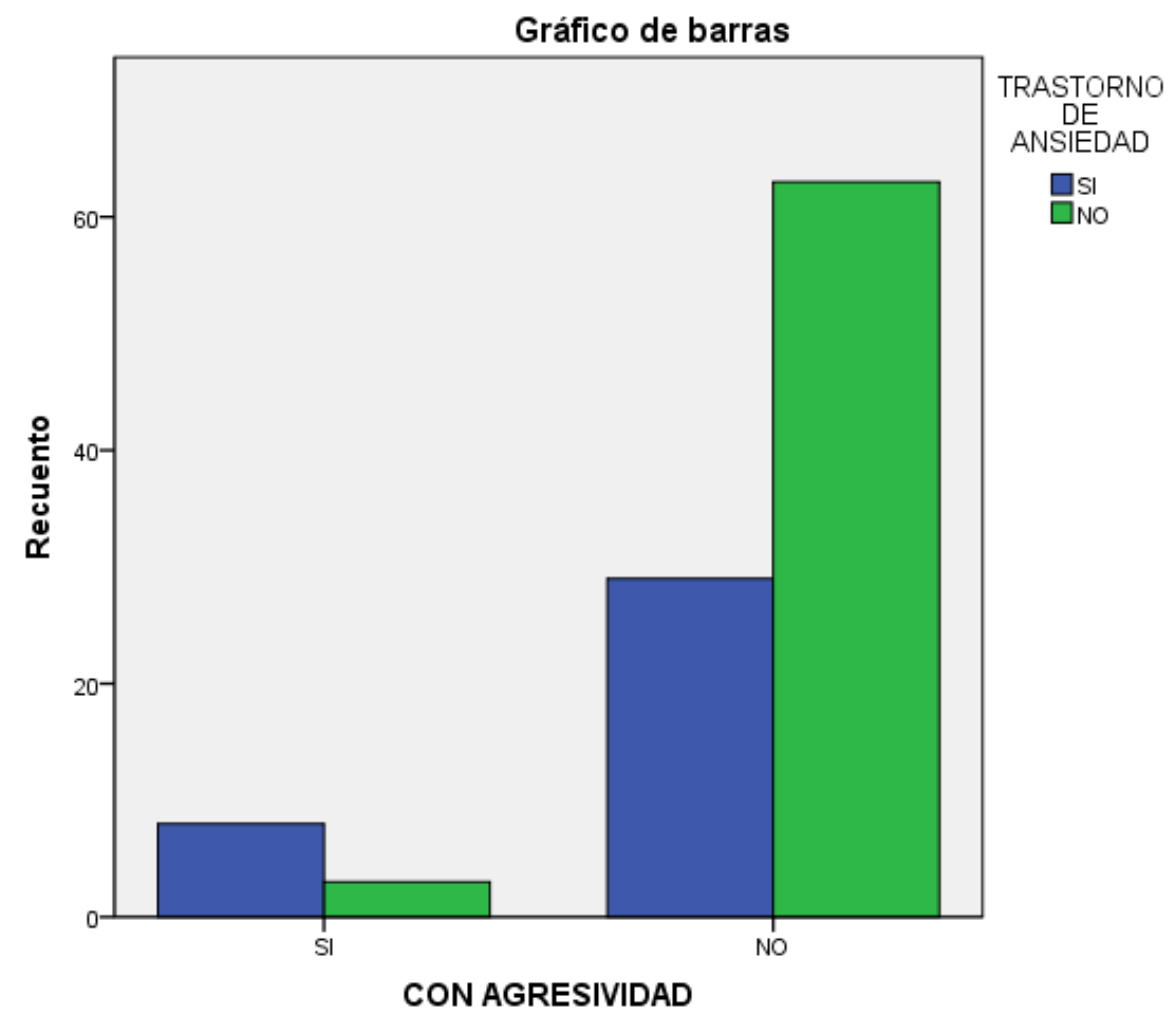

Figura 46. Gráfico de barras

Para la variable agresividad, existen diferencias de significación estadística en caso de padecer Trastorno de Ansiedad comórbido frente al grupo de controles que no lo padecen $(\mathrm{p}=0.016)$, mientras ambos subtipos de TDAH inatento $y$ combinado no muestra diferencias estadísticamente relevantes para tener $t$. ansiedad asociados (0.829). 


\section{- Trastornos por Consumo de Tóxicos}

\section{- Subtipo:}

\begin{tabular}{|c|c|c|c|c|c|}
\hline \multicolumn{6}{|c|}{ SUBTIPO. PRUEBAS DE CHI-CUADRADO } \\
\hline & Valor & gl & $\begin{array}{c}\text { Sig. asintótica } \\
\text { (bilateral) }\end{array}$ & $\begin{array}{c}\text { Sig. exacta } \\
\text { (bilateral) }\end{array}$ & $\begin{array}{l}\text { Sig. exacta } \\
\text { (unilateral) }\end{array}$ \\
\hline $\begin{array}{l}\text { Chi-cuadrado de } \\
\text { Pearson }\end{array}$ & $4,675(a)$ & 1 & ,031 & & \\
\hline $\begin{array}{l}\text { Corrección por } \\
\text { continuidad (b) }\end{array}$ & 2,992 & 1 & 084 & & \\
\hline $\begin{array}{l}\text { Razón de } \\
\text { verosimilitudes }\end{array}$ & 6,855 & 1 & ,009 & & \\
\hline $\begin{array}{l}\text { Estadístico exacto de } \\
\text { Fisher }\end{array}$ & & & & ,037 & 034 \\
\hline $\mathrm{N}$ de casos válidos & 72 & & & & \\
\hline \multicolumn{6}{|c|}{ (a) 2 casillas $(50,0 \%)$ tienen una frecuencia esperada inferior a 5 . La frecuencia mínima esperada es 2,50 } \\
\hline (b) Calculado sólo para & tabla de $2 \times 2$ & & & & \\
\hline
\end{tabular}

Figura 47. Subtipo. Pruebas de Chi-Cuadrado

\begin{tabular}{|c|c|c|c|c|c|}
\hline \multicolumn{6}{|c|}{ TABLA DE CONTINGENCIA. SUBTIPO DE TDAH - ABUSO DE TÓXICOS } \\
\hline & & & \multicolumn{2}{|c|}{ Abuso de Tóxicos } & \multirow{2}{*}{ Total } \\
\hline & & & Si & No & \\
\hline \multirow{6}{*}{$\begin{array}{l}\text { Subtipo de } \\
\text { TDAH }\end{array}$} & \multirow{3}{*}{ Combinado } & Recuento & 6 & 36 & 42 \\
\hline & & $\%$ dentro de SUBTIPO DE TDAH & $14,3 \%$ & $85,7 \%$ & $100,0 \%$ \\
\hline & & $\begin{array}{l}\text { \% dentro de ABUSO DE } \\
\text { TÓXICOS }\end{array}$ & $100,0 \%$ & $54,5 \%$ & $58,3 \%$ \\
\hline & \multirow{3}{*}{ Inatento } & Recuento & 0 & 30 & 30 \\
\hline & & $\%$ dentro de SUBTIPO DE TDAH & $0 \%$ & $100,0 \%$ & $100,0 \%$ \\
\hline & & $\begin{array}{l}\text { \% dentro de ABUSO DE } \\
\text { TÓXICOS }\end{array}$ &, $0 \%$ & $45,5 \%$ & $41,7 \%$ \\
\hline \multirow{3}{*}{\multicolumn{2}{|c|}{ Total }} & Recuento & 6 & 66 & 72 \\
\hline & & $\%$ dentro de SUBTIPO DE TDAH & $8,3 \%$ & $91,7 \%$ & $100,0 \%$ \\
\hline & & $\begin{array}{l}\text { \% dentro de ABUSO DE } \\
\text { TÓxICOS }\end{array}$ & $100,0 \%$ & $100,0 \%$ & $100,0 \%$ \\
\hline
\end{tabular}

Figura 48. Tabla de contingencia. Subtipo de TDAH - Abuso de Tóxicos 


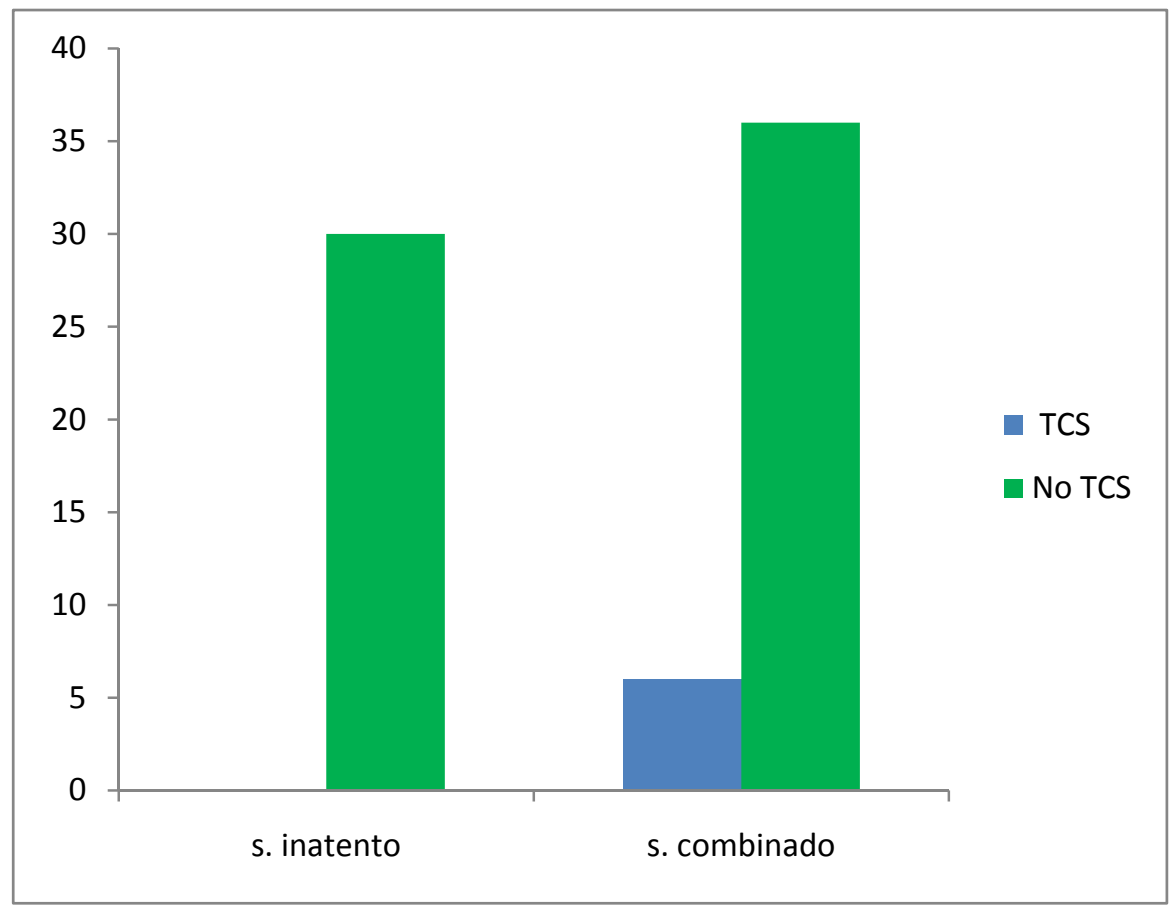

Figura 49. Gráfico de barras

\section{- Agresividad:}

\begin{tabular}{|c|c|c|c|c|c|}
\hline \multicolumn{6}{|c|}{ AGRESIVIDAD. PRUEBAS DE CHI-CUADRADO } \\
\hline & Valor & gl & $\begin{array}{c}\text { Sig. asintótica } \\
\text { (bilateral) }\end{array}$ & $\begin{array}{c}\text { Sig. exacta } \\
\text { (bilateral) }\end{array}$ & $\begin{array}{l}\text { Sig. exacta } \\
\text { (unilateral) }\end{array}$ \\
\hline $\begin{array}{l}\text { Chi-cuadrado de } \\
\text { Pearson }\end{array}$ & $45,818(a)$ & 1 &, 000 & & \\
\hline $\begin{array}{l}\text { Corrección por } \\
\text { continuidad (b) }\end{array}$ & 37,506 & 1 &, 000 & & \\
\hline $\begin{array}{l}\text { Razón de } \\
\text { verosimilitudes }\end{array}$ & 29,847 & 1 &, 000 & & \\
\hline $\begin{array}{l}\text { Estadístico exacto de } \\
\text { Fisher }\end{array}$ & & & &, 000 &, 000 \\
\hline $\mathrm{N}$ de casos válidos & 72 & & & & \\
\hline \multicolumn{6}{|c|}{ (a) 1 casillas $(25,0 \%)$ tienen una frecuencia esperada inferior a 5 . La frecuencia mínima esperada es 0,75 . } \\
\hline (h) Coloulodo ćl nom & tabla de $2 \times 2$ & & & & \\
\hline
\end{tabular}

Figura 50. Agresividad. Pruebas de Chi-Cuadrado 


\begin{tabular}{|c|c|c|c|c|c|}
\hline \multicolumn{6}{|c|}{ TABLA DE CONTINGENCIA. CON AGRESIVIDAD - ABUSO DE TÓXICOS } \\
\hline & & & \multicolumn{2}{|c|}{ Abuso de Tóxicos } & \multirow{2}{*}{ Total } \\
\hline & & & $\mathrm{Si}$ & No & \\
\hline \multirow{6}{*}{ Con Agresividad } & \multirow{3}{*}{ Si } & Recuento & 6 & 3 & 9 \\
\hline & & $\%$ dentro de CON AGRESIVIDAD & $66,7 \%$ & $33,3 \%$ & $100,0 \%$ \\
\hline & & $\begin{array}{l}\text { \% dentro de ABUSO DE } \\
\text { TÓXICOS }\end{array}$ & $100,0 \%$ & $4,5 \%$ & $12,5 \%$ \\
\hline & \multirow{3}{*}{ No } & Recuento & 0 & 63 & 63 \\
\hline & & $\%$ dentro de CON AGRESIVIDAD & $0 \%$ & $100,0 \%$ & $100,0 \%$ \\
\hline & & $\begin{array}{l}\% \text { dentro de ABUSO DE } \\
\text { TÓXICOS }\end{array}$ &, $0 \%$ & $95,5 \%$ & $87,5 \%$ \\
\hline \multirow{3}{*}{\multicolumn{2}{|c|}{ Total }} & Recuento & 6 & 66 & 72 \\
\hline & & $\%$ dentro de CON AGRESIVIDAD & $8,3 \%$ & $91,7 \%$ & $100,0 \%$ \\
\hline & & $\begin{array}{l}\text { \% dentro de ABUSO DE } \\
\text { TÓXICOS }\end{array}$ & $100,0 \%$ & $100,0 \%$ & $100,0 \%$ \\
\hline
\end{tabular}

Figura 51. Tabla de contingencia. Con Agresividad-Abuso de Tóxicos

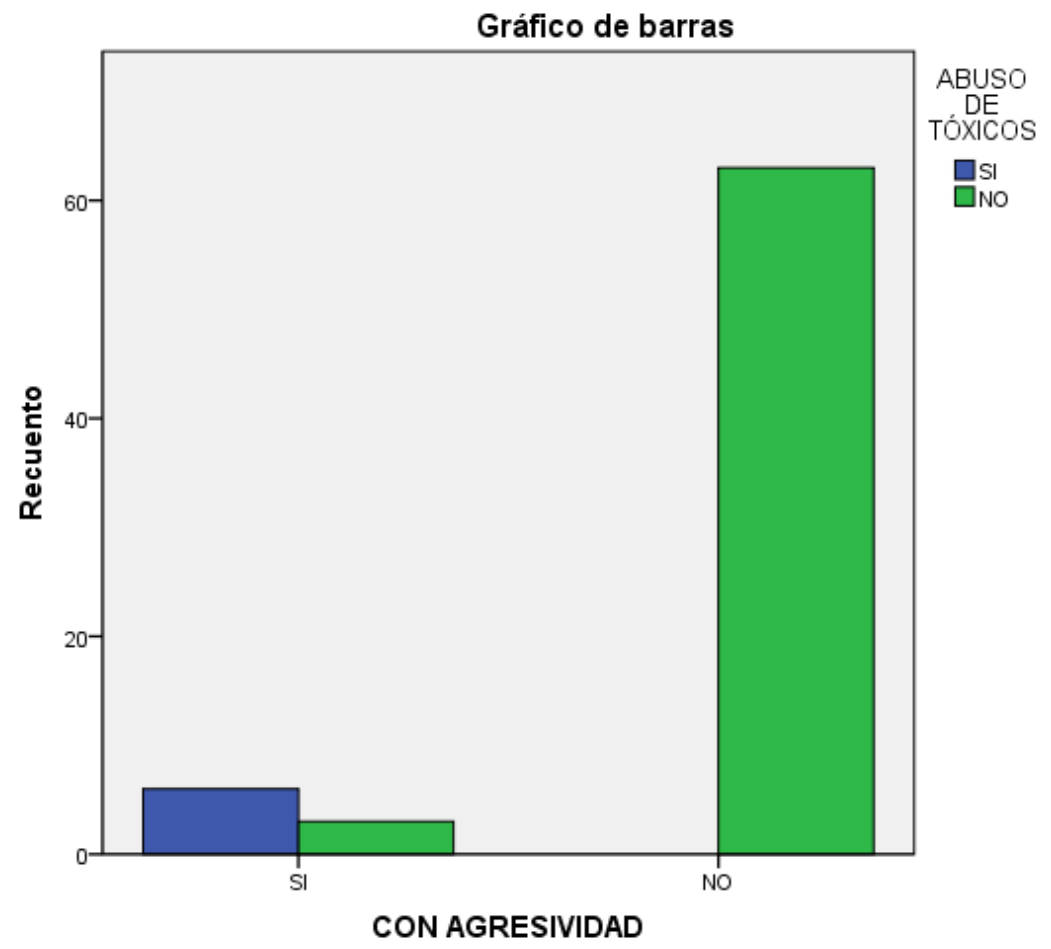

Figura 52. Gráfico de barras 
Si valoramos los datos en relación al Trastorno por Abuso de Tóxicos, obtenemos entre ambos grupos TDAH subtipo inatento y subtipo combinado que existen diferencias estadísticamente significativas $(p=0.037)$. Para los pacientes TDAH tener agresividad está fuertemente relacionado de forma estadísticamente significativa con el consumo de tóxicos $(p=0.000)$. 


\section{Social-Emocional}

\section{- Síndrome de Asperger}

- Subtipo:

\begin{tabular}{|c|c|c|c|c|c|}
\hline \multicolumn{6}{|c|}{ SUBTIPO. PRUEBAS DE CHI-CUADRADO } \\
\hline & Valor & gl & $\begin{array}{l}\text { Sig. asintótica } \\
\text { (bilateral) }\end{array}$ & $\begin{array}{l}\text { Sig. exacta } \\
\text { (bilateral) }\end{array}$ & $\begin{array}{l}\text { Sig. exacta } \\
\text { (unilateral) }\end{array}$ \\
\hline $\begin{array}{l}\text { Chi-cuadrado de } \\
\text { Pearson }\end{array}$ & ,472 (a) & 1 & ,492 & & \\
\hline $\begin{array}{l}\text { Corrección por } \\
\text { continuidad (b) }\end{array}$ &, 108 & 1 & ,742 & & \\
\hline $\begin{array}{l}\text { Razón de } \\
\text { verosimilitudes }\end{array}$ & ,483 & 1 & ,487 & & \\
\hline $\begin{array}{l}\text { Estadístico exacto de } \\
\text { Fisher }\end{array}$ & & & & ,723 & ,376 \\
\hline $\mathrm{N}$ de casos válidos & 75 & & & & \\
\hline \multicolumn{6}{|c|}{ (a) 1 casillas $(25,0 \%)$ tienen una frecuencia esperada inferior a 5 . La frecuencia mínima esperada es 3,96 } \\
\hline (b) Calculado sólo para & abla de $2 x^{\prime}$ & & & & \\
\hline
\end{tabular}

Figura 53. Subtipo. Pruebas de Chi-Cuadrado

\section{- Agresividad:}

\begin{tabular}{|c|c|c|c|c|c|}
\hline \multicolumn{6}{|c|}{ AGRESIVIDAD. PRUEBAS DE CHI-CUADRADO } \\
\hline & Valor & gl & $\begin{array}{l}\text { Sig. asintótica } \\
\text { (bilateral) }\end{array}$ & $\begin{array}{c}\text { Sig. exacta } \\
\text { (bilateral) }\end{array}$ & $\begin{array}{l}\text { Sig. exacta } \\
\text { (unilateral) }\end{array}$ \\
\hline $\begin{array}{l}\text { Chi-cuadrado de } \\
\text { Pearson }\end{array}$ & ,676 (a) & 1 & ,411 & & \\
\hline $\begin{array}{l}\text { Corrección por } \\
\text { continuidad (b) }\end{array}$ & 001 & 1 & ,975 & & \\
\hline $\begin{array}{l}\text { Razón de } \\
\text { verosimilitudes }\end{array}$ &, 546 & 1 & ,460 & & \\
\hline $\begin{array}{l}\text { Estadístico exacto de } \\
\text { Fisher }\end{array}$ & & & & ,407 & ,407 \\
\hline N de casos válidos & 75 & & & & \\
\hline \multicolumn{6}{|c|}{ (a) 2 casillas $(50,0 \%)$ tienen una frecuencia esperada inferior a 5. La frecuencia mínima esperada es 0,48. } \\
\hline (b) Calculado sólo para & ola de $2 x$ & & & & \\
\hline
\end{tabular}

Figura 54. Agresividad. Pruebas de Chi-Cuadrado 
La presencia de Síndrome de Asperger no parece mantener relación estadísticamente significativa ni con el subtipo $(p=0.723)$, ni con la agresividad $(p=0.407)$.

\section{- Trastorno Oposicionista Desafiante}

- Subtipo:

\begin{tabular}{|c|c|c|c|c|c|}
\hline \multicolumn{6}{|c|}{ SUBTIPO. PRUEBAS DE CHI-CUADRADO } \\
\hline & Valor & gl & $\begin{array}{c}\text { Sig. } \\
\text { asintótica } \\
\text { (bilateral) }\end{array}$ & $\begin{array}{c}\text { Sig. exacta } \\
\text { (bilateral) }\end{array}$ & $\begin{array}{l}\text { Sig. exacta } \\
\text { (unilateral) }\end{array}$ \\
\hline $\begin{array}{l}\text { Chi-cuadrado de } \\
\text { Pearson }\end{array}$ & $18,261(a)$ & 1 &, 000 & & \\
\hline $\begin{array}{l}\text { Corrección por } \\
\text { continuidad (b) }\end{array}$ & 16,484 & 1 &, 000 & & \\
\hline $\begin{array}{l}\text { Razón de } \\
\text { verosimilitudes }\end{array}$ & 20,962 & 1 &, 000 & & \\
\hline $\begin{array}{l}\text { Estadístico exacto de } \\
\text { Fisher }\end{array}$ & & & &, 000 &, 000 \\
\hline $\mathrm{N}$ de casos válidos & 109 & & & & \\
\hline \multicolumn{6}{|c|}{ (a) 0 casillas $(, 0 \%)$ tienen una frecuencia esperada inferior a 5. La frecuencia mínima esperada es 13,02} \\
\hline (b) Calculado sólo para & a tabla de $2 x$ & & & & \\
\hline
\end{tabular}

Figura 55. Subtipo. Pruebas de Chi-Cuadrado

\begin{tabular}{|c|c|c|c|c|c|}
\hline \multicolumn{6}{|c|}{ TABLA DE CONTINGENCIA. SUBTIPO DE TDAH - TOD } \\
\hline & & & \multicolumn{2}{|c|}{ TOD } & \multirow{2}{*}{ Total } \\
\hline & & & $\mathrm{Si}$ & No & \\
\hline \multirow{6}{*}{$\begin{array}{l}\text { Subtipo de } \\
\text { TDAH }\end{array}$} & \multirow{3}{*}{ Combinado } & Recuento & 40 & 36 & 76 \\
\hline & & $\%$ dentro de SUBTIPO DE TDAH & $52,6 \%$ & $47,4 \%$ & $100,0 \%$ \\
\hline & & $\%$ dentro de TOD & $93,0 \%$ & $54,5 \%$ & $69,7 \%$ \\
\hline & \multirow{3}{*}{ Inatento } & Recuento & 3 & 30 & 33 \\
\hline & & $\%$ dentro de SUBTIPO DE TDAH & $9,1 \%$ & $90,9 \%$ & $100,0 \%$ \\
\hline & & $\%$ dentro deTOD & $7,0 \%$ & $45,5 \%$ & $30,3 \%$ \\
\hline \multirow{3}{*}{\multicolumn{2}{|c|}{ Total }} & Recuento & 43 & 66 & 109 \\
\hline & & $\%$ dentro de SUBTIPO DE TDAH & $39,4 \%$ & $60,6 \%$ & $100,0 \%$ \\
\hline & & $\%$ dentro de TOD & $100,0 \%$ & $100,0 \%$ & $100,0 \%$ \\
\hline
\end{tabular}

Figura 56. Tabla de contingencia. Subtipo de TDAH - TOD 


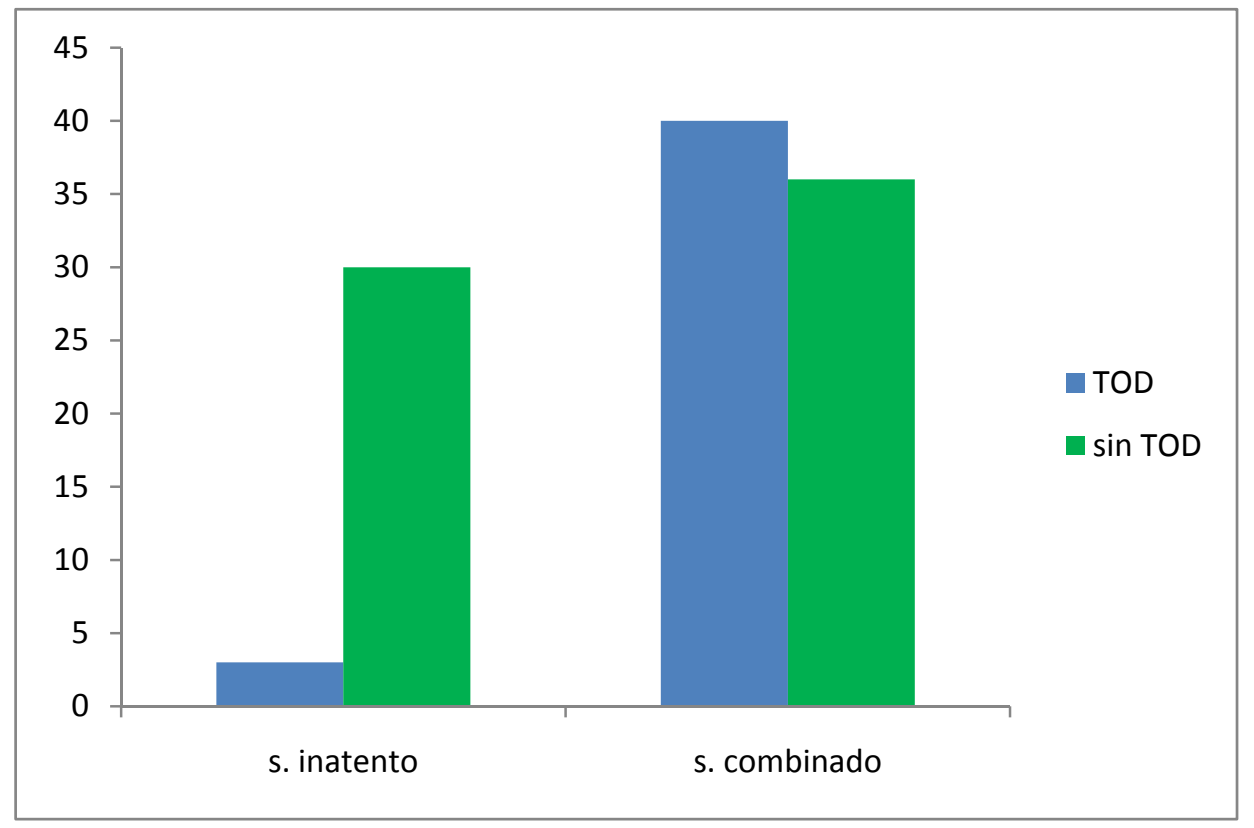

Figura 57. Gráfico de barras

\section{- Agresividad:}

\begin{tabular}{|c|c|c|c|c|c|}
\hline \multicolumn{6}{|c|}{ AGRESIVIDAD. PRUEBAS DE CHI-CUADRADO } \\
\hline & Valor & gl & $\begin{array}{l}\text { Sig. asintótica } \\
\text { (bilateral) }\end{array}$ & $\begin{array}{c}\text { Sig. exacta } \\
\text { (bilateral) }\end{array}$ & $\begin{array}{l}\text { Sig. exacta } \\
\text { (unilateral) }\end{array}$ \\
\hline $\begin{array}{l}\text { Chi-cuadrado de } \\
\text { Pearson }\end{array}$ & $85,329 a$ & 1 & ,000 & & \\
\hline $\begin{array}{l}\text { Corrección por } \\
\text { continuidad (b) }\end{array}$ & 81,665 & 1 & ,000 & & \\
\hline $\begin{array}{l}\text { Razón de } \\
\text { verosimilitudes }\end{array}$ & 100,047 & 1 &, 000 & & \\
\hline $\begin{array}{l}\text { Estadístico exacto de } \\
\text { Fisher }\end{array}$ & & & &, 000 &, 000 \\
\hline $\mathrm{N}$ de casos válidos & 109 & & & & \\
\hline
\end{tabular}

Figura 58. Agresividad. Pruebas de Chi-Cuadrado 


\begin{tabular}{|c|c|c|c|c|c|}
\hline \multicolumn{6}{|c|}{ TABLA DE CONTINGENCIA. CON AGRESIVIDAD - TOD } \\
\hline & & & \multicolumn{2}{|c|}{ TOD } & \multirow{2}{*}{ Total } \\
\hline & & & $\mathrm{Si}$ & No & \\
\hline \multirow{6}{*}{ Con Agresividad } & \multirow{3}{*}{ Si } & Recuento & 40 & 3 & 43 \\
\hline & & $\%$ dentro de CON AGRESIVIDAD & $93,0 \%$ & $7,0 \%$ & $100,0 \%$ \\
\hline & & $\%$ dentro de TOD & $93,0 \%$ & $4,5 \%$ & $39,4 \%$ \\
\hline & \multirow{3}{*}{ No } & Recuento & 3 & 63 & 66 \\
\hline & & $\%$ dentro de CON AGRESIVIDAD & $4,5 \%$ & $95,5 \%$ & $100,0 \%$ \\
\hline & & $\%$ dentro de TOD & $7,0 \%$ & $95,5 \%$ & $60,6 \%$ \\
\hline \multirow{3}{*}{\multicolumn{2}{|c|}{ Total }} & Recuento & 43 & 66 & 109 \\
\hline & & $\%$ dentro de CON AGRESIVIDAD & $39,4 \%$ & $60,6 \%$ & $100,0 \%$ \\
\hline & & $\%$ dentro de TOD & $100,0 \%$ & $100,0 \%$ & $100,0 \%$ \\
\hline
\end{tabular}

Figura 59. Tabla de contingencia. Con Agresividad - TOD

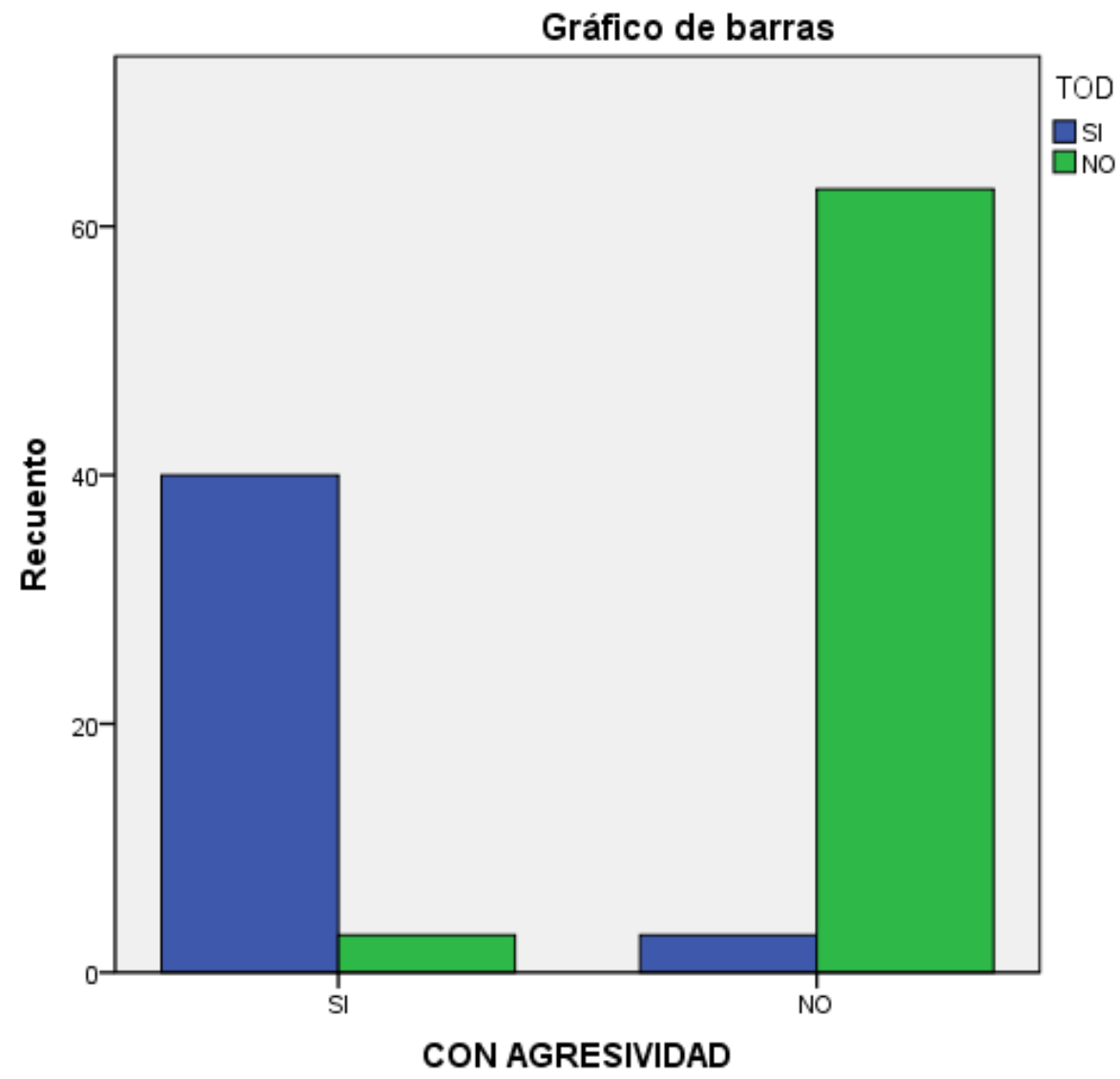

Figura 60. Gráfico de barras 
Los niños y adolescentes del grupo de TDAH subtipo inatento y los del subtipo combinado presentan diferencias estadísticamente significativas para padecer o no Trastorno Oposicionista Desafiante $(p=0.000)$. Como muestra la tabla de contingencia es mayor la frecuencia en el caso de los del subtipo combinado. En la misma línea, los pacientes que entre sus síntomas clínicos relevantes destaca la presencia de agresividad, tienen diferencias de significación estadística para padecer un TOD comórbido $(p=0,000)$.

\section{- Trastorno de Conducta Disocial}

- Subtipo:

\begin{tabular}{|c|c|c|c|c|c|}
\hline \multicolumn{6}{|c|}{ SUBTIPO. PRUEBAS DE CHI-CUADRADO } \\
\hline & Valor & gl & $\begin{array}{l}\text { Sig. asintótica } \\
\text { (bilateral) }\end{array}$ & $\begin{array}{l}\text { Sig. exacta } \\
\text { (bilateral) }\end{array}$ & $\begin{array}{l}\text { Sig. exacta } \\
\text { (unilateral) }\end{array}$ \\
\hline $\begin{array}{l}\text { Chi-cuadrado de } \\
\text { Pearson }\end{array}$ & $15,063(a)$ & 1 &, 000 & & \\
\hline $\begin{array}{l}\text { Corrección por } \\
\text { continuidad (b) }\end{array}$ & 13,333 & 1 &, 000 & & \\
\hline $\begin{array}{l}\text { Razón de } \\
\text { verosimilitudes }\end{array}$ & 17,900 & 1 &, 000 & & \\
\hline $\begin{array}{l}\text { Estadístico exacto de } \\
\text { Fisher }\end{array}$ & & & & ,000 &, 000 \\
\hline N de casos válidos & 98 & & & & \\
\hline
\end{tabular}

Figura 61. Subtipo. Pruebas de Chi-Cuadrado 


\begin{tabular}{|c|c|c|c|c|c|}
\hline \multicolumn{6}{|c|}{ TABLA DE CONTINGENCIA. SUBTIPO DE TDAH - TD } \\
\hline & & & \multicolumn{2}{|c|}{ TD } & \multirow{2}{*}{ Total } \\
\hline & & & $\mathrm{Si}$ & No & \\
\hline \multirow{6}{*}{$\begin{array}{l}\text { Subtipo de } \\
\text { TDAH }\end{array}$} & \multirow{3}{*}{ Combinado } & Recuento & 30 & 36 & 66 \\
\hline & & $\%$ dentro de SUBTIPO DE TDAH & $45,5 \%$ & $54,5 \%$ & $100,0 \%$ \\
\hline & & $\%$ dentro de TC & $93,8 \%$ & $54,5 \%$ & $67,3 \%$ \\
\hline & \multirow{3}{*}{ Inatento } & Recuento & 2 & 30 & 32 \\
\hline & & $\%$ dentro de SUBTIPO DE TDAH & $6,3 \%$ & $93,8 \%$ & $100,0 \%$ \\
\hline & & $\%$ dentro deTC & $6,3 \%$ & $45,5 \%$ & $32,7 \%$ \\
\hline \multirow{3}{*}{\multicolumn{2}{|c|}{ Total }} & Recuento & 32 & 66 & 98 \\
\hline & & $\%$ dentro de SUBTIPO DE TDAH & $32,7 \%$ & $67,3 \%$ & $100,0 \%$ \\
\hline & & $\%$ dentro de TC & $100,0 \%$ & $100,0 \%$ & $100,0 \%$ \\
\hline
\end{tabular}

Figura 62. Tabla de contingencia. Subtipo de TDAH - TD

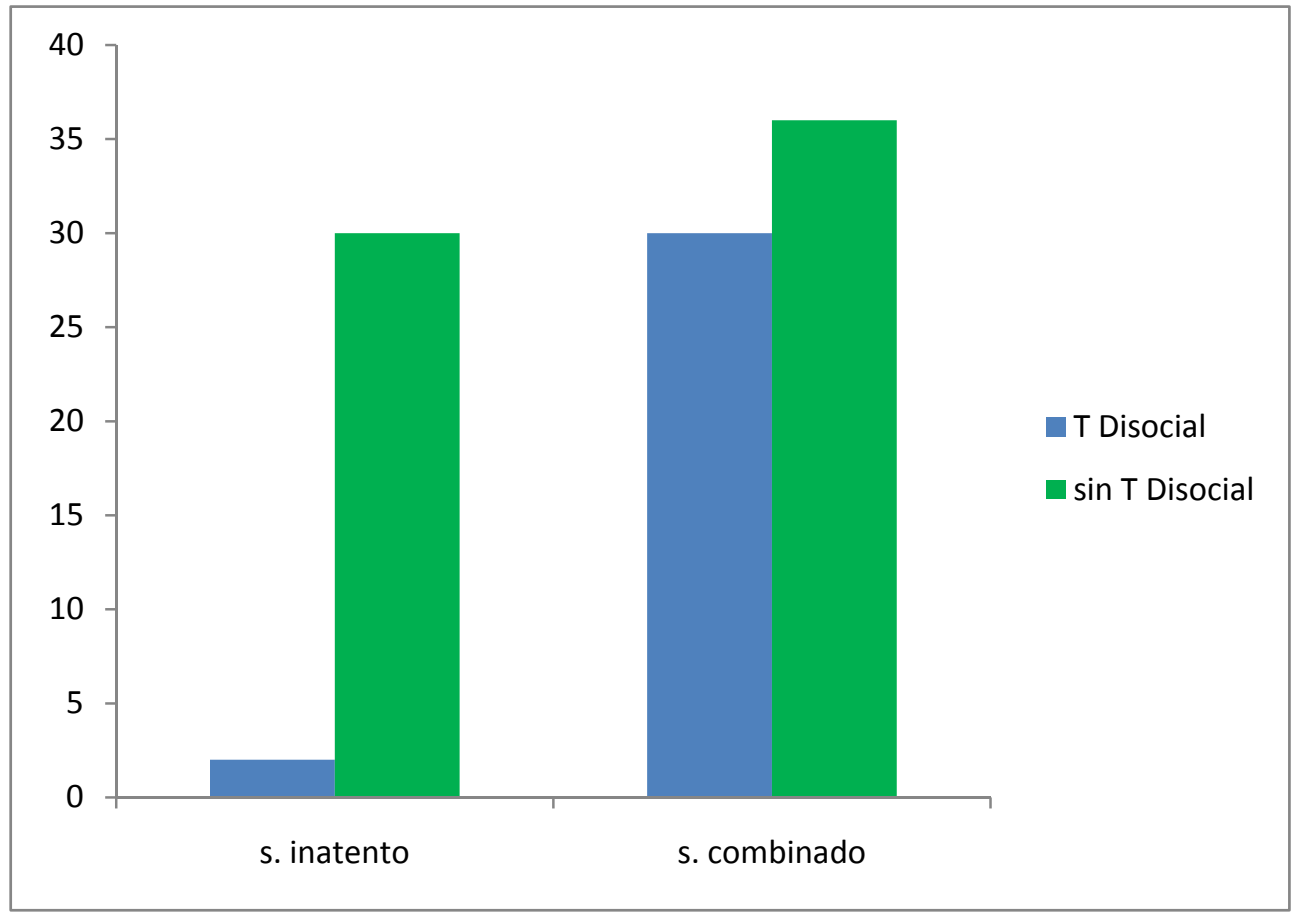

Figura 63. Gráfico de barras 


\section{- Agresividad:}

\begin{tabular}{|c|c|c|c|c|c|}
\hline \multicolumn{6}{|c|}{ AGRESIVIDAD. PRUEBAS DE CHI-CUADRADO } \\
\hline & Valor & gl & $\begin{array}{c}\text { Sig. asintótica } \\
\text { (bilateral) }\end{array}$ & $\begin{array}{c}\text { Sig. exacta } \\
\text { (bilateral) }\end{array}$ & $\begin{array}{l}\text { Sig. exacta } \\
\text { (unilateral) }\end{array}$ \\
\hline $\begin{array}{l}\text { Chi-cuadrado de } \\
\text { Pearson }\end{array}$ & $68,575(a)$ & 1 &, 000 & & \\
\hline $\begin{array}{l}\text { Corrección por } \\
\text { continuidad (b) }\end{array}$ & 64,793 & 1 &, 000 & & \\
\hline $\begin{array}{l}\text { Razón de } \\
\text { verosimilitudes }\end{array}$ & 73,797 & 1 &, 000 & & \\
\hline $\begin{array}{l}\text { Estadístico exacto de } \\
\text { Fisher }\end{array}$ & & & &, 000 &, 000 \\
\hline $\mathrm{N}$ de casos válidos & 98 & & & & \\
\hline
\end{tabular}

Figura 64. Agresividad. Pruebas de Chi-Cuadrado

\begin{tabular}{|c|c|c|c|c|c|}
\hline \multicolumn{6}{|c|}{ TABLA DE CONTINGENCIA. CON AGRESIVIDAD - TD } \\
\hline & & & \multicolumn{2}{|c|}{ TD } & \multirow{2}{*}{ Total } \\
\hline & & & Si & No & \\
\hline \multirow{6}{*}{ Con Agresividad } & \multirow{3}{*}{ Si } & Recuento & 28 & 3 & 31 \\
\hline & & $\%$ dentro de CON AGRESIVIDAD & $90,3 \%$ & $9,7 \%$ & $100,0 \%$ \\
\hline & & $\%$ dentro de TC & $87,5 \%$ & $4,5 \%$ & $31,6 \%$ \\
\hline & \multirow{3}{*}{ No } & Recuento & 4 & 63 & 67 \\
\hline & & $\%$ dentro de CON AGRESIVIDAD & $6,0 \%$ & $94,0 \%$ & $100,0 \%$ \\
\hline & & $\%$ dentro de TC & $12,5 \%$ & $95,5 \%$ & $68,4 \%$ \\
\hline \multirow{3}{*}{\multicolumn{2}{|c|}{ Total }} & Recuento & 32 & 66 & 98 \\
\hline & & $\%$ dentro de CON AGRESIVIDAD & $32,7 \%$ & $67,3 \%$ & $100,0 \%$ \\
\hline & & $\%$ dentro de TC & $100,0 \%$ & $100,0 \%$ & $100,0 \%$ \\
\hline
\end{tabular}

Figura 65. Tabla de contingencia. Con Agresividad - TC 


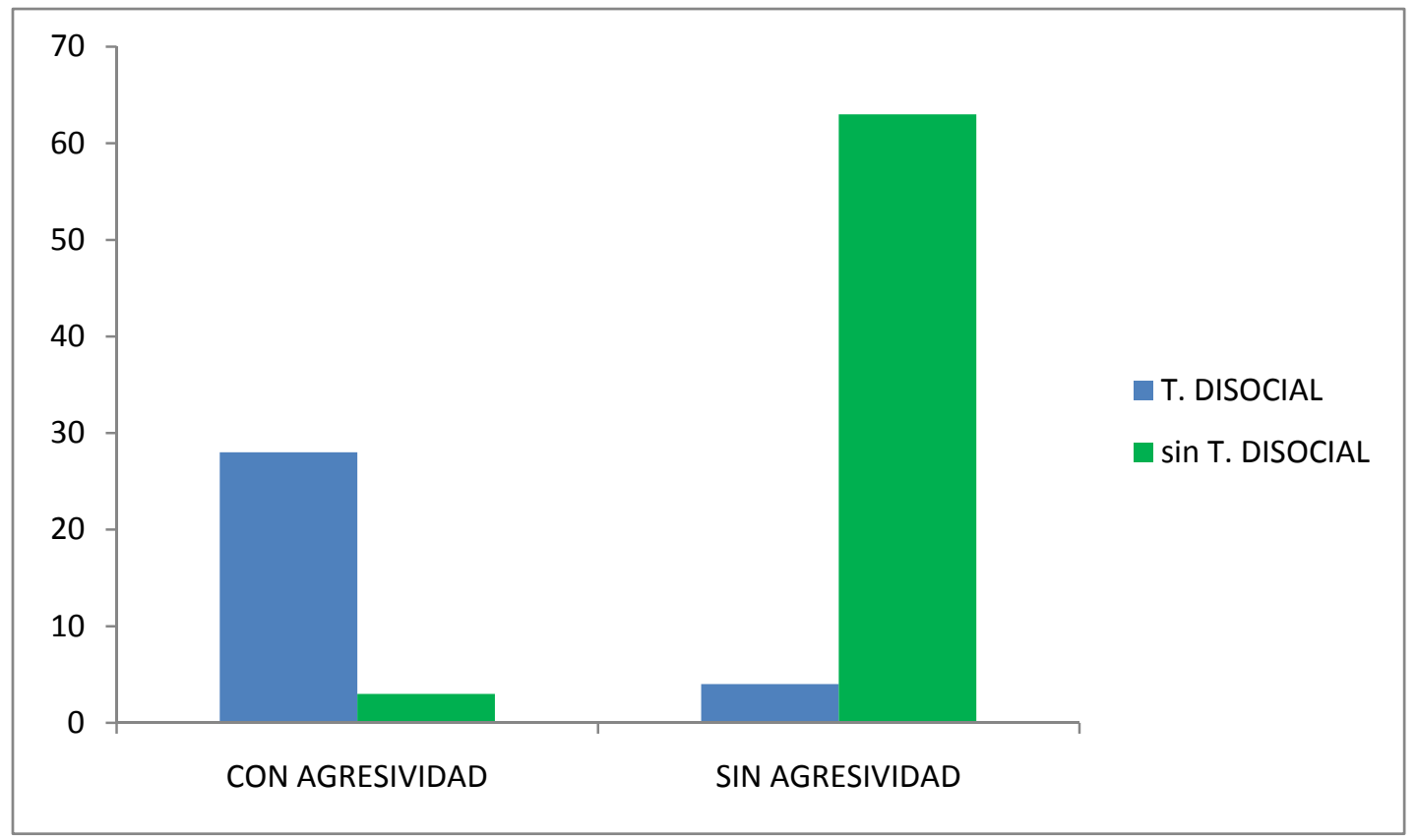

Figura 66. Gráfico de barras

Los niños y adolescentes del grupo de TDAH subtipo inatento y los del subtipo combinado presentan diferencias estadísticamente significativas para padecer o no Trastorno Disocial $(p=0.000)$. Como muestra la tabla de contingencia es mayor la frecuencia en el caso de los del subtipo combinado. En la misma línea, los pacientes que entre sus síntomas clínicos relevantes destaca la presencia de agresividad tienen diferencias de significación estadística para padecer un Trastorno Disocial comórbido $(p=0,000)$. 


\section{- Trastorno de Tics}

\section{- Subtipo:}

\begin{tabular}{|c|c|c|c|c|c|}
\hline \multicolumn{6}{|c|}{ SUBTIPO. PRUEBAS DE CHI-CUADRADO } \\
\hline & Valor & gl & $\begin{array}{c}\text { Sig. asintótica } \\
\text { (bilateral) }\end{array}$ & $\begin{array}{c}\text { Sig. exacta } \\
\text { (bilateral) }\end{array}$ & $\begin{array}{l}\text { Sig. exacta } \\
\text { (unilateral) }\end{array}$ \\
\hline $\begin{array}{l}\text { Chi-cuadrado de } \\
\text { Pearson }\end{array}$ & $1,347(a)$ & 1 & ,246 & & \\
\hline $\begin{array}{l}\text { Corrección por } \\
\text { continuidad (b) }\end{array}$ & ,745 & 1 & ,388 & & \\
\hline $\begin{array}{l}\text { Razón de } \\
\text { verosimilitudes }\end{array}$ & 1,396 & 1 & ,237 & & \\
\hline $\begin{array}{l}\text { Estadístico exacto de } \\
\text { Fisher }\end{array}$ & & & & ,373 & ,195 \\
\hline $\mathrm{N}$ de casos válidos & 80 & & & & \\
\hline \multicolumn{6}{|c|}{ (a) 0 casillas (,0\%) tienen una frecuencia esperada inferior a 5 . La frecuencia mínima esperada es 5,95 } \\
\hline (b) Calculado sólo para & abla de $2 \times 2$ & & & & \\
\hline
\end{tabular}

Figura 67. Subtipo. Pruebas de Chi-Cuadrado

\section{- Agresividad:}

\begin{tabular}{|c|c|c|c|c|c|}
\hline \multicolumn{6}{|c|}{ AGRESIVIDAD. PRUEBAS DE CHI-CUADRADO } \\
\hline & Valor & gl & $\begin{array}{c}\text { Sig. asintótica } \\
\text { (bilateral) }\end{array}$ & $\begin{array}{c}\text { Sig. exacta } \\
\text { (bilateral) }\end{array}$ & $\begin{array}{l}\text { Sig. exacta } \\
\text { (unilateral) }\end{array}$ \\
\hline $\begin{array}{l}\text { Chi-cuadrado de } \\
\text { Pearson }\end{array}$ & $8,350(a)$ & 1 &, 004 & & \\
\hline $\begin{array}{l}\text { Corrección por } \\
\text { continuidad (b) }\end{array}$ & 5,612 & 1 &, 018 & & \\
\hline $\begin{array}{l}\text { Razón de } \\
\text { verosimilitudes }\end{array}$ & 6,315 & 1 &, 012 & & \\
\hline $\begin{array}{l}\text { Estadístico exacto de } \\
\text { Fisher }\end{array}$ & & & &, 016 &, 016 \\
\hline $\mathrm{N}$ de casos válidos & 80 & & & & \\
\hline
\end{tabular}

Figura 68. Agresividad. Pruebas de Chi-Cuadrado 


\begin{tabular}{|c|c|c|c|c|c|}
\hline \multicolumn{6}{|c|}{$\begin{array}{l}\text { TABLA DE CONTINGENCIA. CON AGRESIVIDAD - TRASTC } \\
\text { (INCLUIDO GILLES DE LA TOURETTE) }\end{array}$} \\
\hline & & & \multicolumn{2}{|c|}{$\begin{array}{c}\text { Trastorno de Tics } \\
\text { (incluido Gilles de la } \\
\text { Tourette) }\end{array}$} & \multirow{3}{*}{$\begin{array}{c}\text { Total } \\
7\end{array}$} \\
\hline & & & Si & No & \\
\hline \multirow{6}{*}{ Con Agresividad } & \multirow[b]{3}{*}{$\mathrm{Si}$} & Recuento & 4 & 3 & \\
\hline & & $\%$ dentro de CON AGRESIVIDAD & $57,1 \%$ & $42,9 \%$ & $100,0 \%$ \\
\hline & & $\begin{array}{l}\text { \% dentro de TRASTORNO DE } \\
\text { TICS (INCLUIDO GILLES DE LA } \\
\text { TOURETTE) }\end{array}$ & $28,6 \%$ & $4,5 \%$ & $8,8 \%$ \\
\hline & \multirow[b]{3}{*}{ No } & Recuento & 10 & 63 & 73 \\
\hline & & $\%$ dentro de CON AGRESIVIDAD & $13,7 \%$ & $86,3 \%$ & $100,0 \%$ \\
\hline & & $\begin{array}{l}\text { \% dentro de TRASTORNO DE } \\
\text { TICS (INCLUIDO GILLES DE LA } \\
\text { TOURETTE) }\end{array}$ & $71,4 \%$ & $95,5 \%$ & $91,3 \%$ \\
\hline \multirow{3}{*}{\multicolumn{2}{|c|}{ Total }} & Recuento & 14 & 66 & 80 \\
\hline & & $\%$ dentro de CON AGRESIVIDAD & $17,5 \%$ & $82,5 \%$ & $100,0 \%$ \\
\hline & & $\begin{array}{l}\text { \% dentro de TRASTORNO DE } \\
\text { TICS (INCLUIDO GILLES DE LA } \\
\text { TOURETTE) }\end{array}$ & $100,0 \%$ & $100,0 \%$ & $100,0 \%$ \\
\hline
\end{tabular}

Figura 69. Tabla de contingencia. Con Agresividad - Trastorno de Tics (Incluido Gilles de la Tourette) 


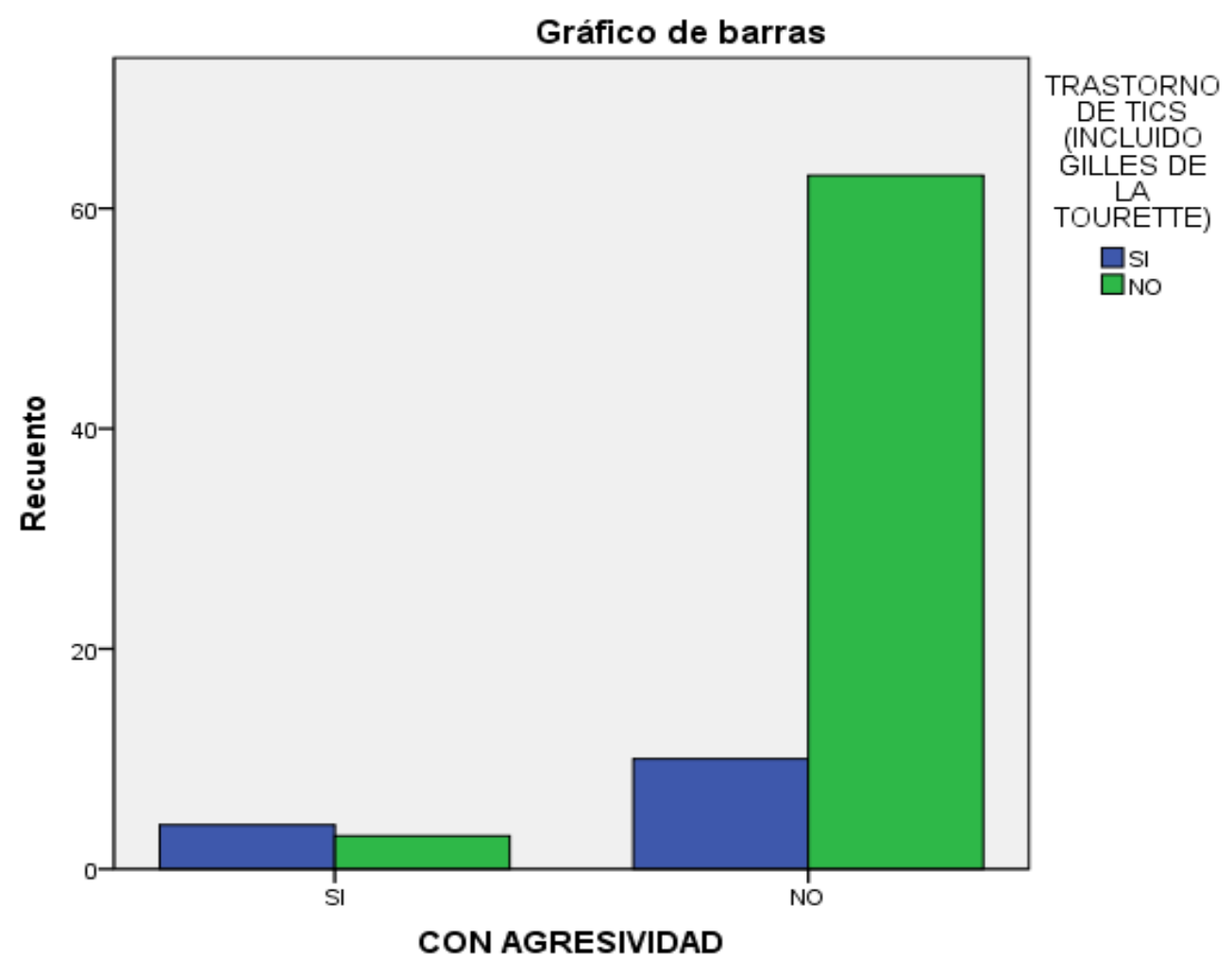

Figura 70. Gráfico de barras

A continuación, mostramos nuestros datos el grupo de TDAH subtipo inatento y el subtipo combinado y observamos que no presentan diferencias estadísticamente significativas para padecer o no Trastorno de tics $(p=0.246)$. Sin embargo, los pacientes que entre sus síntomas clínicos relevantes destaca la presencia de agresividad tienen diferencias de significación estadística para padecer un Trastorno de tics comórbido $(p=0,016)$. 
2.2.4. Analizar la relevancia de la comorbilidad en el cumplimiento terapeútico y en la edad de inicio de la medicación.

Ésta es la gráfica que representa, de forma descripiva, la medicación prescrita en los pacientes y su distribución en ambos grupos: TDAH con comorbilidad y TDAH sin comorbilidad.

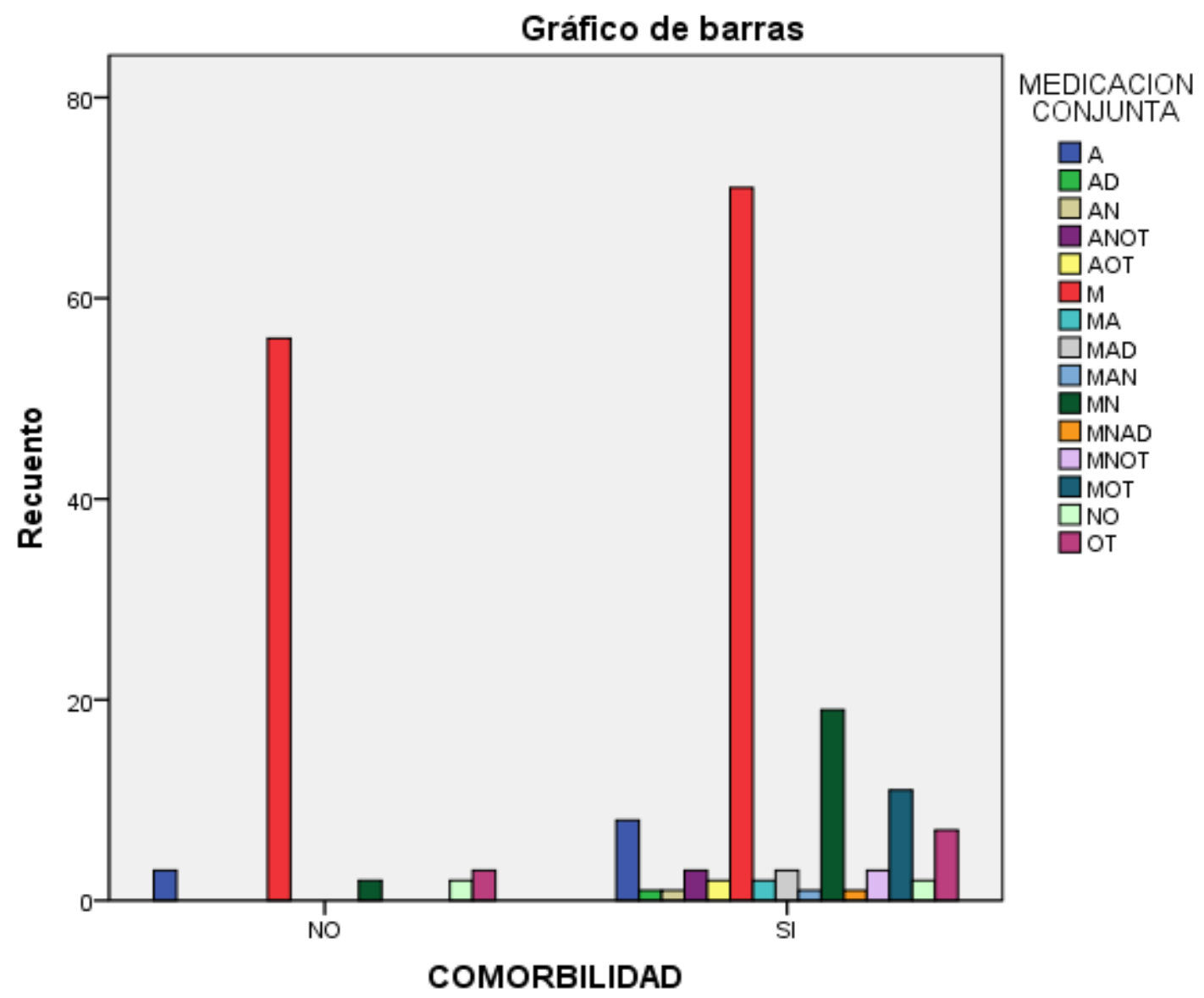

Figura 71. Gráfico de barras. A:atomoxetina/AD:antidepresivos/AN:Atomoxetina+Neuroléptico/ANOT:

atomoxetina+neurolético+otros/AOT:atomoxetina+otros/M:metilfenidato/MA:metilfenidato+atomoxetina/MAD:metilfenidato+antidepresi vos/MAN:metilfenidato+atomoxetina+neuroléptico/MN:metilfenidato+neuroleèptico/MNAD:metilfenidato+neurolético+antidepresivo/MN OT:metilfenidato+neuroléptico+otros/MOT:metilfenidato+otros/NO:neuroléptico+otros/OT:otros(psicoterapia) 


\section{Cumplimiento}

\section{CUMPLIMIENTO Y COMORBILIDAD. PRUEBAS DE CHI-CUADRADO}

\begin{tabular}{|l|c|c|c|}
\hline & Valor & gl & Sig. asintótica (bilateral) \\
\hline Chi-cuadrado de Pearson & $2,678(\mathrm{a})$ & 2 &, 262 \\
\hline Razón de verosimilitudes & 2,858 & 2 &, 240 \\
\hline N de casos válidos & 201 & & \\
\hline
\end{tabular}

Figura 72. Cumplimiento y Comorbilidad. Pruebas de Chi-Cuadrado

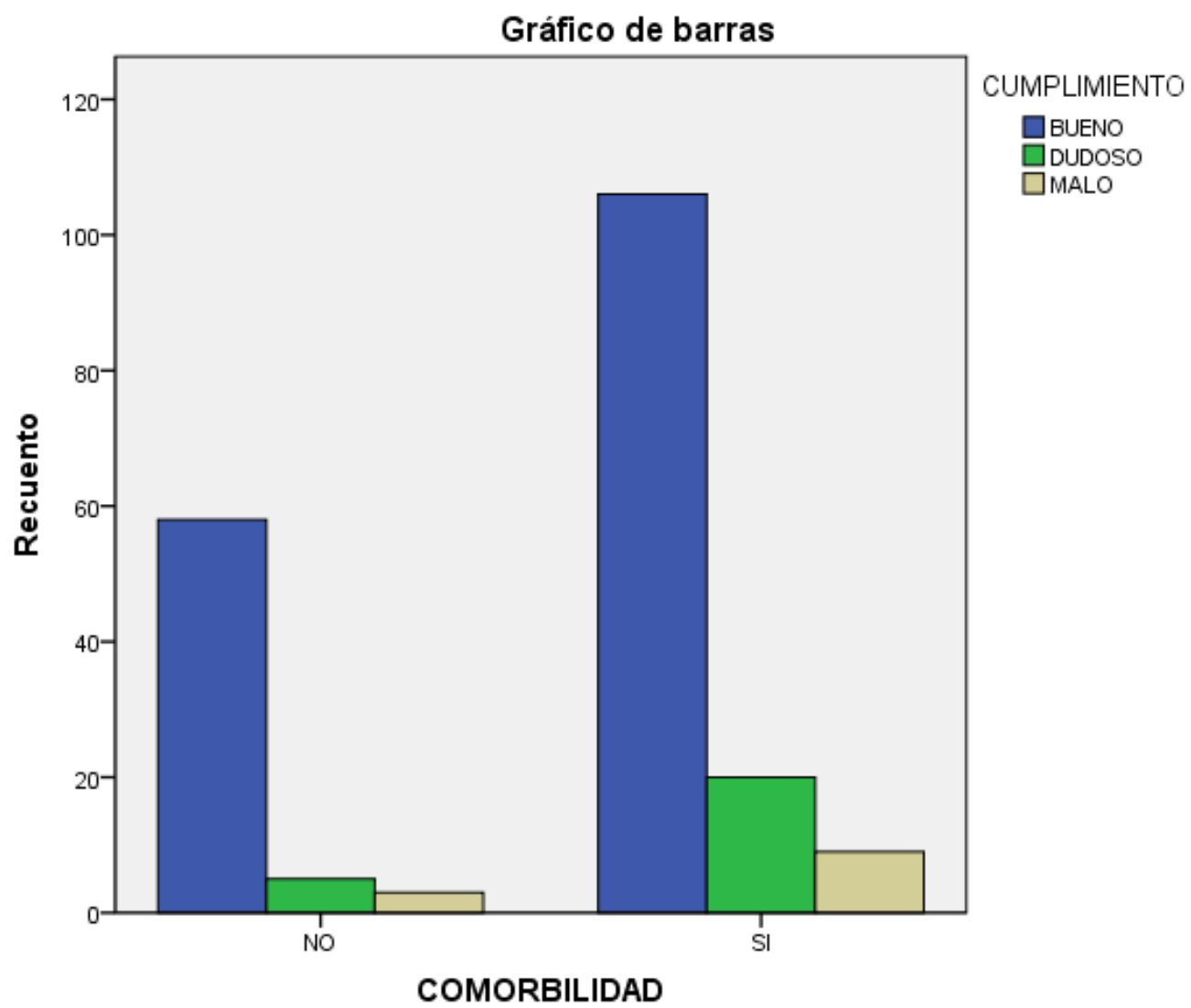

Figura 73. Gráfico de barras

Aunque una de las frecuencias esperadas tiene un valor inferior a 5, al tener tres clases en el cumplimiento y 2 en comorbilidad supone un $16,7 \%$ de las frecuencias esperadas y 
el resultado es valorable en la práctica. No parece estar asociado el cumplimiento a la comorbilidad.

\section{Edad de Inicio}

\section{TABLA DE CONTINGENCIA. COMORBILIDAD- EDAD DE INICIO DEL TRATAMIENTO}

\begin{tabular}{|c|c|c|c|c|c|}
\hline & \multicolumn{2}{|c|}{$\begin{array}{l}\text { Edad de Inicio del } \\
\text { Tratamiento }\end{array}$} & \multirow[t]{2}{*}{ Total } \\
\hline & & & Precoz & Tardío & \\
\hline \multirow{6}{*}{ Comorbilidad } & \multirow{3}{*}{ No } & Recuento & 45 & 21 & 66 \\
\hline & & $\%$ dentro de COMORBILIDAD & $68,2 \%$ & $31,8 \%$ & $100,0 \%$ \\
\hline & & $\begin{array}{l}\text { \% dentro de EDAD DE INICIO } \\
\text { DEL TRATAMIENTO }\end{array}$ & $28,0 \%$ & $52,5 \%$ & $32,8 \%$ \\
\hline & \multirow{3}{*}{ Si } & Recuento & 116 & 19 & 135 \\
\hline & & $\%$ dentro de COMORBILIDAD & $85,9 \%$ & $14,1 \%$ & $100,0 \%$ \\
\hline & & $\begin{array}{l}\text { \% dentro de EDAD DE INICIO } \\
\text { DEL TRATAMIENTO }\end{array}$ & $72,0 \%$ & $47,5 \%$ & $67,2 \%$ \\
\hline \multirow{3}{*}{\multicolumn{2}{|c|}{ Total }} & Recuento & 161 & 40 & 201 \\
\hline & & $\%$ dentro de COMORBILIDAD & $80,1 \%$ & $19,9 \%$ & $100,0 \%$ \\
\hline & & $\begin{array}{l}\text { \% dentro de EDAD DE INICIO } \\
\text { DEL TRATAMIENTO }\end{array}$ & $100,0 \%$ & $100,0 \%$ & $100,0 \%$ \\
\hline
\end{tabular}

Figura 74. Tabla de contingencia. Comorbilidad - Edad de inicio del tratamiento 


\begin{tabular}{|c|c|c|c|c|c|}
\hline \multicolumn{6}{|c|}{ PRUEBAS DE CHI-CUADRADO } \\
\hline & Valor & gl & \begin{tabular}{|c|} 
Sig. asintótica \\
(bilateral)
\end{tabular} & $\begin{array}{l}\text { Sig. exacta } \\
\text { (bilateral) }\end{array}$ & $\begin{array}{l}\text { Sig. exacta } \\
\text { (unilateral) }\end{array}$ \\
\hline $\begin{array}{l}\text { Chi-cuadrado de } \\
\text { Pearson }\end{array}$ & $8,756(a)$ & 1 & ,003 & & \\
\hline $\begin{array}{l}\text { Corrección por } \\
\text { continuidad (b) }\end{array}$ & 7,678 & 1 &, 006 & & \\
\hline $\begin{array}{l}\text { Razón de } \\
\text { verosimilitudes }\end{array}$ & 8,339 & 1 &, 004 & & \\
\hline $\begin{array}{l}\text { Estadístico exacto de } \\
\text { Fisher }\end{array}$ & & & &, 005 & ,003 \\
\hline N de casos válidos & 201 & & & & \\
\hline \multicolumn{6}{|c|}{ (a) 0 casillas (,0\%) tienen una frecuencia esperada inferior a 5. La frecuencia mínima esperada es 13,13} \\
\hline (b) Calculado sólo para & abla de $2 \times 2$ & & & & \\
\hline
\end{tabular}

Figura 75. Pruebas de Chi-Cuadrado

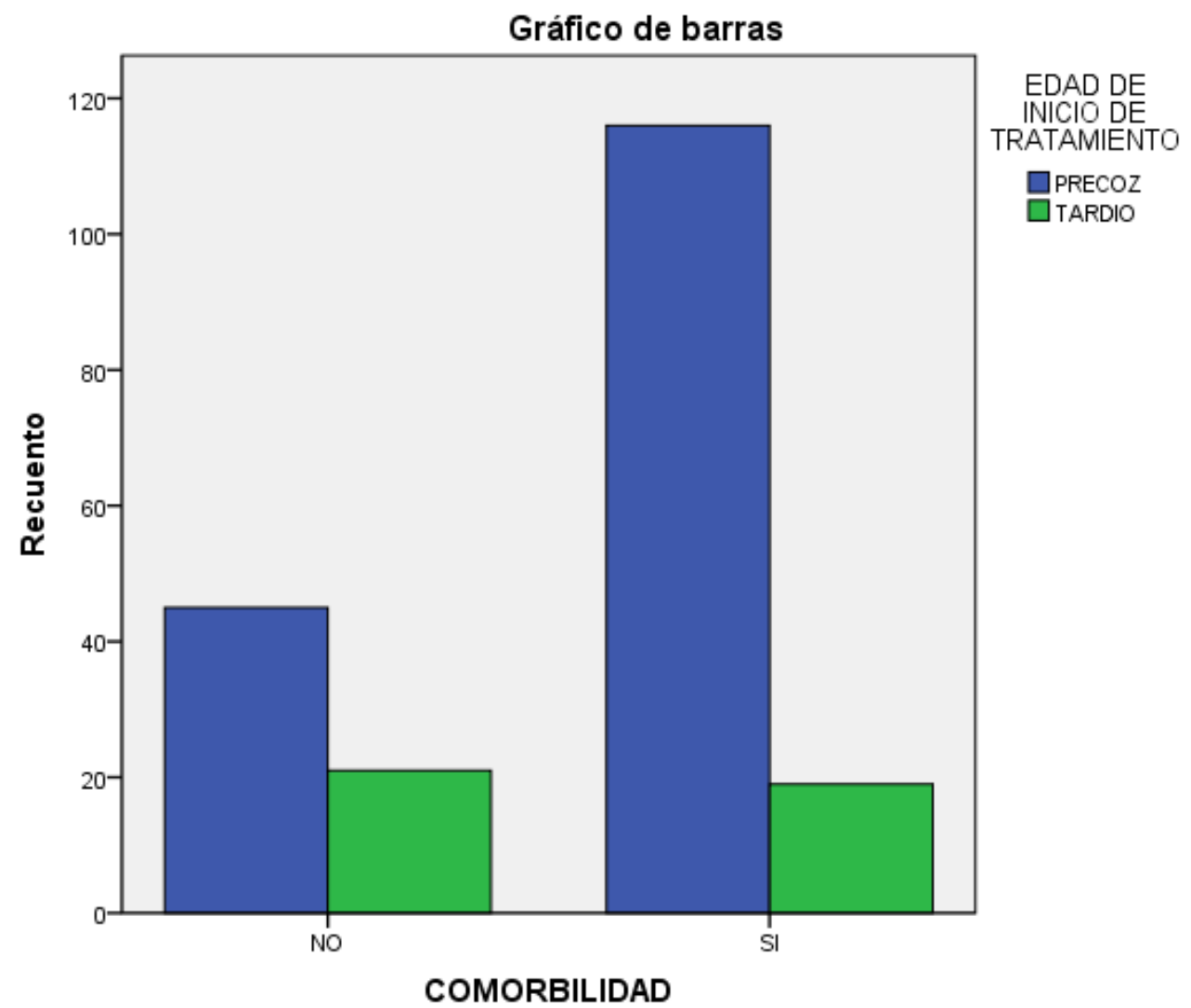

Figura 76. Gráfico de barras 
El grupo de niños/adolescentes que tienen TDAH con comorbilidad psiquiátrica asociada frente a los que no la tienen presentan diferencias estadísticamente significativas $(p=0,003)$ a favor de iniciar tratamiento precozmente.

\subsubsection{Elaborar, relacionando entre sí las variables más relevantes del estudio, árboles de} decisión que faciliten, en la práctica clínica, la detección precoz de la comorbilidad en el paciente TDAH.

Utilizando el programa estadístico WEKA (Waikato Environment for Knowledge Analysis), tratamos de estudiar cómo se comportan las variables de estudio en función de sus resultados y si la relación entre ellas nos puede ayudar a detectar, ante el paciente TDAH de la consulta, otra enfermedad psiquiátrica que esté presente al mismo tiempo.

Se han elaborado cuatro árboles de decisión, uno para tratar de detectar pacientes con comorbilidad en general, y otros tres para la detección de comorbilidades pertenecientes a los tres grandes grupos que hemos definido en nuestro estudio, a modo de clasificación práctica. 
En primer lugar nos propusimos elaborar un árbol de decisión, de alta fiabilidad, para detectar comorbilidad: Evaluando todas las variables del estudio y atendiendo a la comorbilidad, se seleccionan las más relevantes estadísticamente para predecir padecer otra enfermedad psiquiátrica cuando se tiene el diagnóstico de TDAH. En los resultados nos encontramos que, por orden de importancia, la agresividad, los antecedentes personales, y las relaciones sociales son los de mayor relevancia por su capacidad predictora. Siguiendo el árbol que se muestra a continuación el porcentaje de aciertos estimado es del $78 \%$ de los casos.

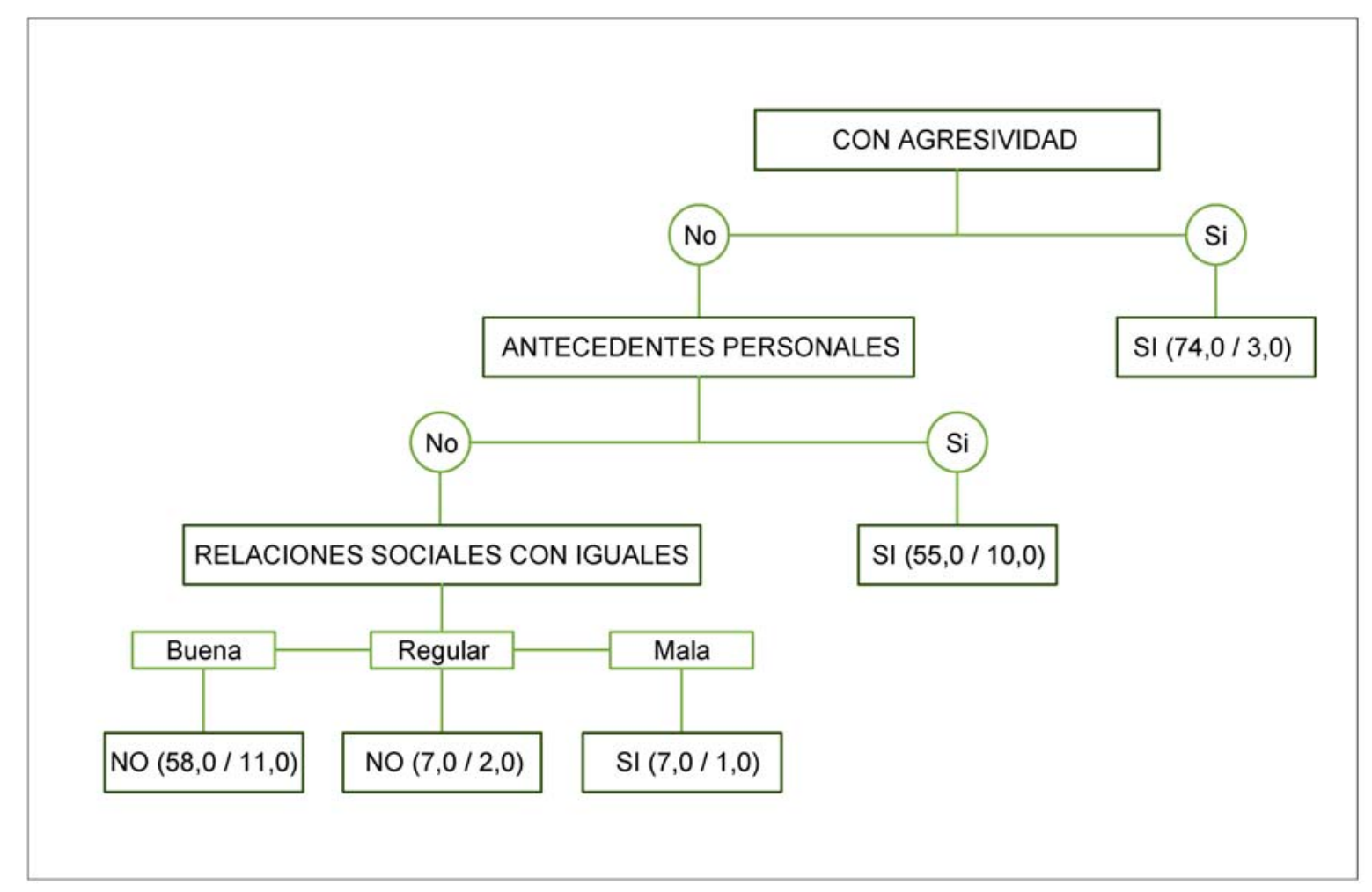

Figura 77. Primer árbol de decisión.Detección de Comorbilidad 
En el Segundo árbol, tratamos de pormenorizar y detectar específicamente los casos con Trastornos del Aprendizaje: De la totalidad de las variables de estudio, tan sólo padecer antecedentes personales de psicológicos-psiquiátricos puede comportarse como una variable predictora de este tipo de trastornos. Porcentaje de acierto 76\% (de 100 pacientes que vienen a la consulta, usando ese árbol de decisión acierto en 76 casos y fallo en 24)

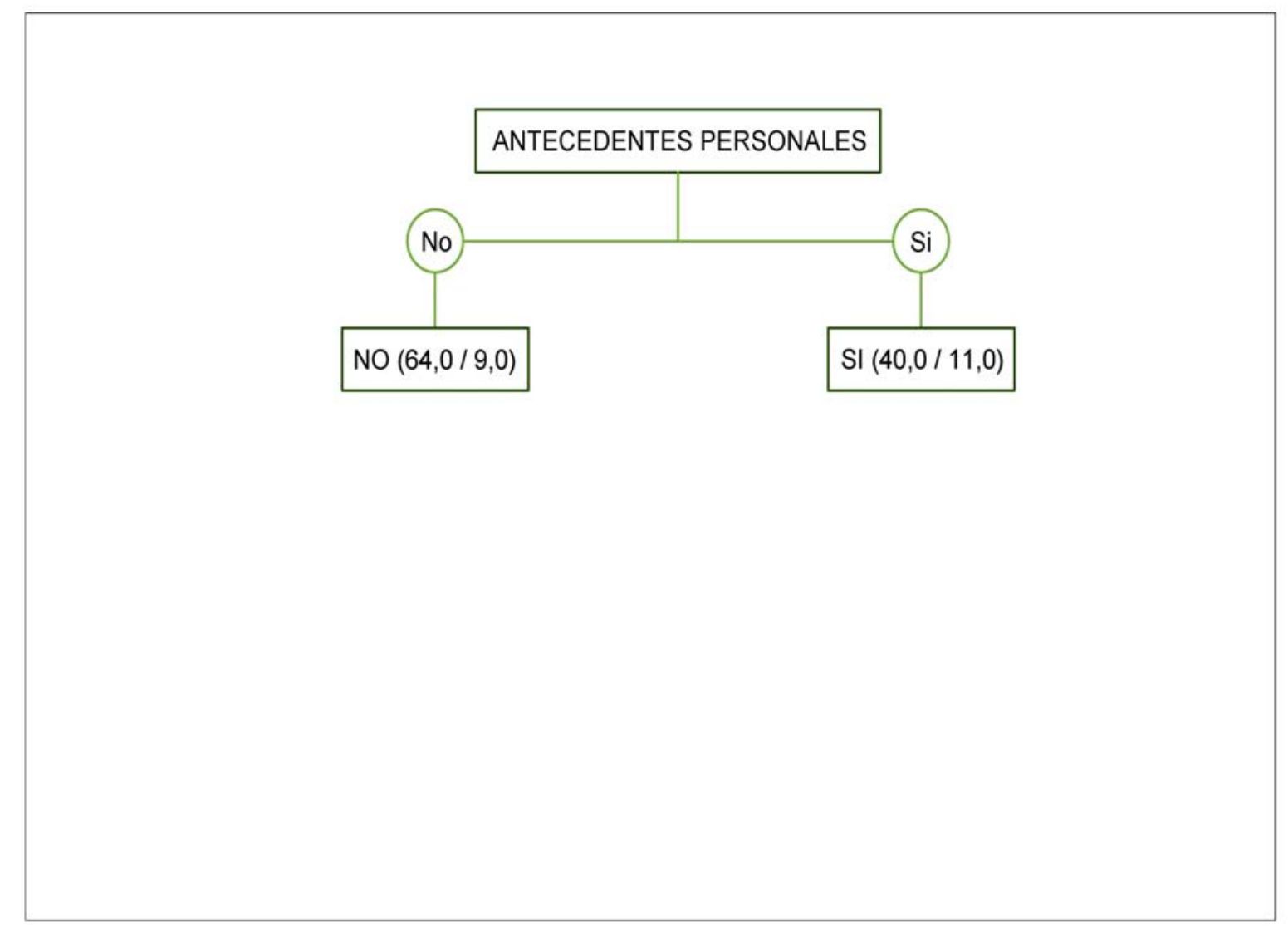

Figura 78. Segundo árbol de decisión. Detección de TA 
En el Tercer árbol, tratamos de detectar específicamente los casos con Trastornos del grupo Excitación- motivación: De la totalidad de las variables de estudio, padecer antecedentes personales de psicológicos-psiquiátricos sigue siendo relevante, pero apoyada por otra variable relaciones sociales con iguales ambas constituyen las variables para detectar este tipo de trastornos. Porcentaje de acierto 83\% (de 100 pacientes que vienen a la consulta, usando ese árbol de decisión acierto en 83 casos y fallo en 17).

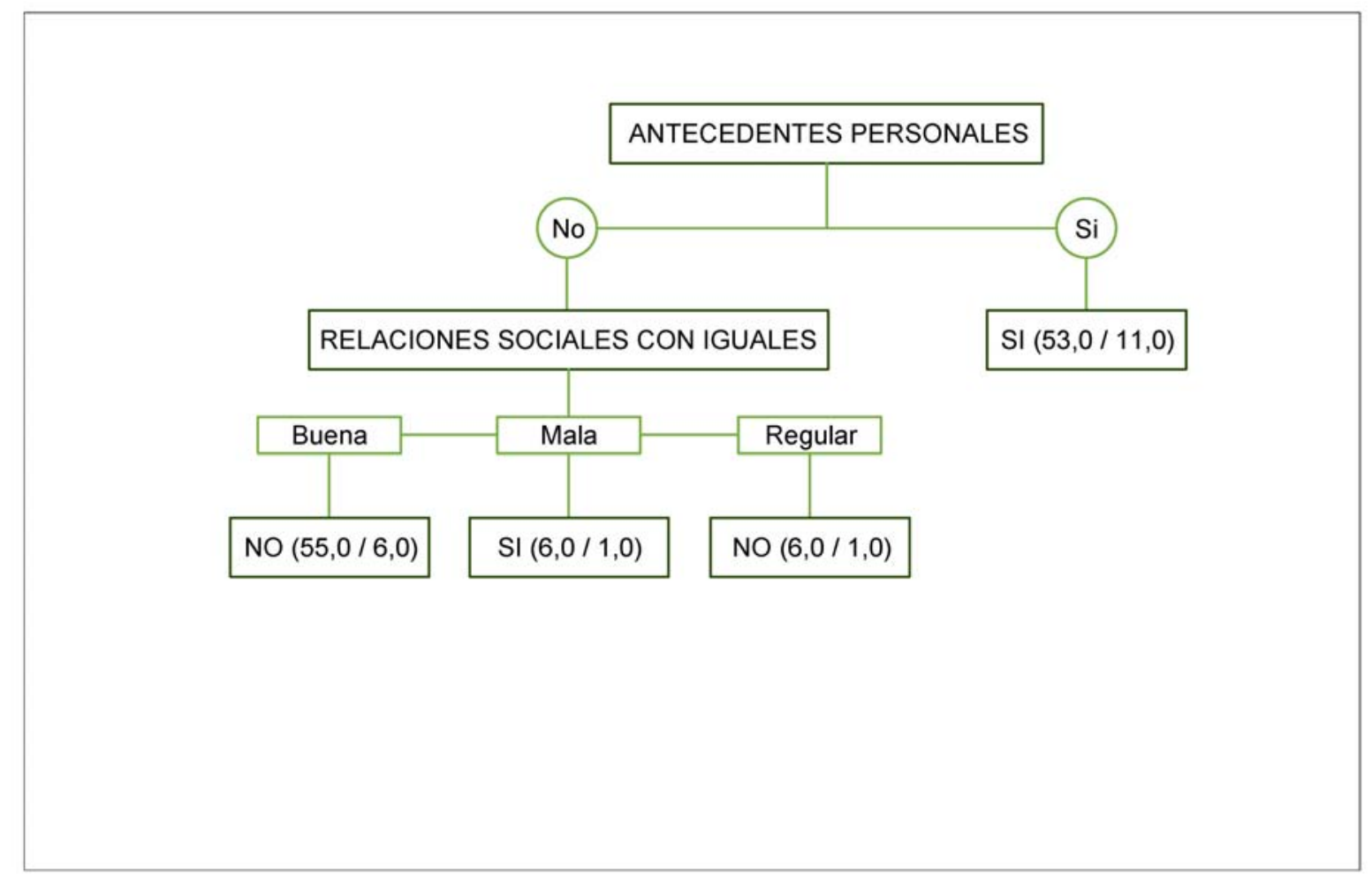

Figura 79. Tercer árbol de decisión. Detección de TEM 
En el Cuarto y último árbol, nos centramos específicamente en detectar los casos con Trastornos del grupo Social-emocional: De la totalidad de las variables de estudio, son de relevancia en la detección, por este orden, el padecer o no agresividad como síntoma clínico relevante, y los antecedentes personales de psicológicos-psiquiátricos. Porcentaje de acierto $85 \%$ (de 100 pacientes que vienen a la consulta, usando ese árbol de decisión acierto en 83 casos y fallo en 15).

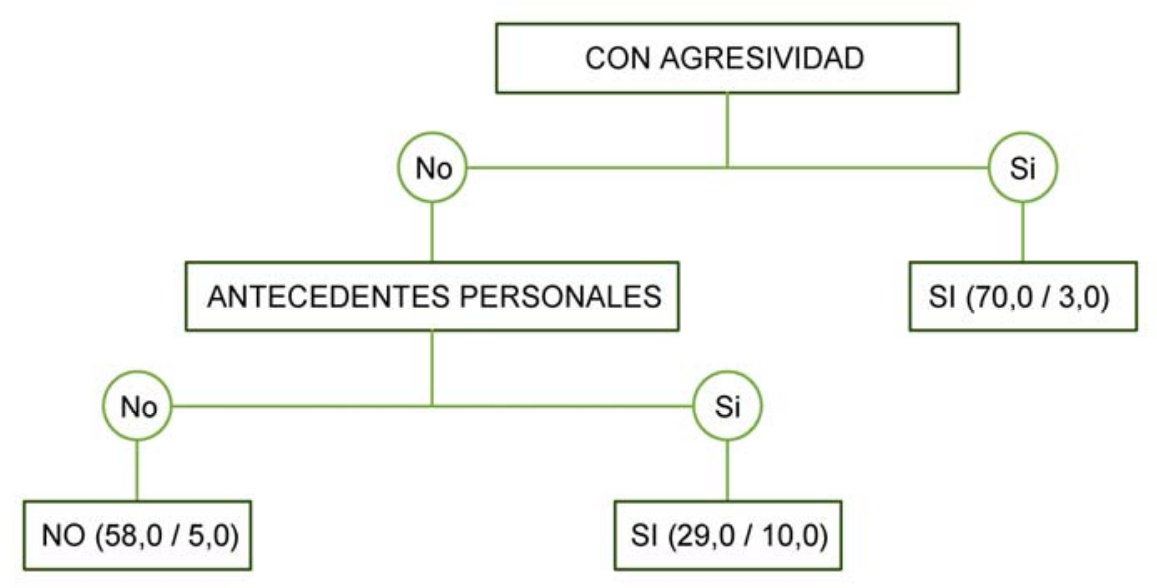

Figura 80. Cuarto árbol de decisión. Detección de TSE 


\section{CAPÍTULO 3. DISCUSIÓN Y LIMITACIONES}

\subsection{Discusión}

\subsubsection{Características Generales de la Muestra}

En lo referente a la proporción de los grupos de edad de nuestro estudio, cabe destacar en primer lugar, que existe una proporción ligeramente superior de pacientes que se encuentran en edades comprendidas entre los 5 y 12 años frente a los que se sitúan entre 13 y 18 (casos y controles respectivamente 55\%/53\% frente a 44\%/46\%). La explicación a este dato es que el TDAH es una enfermedad crónica, que se inicia en la infancia y en la mayoría de los casos se mantiene hasta la vida adulta. Concretamente según diversas estimaciones el $80 \%$ de los niños y niñas afectados de TDAH seguirán presentando síntomas durante la adolescencia (Klein y Mannuzza 199191; Mannuzza et al., 1998; Biederman et al., 1996, 1998), esta proporción es la misma que obtenemos nosotros en nuestra muestra de adolescentes.

Otro dato a destacar es la diferencia de prevalencia por género, existencia de un mayor número de varones (casos/controles 77\%/84\%) frente a mujeres (casos/controles 22\%/15\%). Según revisiones recientes (J. San Sebastián; C. Soutullo y A. Figueroa 2010) el TDAH se da y se diagnostica más en varones (relación niño/niña de 4:1) aunque existe un infradiagnóstico en las niñas. Otros autores especifican que las escalas de valoración psicopatológica y/o conductual no incluyen ítems específicos para chicas (Knellwolf et al., 2008). Los rangos de prevalencia niños/niñas varían en otros estudios, entre $2 / 1$ a 5/1 (Criado et al., 2003) 
En lo referente a los subtipos de diagnóstico confirmamos una mayor prevalencia del subtipo combinado frente al inatento (casos/controles $74 \% / 54 \%$ frente al $25 \% / 45 \%$ ), que se hace más importante en el grupo de casos (posiblemente porque el subtipo combinado, ya veremos más adelante, se relaciona con más comorbilidad). Las investigaciones realizadas en este aspecto son coincidentes en determinar que para ambos sexos, el subtipo combinado es el más frecuente, aunque en el inatento, hay un mayor porcentaje de chicas en las que los síntomas de hiperactividad e impulsividad pueden aparecer con mayor intensidad. (Knellwolf et al., 2008)

Al evaluar el nivel socio-económico de las familias de nuestros sujetos de estudio, encontramos, para ambos grupos, que la gran mayoría pertenecen a la clase media (casos/controles 75\%/87\%), siendo llamativo el dato de que de la pequeña proporción que se sitúan en un nivel socio-económico alto lo hacen en el grupo de los controles (casos/controles $2 \% / 10 \%$ ) y viceversa para las familias de las clases más desfavorecidas (casos/controles 22\%/1\%). Esto ya lo apuntaban autores como Weiss y Hechtman (1993) quienes relacionaban especialmente los problemas de aprendizaje y las conductas antisociales con el bajo nivel socioeconómico parental.

\subsubsection{Discusión por objetivos planteados}

- 1) Determinar las características clínico-epidemiológicas de los niños y adolescentes con TDAH frente a los que tienen TDAH y comorbilidad:

Atendiendo a los antecedentes familiares observamos como en ambos grupos, TDAH con y sin comorbilidad, existen altas proporciones de antecedentes familiares psiquiátricos (casos/controles 77\%/85\%) y no hay diferencias en pertenecer a un grupo o a otro. Si cabe, parece haber una mayor proporción del grupo de controles que comunican la existencia de dichas patologías en sus 
historias familiares. Este dato que puede sorprender inicialmente, lo explicamos, teniendo en cuenta la elevada heredabilidad del diagnóstico que ambos grupos comparten, el TDAH.

Si nos atenemos sólo al TDAH y la influencia para padecerlo de los antecedentes familiares, vemos que investigaciones de corte genético, ponen de manifiesto que los hijos de padres con TDAH tienen hasta un $50 \%$ de probabilidad de padecer el mismo problema (Faraone, Biederman, Jetton, Tsuang, 1997).

Otros autores añaden que los antecedentes familiares de enfermedades psiquiátricas son un factor que aparece como una variable significativa en los sujetos que experimentan el trastorno (Willcut, Penington, Chabildas, Friedman y Alexandre, 1999; Wilens y cols., 2002). Los estudios de autores como Biederman (1996), Taylor (1996), Fisher (1993) y Fergusson (1996) indican que los antecedentes familiares de padres con psicopatología, ya sea TDAH u otras, se asocian con un riesgo incrementado y problemas emocionales de los niños y en la adolescencia.

Parece ser, para autores como Serrano y colaboradores (2003), que la relevancia de las enfermedades psiquiátricas es de mayor influencia en la aparición del TDAH que las complicaciones perinatales.

En lo relativo a padecer antecedentes personales de tratamiento psicológicopsiquiátrico, la presencia de antecedentes se encuentra muy aumentada en nuestro grupo de casos; El $62 \%$ ha acudido previamente a consulta psicológica o psiquiátrica. Sin embargo, el $16 \%$ de los pacientes del grupo control tiene historia previa de consultas en salud mental.

A parte de los factores pre y perinatales que se han identificado en relación con padecer TDAH, existen otros de la primera infancia que requieren de forma 
temprana la atención en consulta psicológica-psiquiátrica del niño (son estos en los que nosotros nos hemos centrado en nuestro estudio). Para autores como Biederman et al. (2002) los problemas de relaciones familiares son más frecuentes en las familias de niños con TDAH, y aunque puede ser una consecuencia, cada vez son más los estudios que lo consideran un factor de riesgo en sí mismo.

Es por tanto de gran relevancia clínica esta variable, porque es verdaderamente infrecuente en los niños que acuden a consulta (no tanto, por razones obvias en el adolescente), ya que las alteraciones de conducta, la inquietud, los problemas de aprendizaje...son normotolerados en la primera infancia y las familias no suelen ser proclives a pedir opinión facultativa. En esta linea Marakowitz y Campbell, (1998), señalan que las dificultades en los síntomas centrales del TDAH se pueden detectar con claridad entre los 6 y los 9 años y se incrementa de forma pronunciada con la edad. Muchos de los síntomas que presenta el niño con TDAH en los primeros años los manifiesta también el niño normal, por lo cual resulta muy difícil diferenciar un niño caprichoso y desobediente de un niño con TDAH.

Se acepta actualmente, que la presencia de determinados genes afectaría la sensibilidad individual a ciertos factores ambientales (Lehn y cols., 2007; Thapar y cols., 2007)

Al evaluar los datos referentes a la historia académica de los pacientes de nuestro estudio, observamos como la frecuencia con la que los rendimientos se sitúan en niveles de "malos" o "fracaso" son muy altas, para los integrantes del grupo casos, y altas, aunque no tanto como en el grupo anterior, para los casos (controles/casos 63\%/ 28\%). Spencer J. (2007) ya señaló que, los escolares con TDAH, presentan más dificultades de aprendizaje que el resto de la población infantil. Este hecho es una de las principales causas de fracaso escolar. Alrededor 
del $70 \%$ de niños TDAH presentan alguna dificultad de aprendizaje (Mayes, et al., 2000) y por ello obtienen un rendimiento académico inferior al de sus compañeros (Barkley, 1990; Casey y Schlosser, 1996). Esas dificultades de aprendizaje pueden justificar por qué el grupo de casos (TDAH con comorbilidad) tiene más riesgo de fracaso (como vemos en nuestro estudio). No obstante, al hablar de que el niño/adolescente con TDAH, tenga un trastorno de aprendizaje comórbido o no, diversos autores (Barkley, Du Paul y McMurray, 1990; Faraone y cols., 1993) apuntan datos bastante negativos como que $30-40 \%$ de los niños TDAH asisten a educación especial, $46 \%$ suspenden, un $30 \%$ necesitan repetir curso y entre un $10-35 \%$ fracasan al acabar la secundaria.

Al observar los resultados obtenidos en relaciones sociales vemos que las familias y los pacientes comunican que, con frecuencia, hay dificultades en este aspecto. Entre padres e hijos los del grupo control comunican relación regular en el $30 \%$ de los sujetos y mala en un $6 \%$. Estas frecuencias están muy incrementadas en los individuos del grupo de casos 39\% regular y $36 \%$ malas relaciones. Entre profesores-alumnos mientras los controles informan de $22 \%$ de relaciones regulares y ninguna mala, los casos tienen en un 34\% relación con sus profesores clasificada como regular, la cifra de los que las consideran malas se eleva al $29 \%$. Por último, la relación con iguales también se encuentra más dañada en los pacientes tdah con comorbilidad, comunicando un $30 \%$ de relación mala con otros pares, frente al $1 \%$ de los controles, y considerando que sus relaciones son regulares en un $34 \%$ y $12 \%$ respectivamente (para casos y controles). Diversas investigaciones, acerca de las relaciones padres-hijos, muestran que los padres de niños con TDAH y TOD asociado, tienen prácticas de disciplina más autoritaria y sobrerreactiva (Alizadeh y Andries, 2002; Lange y cols., 2005; Woodward y cols., 1998), frente a otros padres que emplean un estilo de disciplina de mayor permisividad unido a un bajo nivel de comunicación entre padres-hijos (Keown y 
Woodward, 2002). Las relaciones familiares de los niños TDAH suelen estar resentidas, aumenta el estrés parental y los padres expresan sentimientos de impotencia y de fracaso.

El profesorado tiene un papel crucial en la detección del trastorno; El diagnóstico se suele realizar cuando comienza la educación primaria. Aparecen problemas de rendimiento escolar, el niño se distrae fácilmente, presenta conducta desadaptada en el aula, tiene dificultades para aceptar las normas y respetar al profesorado como figura de autoridad, siendo la percepción de los profesores como alumnos molestos y difíciles de manejar (Jonhston et al., 2001).

En estudios realizados acerca de las habilidades sociales del niño/adolescente TDAH con iguales, se ha observado que en muchas ocasiones son rechazados por sus compañeros por sus comportamientos oposicionistas, agresivos, disruptivos y más molestos (Barkley, 1991). Además, presentan más problemas para seguir reglas, muestran poca motivación por el deporte y manifiestan problemas de disciplina, ante la órdenes del entrenador, (Pascual-Castroviejo, 2004).

Atendiendo a la gravedad de los síntomas, nuestros resultados reflejan importancia de la comorbilidad al hablar de deterioro funcional; El grupo de casos, frente al de controles, tiene una proporción casi el doble de veces mayor de individuos considerados como graves. Obtenemos frecuencias del $42 \%$, frente al $24 \%$, y mucho menor de los considerados como de síntomas leves $2 \%$, frente al $15 \%$. Aunque es muy infrecuente requerir ingreso en unidad de hospitalización, los 4 que lo necesitaron de entre los 201, tenían comorbilidad acompañante. 
- 2) Evaluar la frecuencia de comorbilidad psiquiátrica de los niños y adolescentes con TDAH de la muestra y la influencia de las variables sexo, grupo de edad, subtipo, agresividad:

Comparando nuestro grupo de pacientes diagnosticados únicamente de TDAH con el de TDAH con comorbilidad acompañante, sólo las variables subtipo y agresividad mostraron ser de significación estadística, como se observa a continuación. La edad y la comorbilidad, al igual que el género y la comorbilidad, no parecen estar relacionadas, al menos, a nivel general. Respecto a la falta de asociación, que observamos en nuestros datos, de la edad de presentación de los síntomas de TDAH y padecer o no comorbilidad, hay estudios en esta misma línea para determinadas patologías. Por ejemplo, para los Trastornos por Consumo de Sustancias, recientes estudios demuestran que, incluso en adultos con un inicio relativamente tardío del TDAH, el riesgo de consumo es similar al de los que cumplen por completo los requisitos para que, en edad temprana, se les diagnostique de TDAH (Faraone et al., 2007).

No obstante, si esta valoración de edad y género, la desglosáramos por patologías concretas, posiblemente, hallaríamos que algunas se ven afectadas por la edad y el sexo del paciente. Esto lo describimos, más detalladamente, al hablar de las limitaciones de nuestro trabajo.

En lo referente al subtipo, y a padecer o no agresividad como síntoma clínico relevante, encontramos fuerte asociación (especialmente en ésta última) entre éstas con la comorbilidad.

Obtuvimos, por tanto, que el TDAH subtipo combinado tienen un riesgo 2,4 veces el de los TDAH de predominio inatento para tener comorbilidad. 
En cuanto a padecer agresividad entre los síntomas clínicos relevantes, el riesgo de padecer comorbilidad que obtuvimos, entre nuestros datos, fue de 23 veces para los pacientes que tenían agresividad entre sus síntomas clínicos. Es decir que, los pacientes con agresividad entre sus síntomas clínicos relevantes, tienen un riesgo 23 veces mayor que el de los no agresivos para tener comorbilidad.

- 3) Evaluar los tipos de comorbilidad más prevalentes en los pacientes TDAH y la influencia de las variables subtipo y agresividad:

Atendiendo a las patologías agrupadas en los tres grandes bloques:

El grupo de pacientes con TDAH de nuestro estudio, que presentaba simultáneamente trastornos del Lenguaje-Aprendizaje, supone el 18\% $(n=38)$. Para Pastor y Reuben (2008) resulta llamativo como el porcentaje de niños entre 6-17 años con TDAH ha aumentado en los últimos años (en muestras de niños y adolescentes estadounidenses de 1997 a 2006), mientras que el porcentaje de niños con Trastorno de Aprendizaje ha permanecido estable. Los dos trastornos aparecen simultáneamente en el $15-40 \%$ de los casos (Willcutt y Pennington, 2000). Estos datos coinciden con los encontrados en nuestra muestra, si bien otros trabajos establecen proporciones en las que se presentan ambos trastornos que llegan hasta el $70 \%$ de los casos (Mayes y Calhoun., 2006). Esta disparidad de resultados, se ha tratado de explicar por la existencia de un sesgo de evaluador, los padres y profesores de niños con Trastornos de Aprendizaje pueden comunicar con más facilidad síntomas de déficits atencionales, sin embargo, para Willcutt es poco probable que esto constituya una explicación de todos los casos de comorbilidad entre TDAH y problemas de aprendizaje (Willcutt et al., 2005b). 
En lo que se refiere más específicamente a los Trastornos de Aprendizaje (mayoritariamente al trastorno de lectura), el $15 \%$ de los niños/adolescentes estudiados los presentan. Está, por tanto, en la línea de los estudios realizados por Shaywitz (1998) que cataloga al trastorno de lectura, como el trastorno de aprendizaje, más frecuente y mejor estudiado, que afecta a un 5-10\% de la población escolar. El porcentaje, está levemente por debajo de lo que Barkley ha detectado en sus trabajos (2006), entre el 8 y el 39\%, con tratornos de lectoescritura.

En lo referente a trastornos de Excitación-Motivación los presentan el 26\% ( $n=54)$ de los sujetos del estudio. Los sujetos de nuestro estudio que, además de padecer TDAH, tenían asociado un Trastorno Depresivo suponen alrededor de un 8\%. Según Tomas Spencer (2000), la Depresión o la Distimia aparecen en el 15 al $75 \%$ de los niños y adolescentes con TDAH.

Este dato, supone más del doble del límite mínimo de los que nosotros hemos identificado en nuestra muestra. Cabe explicarlo en base al infradiagnóstico que se realiza de los trastornos del ánimo (tanto depresión como trastorno bipolar) en nuestro medio, frente a las poblaciones infanto-juveniles americanas. Son numerosos los estudios que hablan de los síntomas subliminales depresivos, que hacen que la depresión pase desapercibida, a pesar de producir deterioro importante (Lewinsohn y cols., 2000; Scahill y cols., 1999). Por otro lado, otro factor implicado el infradiagnóstico, es la variabilidad de la información. Los profesionales deben recoger la información de varios informantes, especialmente cuando están implicados niños. El escaso acuerdo se puede explicar por 1) aspectos psicométricos, 2) el hecho de que los niños se comportan de forma diferente en contextos diferentes, 3) sesgo de observador. Ha habido debate sobre cómo integrar la información que viene de varios informantes. Como señaló Jennsen (2003), “es probable que diferentes estrategias de decisión den lugar a 
diferentes tasas de comorbilidad", lo que Gadow (2002) describió como "variabilidad específica de la fuente". Braaten (2001), publicó que la depresión confirmada por los niños era más leve y breve que la comunicada por los padres.

La superposición de síntomas, hace también al Trastorno Bipolar una patología de difícil detección cuando presenta comórbidamente con el TDAH (Milberger y cols., 1995; Giedd, 2000). Alrededor del 1,9\% de los sujetos de nuestra muestra presentan este diagnóstico comórbido (siendo todos ellos adolescentes). Costello (2003) realizó un estudio comunitario en el que no encontró casos de manía ni hipomanía en niños. Lewinsohn (1995) encontraron que la tasa de manía real era del $0,1 \%$ en adolescentes de 14 a 18 años. Sin embargo, si consideramos la hipomanía en los adolescentes y dependiendo de lo laxos que sean los criterios diagnósticos para T.B II las tasas aumentan desde el 2,6 al 10\% (Angst y Sellaro, 2000; Hirschfeld y Vornik, 2004; Judd y Akiskal, 2003). Según el estudio MTA el 2,2\% de los pacientes TDAH sería también sugestivo de diagnóstico de T.B.

En lo relativo a Trastornos de Ansiedad, encontramos una proporción de un $18 \%$ de los pacientes que los padecen. Según los estudios de Douglas Mennin y colaboradores, realizados en el año 2000 , identificaban que el $17 \%$ de los pacientes con TDAH tiene a su vez un deterioro grave por ansiedad. Este resultado es, por tanto, similar al obtenido en nuestro estudio. Nosotros, para diagnosticar a los pacientes de ansiedad, como trastorno, ésta tiene que producir un deterioro clínicamente significativo (ya que si no, se considera únicamente como ansiedad rasgo). Sin embargo, el estudio MTA (1999) sitúa entre el 25-35\% la frecuencia de los trastornos de ansiedad en pacientes TDAH, (incluyendo entre los trastornos de ansiedad: angustia, fobia, trastorno obsesivo compulsivo, ansiedad generalizada y ansiedad de separación). 
Dentro de los Trastornos de Ansiedad, si nos referimos unicamente al TOC, nosotros, tan sólo detectamos que un $0,49 \%$ de los casos. Esta es una frecuencia muy baja, al compararlo con los pocos estudios que se han publicado al respecto, y en los que se habla de superposición de TDAH/ TOC o TOC/TDAH en el 6\% de los casos (Toro et al., 1992). Posiblemente, se necesiten más estudios que se centren en éstas dos patologías.

Por último, en este bloque, abordamos la proporción con la que observamos Trastornos por Consumo de Tóxicos en los pacientes del estudio, que suponen el $3 \%$. Barkley (2006) encuentra un riesgo de 2-5 veces mayor que en controles normales, si hay comorbilidad con trastorno disocial. Los estudios que se han realizado confirman relación entre TDAH y abuso de tóxicos pero en estrecha relación con trastornos de conducta asociados y del ánimo (Biederman et al., 1997; Mannuzza et al., 1993; Lambert et al., 1997).

Los trastornos del grupo Social-Emocional suponen el $45 \%$ de los casos de comorbilidad de los pacientes TDAH de nuestro estudio. En primer lugar, tenemos, en una proporción muy elevada, el grupo comórbido de Trastorno Oposicionista Desafiante, suponiendo el $21 \%$ de los casos, seguido del Trastorno de Conducta Disocial presente en el $16 \%$ de los pacientes TDAH de nuestro estudio. Esto supone un total del $37 \%$ de los casos. Datos de diferentes estudios epidemiológicos indican que los diagnósticos categóricos de TOD y TC están presentes en el 40-70\% de los casos (Szatmari et al., 1989a; Maughan et al., 2004). El estudio MTA (1999) arrojó datos similares 40-60\%.

La frecuencia con que se presenta en comorbilidad el Síndrome de Asperger en los sujetos de nuestra muestra es de un $4 \%$ de los casos. El $74-85 \%$ de los diagnosticados de síndrome de Asperger, tienden a cumplir también los criterios diagnósticos de TDAH (Goldstein y Schwebach, 2004; Yoshida y Uchiyama, 
2004). No se dispone aún de datos, acerca de la superposición de síndrome de Asperger dentro de la población de niños TDAH.

El trastorno de tics, supone el $9 \%$ de los pacientes TDAH estudiados, cuyo resultado es similar al 10,9\% que detectó el estudio MTA en sus resultados.

De los estudios inferenciales obtenemos los siguientes resultados:

El padecer Trastorno del Lenguaje o Trastorno del Aprendizaje, no parece tener relación con el subtipo de TDAH que se padezca. Tanto el subtipo de TDAH combinado, como el de predominio de déficit de atención, tienen entre sus síntomas la disfunción ejecutiva. Los estudios que se han realizado acerca de este grupo de comorbilidades evidencian que existe un estrecho vínculo entre el déficit de atención, como dimensión sintomática predominante, y deterioros de la función académica y de los procesos cognitivos o psicológicos (Castellanos y cols, 2005; Currie y Stabile, 2006). No se han conseguido definir diferencias sistemáticas, constantes, entre los síntomas de TDAH con y sin trastorno del aprendizaje asociado (Pennington y cols., 1993; Robins 1992).

Mientras los Trastornos del Lenguaje no parecen estar relacionados estadísticamente con la agresividad del paciente, si lo están los pacientes de nuestro estudio que tienen trastornos del Aprendizaje. Según Brown (2010), "mientras la atención se refiere a un conjunto de complejos procesos cognitivos, la conducta de falta de atención se define como la conducta de suspensión de la tarea e insiste en la frecuencia con la que el niño aparta la mirada de los estímulos relevantes de la tarea durante una actividad específica (p. ej. deberes del colegio, jugar a futbol, jugar a videojuego...)". Por definición, todos los pacientes con TDAH, tendrán síntomas conductuales de falta de atención que 
generan deterioro, y más relevantes si, además, los síntomas son causantes en sí mismos de problemas de comportamiento no sólo atencional sino motor y de control emocional.

Respecto a nuestros resultados obtenidos en las patologías del bloque de Excitación-motivación: Encontramos que en nuestro grupo de pacientes TDAH, no hay diferencias entre ambos subtipos para padecer Depresión, pero la agresividad sí parece estar relacionada con los trastornos afectivos.

Estudios realizados en este aspecto, arrojan resultados contradictorios, si bien Carlson y colaboradores, en un grupo muestral de 616 niños seguidos en el Stony Brook Child and Adolescent Psychiatry outpatient clinic, entre 1999 y 2002, detectaron que, de 92 niños que tenían TDAH y depresión, 50\% eran del subtipo combinado frente al $17 \%$ que eran del inatento. Gadow y colaboradores en 2004 comunicaron la gran variabilidad de datos, a este respecto, en función de la fuente. Encontraron que, tanto los profesores como las madres, indicaban a los niños con TDAH subtipo combinado mayores puntuaciones en escalas de depresión frente al grupo hiperactivo-impulsivo. Sin embargo, observaron que los profesores, pero no las madres, puntuaron el grupo de TDAH con falta de atención como más distímico que el grupo hiperactivo-impulsivo.

No obstante, en lo referente a nuestros datos, es muy posible que parte de los trastornos de conducta, que constituyen la queja dominante de profesores y padres, tengan subyacente una depresión que no se manifiesta como síntomas de tristeza, sino como irritabilidad-agresividad y por ello no es comunicada por los cuidadores (pasando desapercibida en consulta), mientras que, en niños inatentos, sea más fácil detectarla (por ser más similar a lo que experimentan los adultos cuando la padecen). 
Mucho se ha escrito, sobre las diferencias entre los síntomas de manía en la infancia, frente a los que se presentan en la edad adulta. Para autores como Giedd (2000) y Carlson (1999), los síntomas transversales de la manía (entre ellos la irritabilidad) y el TDAH (con sus rabietas por baja tolerancia a la frustración) sean prácticamente indistinguibles. No es de extrañar, por ello, que la agresividad-irritabiliad se presente en relación estrecha con los trastornos del ánimo, máxime teniendo en cuenta que constituye el criterio A de la clasificación DSM-IV para el diagnóstico de la manía y la depresión en la infancia y adolescencia. Los síntomas del estado de ánimo deben permitir distinguir entre manía y TDAH, aunque el estado de ánimo irritado y deprimido es muy similar a los problemas del ánimo asociados a los niños con TDAH, como "baja tolerancia a la frustración, explosiones de ira y de ostentación de mando, testarudez, insistencia excesiva y frecuente de que se satisfagan las peticiones, labilidad anímica, disforia, sensación de rechazo por los iguales y baja autoestima" (American Psychiatric Association, 2000, págs. 87-88). Cuando se hace un diagnóstico de manía se debe tener en consideración el nivel de desarrollo del niño para evaluar si la alegría/irritabilidad es significativa como síntoma (Carlson y Meyer, 2006; Harrington y Myatt, 2003).

En el caso de la comorbilidad como Trastornos de Ansiedad nuestros resultados indican que los pacientes con subtipo combinado y los que tienen subtipo inatento tienen riesgo similar de padecer ansiedad. Esto está en sintonía con los estudios más recientes, si bien, la creencia clínica preexistente era que, los trastornos de ansiedad, tienen más riesgo de presentarse en el subtipo inatento del manual DSM-IV. Autores como Byun (2006) y Power (2004), muestran que el tipo combinado y el tipo inatento tienen niveles similares de ansiedad. No hay datos constantes que indiquen que el TDAH (o sus subtipos) se asocien de forma diferencial a los diferentes tipos de trastornos de ansiedad infantiles. 
En lo referente la agresividad, los niños y adolescentes agresivos son los que no tienen más riesgo de tener trastorno de ansiedad. Tampoco en este aspecto encontramos resultados homogéneos. Loney y colaboradores (1981), encontraron que los niños prepuberales con TDAH que no tenían agresividad, tenían un aumento del riesgo de presentar deterioro cognitivo y síntomas de ansiedad en la adolescencia. Pilska $(1989,1992)$ observó que, los profesores de los niños con TDAH y ansiedad comórbidos, consideraban que tenían menos déficit de atención, hiperactividad y menos conductas agresivas que los TDAH no ansiosos. Sin embargo, al contrario, Livingston y colaboradores (1990) comunicaron resultados opuestos, los niños con TDAH y ansiedad tenían más falta de atención y eran más hiperactivos y agresivos que los no ansiosos.

En lo relativo a los Trastornos por Consumo de Tóxicos encontramos cómo se relaciona tanto con tener un TDAH subtipo combinado, como con la presencia de síntomas de agresividad. En un estudio realizado por Kellam y colaboradores (1980) en Chicago, "Woodlawn Study", observaron que los niños considerados como agresivos, inquietos, impulsivos y con falta de atención, tenían mayores tasas de consumo de sustancias años después en la adolescencia (y edad adulta temprana). Además, como parte de un estudio prospectivo de TDAH en comparación con controles sanos, encontramos diferencias del riesgo de presentar TCS en adolescentes con TDAH frente a los sanos. Esas diferencias, se explicaron por la asociación de la comorbilidad, concretamente con Trastorno Bipolar o Trastorno Disocial, ambos en los cuales la agresividad supone uno de los síntomas cardinales (Biederman y cols., 1997) 
En el grupo de patologías incluidas bajo el epígrafe de Social-emocional encontramos que, tanto el Trastorno Oposicionista Desafiante como el Trastorno de Conducta Disocial, se encuentran con más frecuencia en pacientes TDAH subtipo combinado y/o en los que presentan agresividad como síntoma clínico relevante.

Las relaciones entre los síntomas del TDAH combinado (Inatención, Impulsividad e Hiperactividad) y los problemas de conducta están tan estrechamente relacionadas que, numerosos autores lo consideran como diferentes manifestaciones de una misma patología. Estudios como los de Pillow (1998), Tries y Laprade (1993) han utilizado métodos factoriales para evaluar si el dominio de la hiperactividad es diferente de los dominios de problemas de conducta y agresividad. Concluyeron que no podía demostrarse con los resultados obtenidos que los problemas de conducta y los de hiperactividad fueran entidades diferentes. Otras series de estudios, (Reeves y cols., 1987; Werry y cols., 1987) también concluyeron que había poca base para distinguir los diversos grupos diagnósticos. A pesar de esta aparente continuidad sintomática, dentro del mismo espectro de patología conductual, otros autores abogan por la diferenciación entre TDAH y problemas del comportamiento (Maughan y cols., 2004; Schachar y Tannock, 1993; Szatmari y cols., 1989; etc). De nuevo, nos encontramos ante discrepancias de opinión entre los diversos expertos, aunque la relación entre agresividad y subtipo con este tipo de problemas de conducta es incuestionable.

En lo referente a la presencia de agresividad en los pacientes TDAH, estudios como los de MacDonald y Achenbach predijeron totalmente la evolución antisocial, en niños seguidos durante un periodo de 6 años hasta la adolescencia, por la aparición simultánea de TDAH con agresividad en la infancia. 
En lo referente a los resultados obtenidos para el Trastorno de Tics, si bien el subtipo de TDAH padecido no ha demostrado ser de significación estadística, la agresividad se presenta como vinculada a padecer con más frecuencia tics asociados al TDAH. Aunque los tics de forma aislada han demostrado en diversos estudios producir escaso deterioro (Spencer y cols., 1999, 2001b), ya desde los primeros estudios que se centraban en Trastorno de Guilles de la Tourette (TGT), se apuntaba las desadaptaciones comportamentales de estos pacientes. Ya Modofsky (1974) describió en sus sujetos de estudio disfunción social, familiar y conducta perturbadora. En dos estudios de nominación entre iguales (Badewn, 1998 y Stokes, 1991) encontraros resultados similares en sus niños con TGT. Los primeros estudios clínicos encontraron asociación significativa entre la gravedad de los tics y la alteración de conducta (Comings y Comings, 1987; Rosenberg, 1984, 1995).

- 4) Analizar la relevancia de la comorbilidad en el mejor o peor cumplimiento de la prescripción facultativa y según la edad de inicio de la medicación.

Al evaluar cómo se comporta la comorbilidad ante la evolución y el tratamiento, no encontramos asociación estadísticamente relevante entre la edad de presentación de los síntomas de TDAH y padecer o no comorbilidad. Hay estudios en esta misma línea para determinadas patologías, por ejemplo para los Trastornos por Consumo de Sustancias, recientes estudios demuestran que incluso en adultos, con un inicio relativamente tardío del TDAH, el riesgo de consumo de sustancias está tan elevado como los que cumplen por completo los requisitos, para el diagnóstico de TDAH, en una edad más temprana (Faraone et al., 2007).

Por último, y tras exponer cómo la comorbilidad empeora la clínica y pronóstico de los niños y adolescentes con TDAH, no nos resulta extraño que el padecer comorbilidad se asocie a un inicio precoz de tratamiento en consultas de salud 
mental. Biederman y colaboradores (2001) detectaron como, en sus pacientes con TDAH y comorbilidad asociada (como trastornos de conducta, trastorno bipolar, trastorno oposicionista desafiante y abuso de tóxicos) conllevaba peor pronóstico e intervenciones sanitarias más tempranas. La GPC (2010) advierte que a pesar de no existir evidencia científica de cómo la intervención precoz mejora el pronóstico del TDAH, es considerado que el diagnóstico precoz y el tratamiento adecuado mejorarán la evolución en la mayoría de los casos.

- 5) Elaborar árboles de decisión que faciliten, en la práctica clínica, la detección precoz de la comorbilidad en el paciente TDAH.

Las variables de nuestro estudio, referentes a nuestros pacientes con nuestros pacientes con Trastorno de Déficit de Atención e Hiperactividad, que han demostrado ser de mayor relevancia estadística para establecer algoritmos de decisión son: la agresividad, los antecedentes personales y las relaciones sociales establecidas con iguales. 


\subsection{Limitaciones de nuestro estudio}

En primer lugar, al evaluar nuestros resultados, somos conscientes de que al tratarse de una muestra clínica, no sean completamente extrapolables a la población general. Esto es porque, quienes buscan tratamiento en las consultas de Salud Mental, forman parte de una población seleccionada, probablemente caracterizada por enfermedades más graves y complicadas que los sujetos procedentes de la población general. Si bien, los pacientes de la población pueden sufrir problemas similares, pero se mantienen alejados de consultas y hospitales. Además, una persona con un deterioro leve y más recursos económicos, puede buscar el tratamiento en la medicina privada de la comunidad, cuyos historiales no se incluyen normalmente en los estudios clínicos; Otros pueden adaptarse a una forma menos intensa del mismo problema sin buscar ningún tratamiento. Por tanto, los estudios que describen las tasas de enfermedades asociadas para poblaciones clínicas, podrían pasar por alto toda una gama de sujetos con problemas similares que no son suficientemente graves o complicados como para buscar ayuda médica.

En el lado opuesto estarían los estudios epidemiológicos, que seleccionando sujetos de la población general al azar, se les solicita la colaboración para responder si padecen determinados síntomas psiquiátricos. Con este tipo de información se pueden obtener datos útiles de los problemas psiquiátricos, que experimentan los sujetos de la población, pero se enfrentan a otro tipo de limitación y es subestimar la frecuencia real de dichos trastornos psiquiátricos. Es improbable que, personas que no conocen al investigador y que no van a recibir de él ningún beneficio, comuniquen completamente sus dificultades personales que en muchos casos supones vergüenza o preocupación.

Por otra parte, al incluir los diferentes tipos de comorbilidad, nos enfrentamos a la situación de que trastornos como el Obsesivo Compulsivo, o el síndrome de Asperger, e incluso el Trastorno Bipolar en la infancia son verdaderamente infrecuentes (no sólo por la baja incidencia, sino también, por la tendencia conservadora que hace esperar, para 
ver la evolución, ante sospechas diagnósticas de semejante gravedad y cronicidad) y eso, nos supone limitaciones obvias a la hora de analizar y extrapolar resultados.

En lo referente a la recogida de datos nos enfrentamos a la limitación de recibir la información de informantes que, por la edad de los pacientes, muchas veces son los padres o cuidadores, con la subjetividad que ello conlleva a la hora de comunicar la presencia de sintomatología (tanto por exceso como por defecto).

También, con intención de no elevar la farragosidad de nuestro estudio, decidimos seleccionar entre los tres bloques de comorbilidades (Lenguaje-Aprendizaje/ ExcitaciónMotivación y Social-Emocional) las variables que parecían más relevantes e influyentes, decidiéndonos por tanto a desgranar cómo el subtipo de TDAH y la agresividad afectaban a los diferentes tipos de trastornos. Somos conscientes de que desglosando pormenorizadamente por cada patología concreta, variables como el género o la edad, que a nivel general no se mostró estadísticamente significativa, podrían serlo, por ejemplo, en el padecimiento de trastornos depresivos o distímicos (Carlson y cols., 2005; Biederman y cols., 1996b). Posiblemente, esta profundización nos motive a realizar estudios posteriores de éstos aspectos.

A pesar de las limitaciones ya mencionadas, los resultados del estudio ponen de relieve cómo el Trastorno de Déficit de Atención e Hiperactividad, en niños y adolescentes de nuestro medio, se presentan con mucha frecuencia asociados a tasas elevadas de otros trastornos psiquiátricos y que tienden a complicar la presentación clínica del síndrome y ensombrecen el pronóstico. El estudio MTA (1999), que encontró comorbilidad en el $70 \%$ de los pacientes, para cumplir al menos los criterios DSM-IV para otro trastorno, supuso una gran aportación para el conocimiento del TDAH y comorbilidad, pero presentó entre sus limitaciones la edad y el género de los sujetos estudiados, ya que el $80 \%$ eran varones y en lo referente a la edad sólo se trataba de niños pequeños (7 a 9 años). Tampoco en el subtipo incluyó nada más que a TDAH combinado, excluyendo de entre 
ellos a los que no tenían síntomas significativos del tipo hiperactivo-impulsivo. Siendo probable que el perfil de la comorbilidad de los adolescentes TDAH, especialmente mujeres y de predominio déficit de atención, sea diferente.

Nuestro estudio, trata de arrojar datos de lo que puede presentarse en una consulta de salud mental infanto-juvenil en nuestro medio, en lo que al paciente TDAH se refiere. Hemos tratado de identificar variables que puedan ponernos en alerta de encontrar trastornos acompañantes en nuestros niños y adolescentes TDAH como son los antecedentes personales de consulta en ESM (ya sea con psiquiatra o psicólogo), la presencia de agresividad como síntoma clínico relevante y las relaciones sociales con iguales, para los diferentes bloques de trastornos clasificados. El objetivo es que, poco a poco, se unifiquen los criterios tanto de detección como de intervención tanto en la clínica, como en los colegios y familias. El tratamiento del TDAH es multidisciplinar, el tratamiento farmacológico ha mostrado ser efectivo a largo plazo en el control de los síntomas según la evidencia científica (AAP, 2005 y SIGN, 2005) pero es preciso una mayor implicación de padres y profesores en la detección y control de síntomas y consecuencias.

Queda mucho trabajo por hacer para intentar encontrar resultados homogéneos. Las tasas de prevalencia son dispares según los criterios diagnósticos empleados, el origen de las muestras, la metodología y las edades y sexo escogidos (Benjumea, 2006). Esta es, nuestra pequeña aportación al conocimiento del Trastorno de Déficit de Atención e Hiperactividad y la Comorbilidad Psiquiátrica acompañante, y lo que suponen para el niño y el adolescente afectado en todos los aspectos de la vida del paciente (social, familiar, académico y emocional). 


\section{CAPÍTULO 4. CONCLUSIONES}

- 1. De entre los pacientes que acuden a consulta de Salud Mental Infanto-Juvenil del área de León, existe una proporción ligeramente superior de pacientes con TDAH que se encuentran en edades comprendidas entre los 5 y 12 años frente a los que se sitúan entre 13 y 18 , y tanto para los pacientes que presentan comorbilidad como para los que no, la distribución de edad es similar : casos/controles $55 \% / 53 \%$ frente a $44 \% / 46 \%$

- 2. Dentro de los pacientes con TDAH, que acuden a consulta en nuestra Unidad, hay una diferencia de prevalencia por género siendo mayor el número de varones (casos/controles 77\%/84\%) frente a mujeres (casos/controles $22 \% / 15 \%)$.

- 3. En lo que se refiere al subtipo de diagnóstico (inantento o combinado) confirmamos una mayor prevalencia del subtipo combinado frente al inatento (casos/controles $74 \% / 54 \%$ frente al $25 \% / 45 \%$ ), y esta frecuencia es mayor en caso de tener comorbilidad psiquiátrica.

- 4. Habitualmente se trata de familias de clase media (casos/controles $75 \% / 87 \%$ ). La pequeña proporción que se sitúan en un nivel socio-económico alto lo hacen en el grupo de los TDAH sin comorbilidad y para las familias de las clases más desfavorecidas es más frecuente que el paciente TDAH tenga comorbilidad psiquiátrica acompañante.

- 5. Los antecedentes familiares se detectan en la mayoría de nuestros pacientes con trastorno de déficit de atención e hiperactividad, tengan o no comorbilidad (casos/controles $77 \% / 85 \%)$. 
- 6. En lo referente a los antecedentes personales de tratamiento psicológicopsiquiátrico, nuestro grupo de casos que los presenta, representa casi el doble frente a los que no los tienen; constatando que el $62 \%$ ha acudido previamente a consulta psicológica o psiquiátrica. Sin embargo, el $16 \%$ de los pacientes del grupo control tiene historia previa de consultas en Salud Mental.

- 7. Los pacientes TDAH obtienen con mucha frecuencia malos resultados académicos. Las frecuencias con las que se sitúan en niveles de "malos" o "fracaso" son muy altas para los integrantes del grupo casos ,y son altas, aunque no tanto como en el grupo anterior, para los casos (controles/casos $63 \% / 28 \%)$.

- 8. Las relaciones sociales también se caracterizan por estar más deterioradas en los pacientes con TDAH que tienen comorbilidad, tanto a nivel familiar, como escolar o como con iguales. Entre padres e hijos los del grupo control comunican relación regular en el $30 \%$ de los sujetos y mala relación en un $6 \%$. Estas frecuencias están muy incrementadas en los individuos del grupo de casos teniendo como resultados $39 \%$ regular y 36\% malas relaciones. Entre profesores-alumnos mientras los controles informan de $22 \%$ de relaciones regulares y ninguna mala, los casos tienen en un 34\% relación con sus profesores clasificada como regular y la cifra de los que las consideran malas se eleva al 29\%. Por último, la relación con iguales también se encuentra más dañada en los pacientes TDAH con comorbilidad, comunicando un $30 \%$ de relación mala con otros pares, frente al $1 \%$ de los controles, y considerando que sus relaciones son regulares en un $34 \%$ y $12 \%$ respectivamente (para casos y controles).

- 9. Atendiendo a la gravedad de los síntomas los pacientes con TDAH y comorbilidad tienen mayor gravedad de presentación sintomática. El $42 \%$ de los 
casos son considerados como pacientes graves frente al $24 \%$ de los controles. La diferencia entre los casos y controles que se consideran como pacientes leves es aún mayor, $2 \%$ de los casos frente al $15 \%$ de los controles. Aunque es muy infrecuente requerir ingreso en unidad de hospitalización, encontramos que el $100 \%$ tenían comorbilidad acompañante.

- 10. El perfil del paciente tipo TDAH sin comorbilidad, que acude a consulta, sería un varón $(84 \%)$, de menos de 13 años $(53 \%)$, de clase media $(87 \%)$, con antecedentes familiares de patología psiquiátrica (84\%) pero sin antecedentes personales (84\%), con síntomas de subtipo combinado (54\%) o inatento (45\%), rendimientos académicos medios (35\%) y relaciones sociales buenas con padres $(63 \%)$, profesores $(77 \%)$ e iguales $(86 \%)$.

- 11.El perfil del paciente tipo TDAH con comorbilidad que acude a consulta de salud mental es un niño varón (77\%), menor de 13 años (55\%), de clase media (75\%), antecedentes familiares de patología psiquiátrica $(77 \%)$ y personales $(62 \%)$, con síntomas de TDAH subtipo combinado (74\%), malos rendimientos académicos (63\%) y deterioro de relaciones sociales con sus padres $(75 \%)$, profesores (63\%) e iguales (64\%).

- 12. Respecto al estudio estadístico inferencial de nuestro trabajo con respecto a la comorbilidad psiquiátrica en general, encontramos como variables sociodemográficas y clínicas significativas:

- El subtipo diagnóstico: TDAH combinado $(p=0.04)$

- El síntoma agresividad: sí $(p=0.00)$

- El inicio de tratamiento: precoz (0.003) 
- 13.En lo relativo al estudio pormenorizado de las diferentes posibles comorbilidades encontramos:

- La frecuencia de presentación de las diferentes comorbilidades en Lenguaje-Aprendizaje supone el 18\%, los Trastornos de ExcitaciónMotivación los representa el 27\% ( Trastorno Depresivo suponen alrededor de un 8\%; Trastorno Bipolar alrededor del 1\%; Trastornos de Ansiedad un 18\%; Trastornos por Consumo de Tóxicos 3\%) y el bloque de SocialEmocional supone el 45\% (Trastorno Oposicionista Desafiante y Trastorno de Conducta presente en el 37\%; Trastorno de Tics supone el $9 \%)$.

- En los estudios inferenciales encontramos:

a) La agresividad en los pacientes TDAH muestra una relación estadísticamente significativa con la presencia comórbida de trastornos del aprendizaje $(\mathrm{p}=0.01)$

b) En los pacientes que padecen TDAH agresivos tienen diferencias estadísticamente significativas para padecer Depresión y/o Manía frente al subtipo combinado $(p=0,008)$.

c) Los pacientes que tienen más riesgo de Trastornos de Ansiedad son los agresivos $(\mathrm{p}=0.016)$.

d) Tanto el subtipo de TDAH combinado como la presencia de agresividad son variables de relevancia para padecer Trastornos por Consumo de Tóxicos ( $\mathrm{p}=0.037$ y $\mathrm{p}=0.00$ respectivamente). 
e) Los pacientes que tienen más riesgo de Trastornos Oposicionista Desafiante son los TDAH combinados $(p=0.00)$ y los que tienen agresividad $(\mathrm{p}=0.00)$.

f) Los pacientes que tienen más riesgo de Trastorno de Comportamento Disocial son los TDAH combinados $(p=0.001)$ y los que tienen agresividad $(\mathrm{p}=0.00)$.

g) Los Trastornos de Tics (incluido Guilles de la Tourette) se presentan con más frecuencia en pacientes TDAH con agresividad como síntoma clínico relevante. 


\section{TÍTULO IV. REFERENCIAS BIBLIOGRÁFICAS}

1. Adesida O y Foreman D. A support for parents of children whit hyperkinetic disorder: An empowerment model. Clinical Child Psychology and Psychiatry, 4: 567-578, 1999

2. Alexander GE, Delong MR y Strick PL. Parallel organization of functionally segregated circuits linking basal ganglia and cortex. Annuary Rewiew Neuroroscience, 9: 357-381, 1986

3. American Academy of Child and Adolescent Psychiatry. Practice parameters for the assessment and treatment of children, adolescents and adults with attention deficit disorder. Journal American Academy of Child and Adolescent Psychiatry, 36 (10 suppl): 85-121, 1997

4. American Academy of Pediatrics. Clinical practice guideline: Treatment of the school-aged child with attention deficit/hyperactivity disorder. American Academy of Pediatrics, 108: 1033-1044, 2001

5. American Psychiatric Association. Diagnostic and Statistical Manual of Mental Disorders. (2nd edition).Washington, DC: Author. 1968

6. American Psychiatric Association. Diagnostic and Statistical Manual of Mental Disorders (3rd edition).Washington, DC: Author. 1980

7. American Psychiatric Association. Diagnostic and Statistical Manual of Mental Disorders: DSM-III-R (3rd edition rev). Washington, DC: Author. 1987

8. American Psychiatric Association (1995). Diagnostic and statistical manual of mental disorders (4th edition).Washington, DC: Author. (DSM-IV Manual Diagnóstico y Estadístico de los Trastornos Mentales. Barcelona, Masson. (1994) 
9. American Psychiatric Association (2000). Diagnostic and statistical manual of mental disorders (4th edition rev).Washington, DC: Author. (DSM-IV-TR Manual Diagnóstico y Estadístico de los Trastornos Mentales. (2002). Barcelona. Masson.

10. American Psychiatric Association. DSM-IV TR Manual diagnóstico y estadístico de los trastornos mentales IV .Texto revisado. Barcelona: Masson. 2001.

11. Anderson JC, Williams S, McGee R, Silva PA. DSM-III disorders in preadolescent children. Arch Gen Psychiatry, 44: 69-76, 1987

12. Andrés MA, Catalá MA, Gómez-Beneyto M. Prevalence, comorbidity, risk factors and service utilisation of disruptive behaviour disorders in a community simple of children in Valencia (Spain). Social Psychiatry and Psychiatric Epidemiology, 34(175):179, 1999

13. Angst J, Sellaro R: Historical perspectives and natural history of bipolar disorders. Biological Psychiatry, 48: 445-457, 2000

14. Arnsten AF. Fundamentals of attention-deficit/hyperactivity disorder: circuits and pathways. Journal of Clinical Psychiatry, 67 Suppl 8:7-12, 2006

15. Artigas-Pallares, J. Comorbilidad en trastorno por déficit de atención/hiperactividad. Revista Neurología, 36,(Supl1): 568-78. 2003

16. Asherson P, Kuntsi $\mathrm{J}$ y Taylor $\mathrm{E}$. Unravelling the complexity of attention déficit hyperactivity disorder: A behavioral fenetic approach. The Britis Journal of Psychiatry, $187,103-105,2005$

17. August GJ, Stewart MA, Holmes CS. A four-year follow-up of hyperactive boys with and without conduct disorder. The Britis Journal of Psychiatry. Aug143:192-8, 1983

18. August GJ y Ganfinkel GD. Comorbility of ADHD and Reading Disability Among Clinic Referred children. Journal of Abnormal Child Psychology, 18: 29-45, 1990 
19. Babinski LM, Hartsough CS, Lambert NM. Childhood conduct problems, hyperactivity-impulsivity, and inattention as predictors of adult criminal activity. Journal of Child Psychology and Psychiatry. Mar;40(3):347-55, 1999

20. Bagot R, Meaney MJ. Epigenetics and the Biological Basis of Gene Environment Interactios. Journal of the American Academy of Child and Adolescent Psychiatry. 49(8):752-771, 2010

21. Barkley RA, Biederman J. Toward a broader definition of the age-of-onset criterion for attention déficit/hyperactivity disorder. Journal of the American Academy of Child and Adolescent Psychiatry 36: 1204-1210, 1997.

22. Barkley RA. The Nature of ADHD. Attention-Deficit Hyperactivity Disorder. A Handbook for diagnosis and treatment. 3. ${ }^{a}$ ed. London: The Guilford Press: 3-75, 2006

23. Barkley RA, editor. Attention-Deficit Hyperactivity Disorder. A Handbook for diagnosis and treatment. 3. ${ }^{\mathrm{a}}$ ed. London: The Gilford Press: 77-121, 2006

24. Barkley RA. Symptoms, diagnosis, prevalence and gender differences. En: Barkley RA, editor. Attention-Deficit Hyperactivity Disorder. A Handbook for diagnosis and treatment. 3. ${ }^{a}$ ed. London: The Gilford Press: 77-121, 2006

25. Barkley RA. The Nature of ADHD. History. En: Barkley RA, editor. Attention-Deficit Hyperactivity Disorder. A Handbook for diagnosis and treatment. 3. ${ }^{a}$ ed. London: The Guilford Press, 2006

26. Barkley RA, DuPaul GJ y McMurray MB. Attention deficit disorder whit and without hyperactivity: Clinical response to three dose levels of metihylphenidate. Pediatrics, 87: 519-531, 1991 
27. Barkley RA y Biederman J. Toward a broader definition of the age of onset criterion for attention deficit hyperactivity disorder. Journal of the American Academy Child and Adolescent Psychiatry, 36: 1204-1210, 1997

28. Barkley RA, and Bierderman. "Toward a broader definition of the age-of-onset criterion of attention-deficit disorder". Journal of the American Academy of Child and Adolescent Psychiatry 36 (9): 1204-1210, 1997

29. Barkley RA, Fisher M, Edelbrock CS y Smallish L. The adolescent outcome of hyperactive children diagnosed by research criterial. An 8 year prospective follow-up study. Journal of the American Academy of child and Adolescent Psychiatry, 29: 546-557. 1990

30. Barkley R y Cunningham $\mathrm{C}$. The effects of methylphenidate on the motherchild interactions of hyperactive children. Archives of General Psychiatry, 36, 201-208, 1979

31. Barkley R, Fischer M, Smallish L y Fletcher K. Young Adult Outcome of Hyperactive Children: Adaptive Functioning in Major Life Activities. Journal of the American Academy of Child and Adolescent Psychiatry, 45: 192-202, 2006

32. Barkley RA. Hyperactivity. En Mash E y Terdal L (Eds), Behavioral Assessment of Childhood Disorders. New York: Guilford Press, 1981

33. Barkley RA. Guidelines for defining hyperactivity in children. En Lahey B y Kazdin A (Eds.), Advances in Clinical Child Psychology, New York, Plenum Press, 1982

34. Barkley, R.A. (1982). Guidelines for defining hyperactivity in children. En B. Lahey y A. Kazdin (Eds), Advances in Clinical Child Psychology, New York, Plenum Press.

35. Barkley RA. Attention deficit/hyperactivity disorder: A Handbook for diagnosis and treatment. New York, Guilford Press: 74-105, 1990 
36. Barkley RA. Attention deficit/hyperactivity disorder: A Handbook for diagnosis and treatment. New York, Guilford Press: 74-105, 1990

37. Barkley RA. Impaired delayed responding: a unified theory of attention deficit/ hyperactivity disorder. En Disruptive Behaviour Disorders: Essays in Honor of Herbert Quay, (ed. D.K. Routh), Plenum, New York, 1994

38. Barkley RA. Behavioral inhibition, sustained attention, and executive functions: constructing a unifying theory of ADHD. Psychological Bulletin, 121: 65-94, 1997

39. Barkley RA. Attention-deficit hyperactivity disorder. Scientific American, 279: 44-49, 1998

40. Barkley RA. Attention-deficit hyperactivity disorder. Scientific American, 279: 44-49, 1998

41. Barkley RA, Dupaul GJ y McMurray MB. A comprehensive evaluation of attention deficit disorder with and without hyperactivity as defined by research data. Journal of Consulting and Clinical Psychology, 58: 775-789, 1990

42. Barry $\mathrm{T}$, Dunlap $\mathrm{S}$, Cotton $\mathrm{S}$, Lockman $\mathrm{J}$ y Wells. The influence of maternal stress and distress on disruptive behavior problems in boys. Journal of the American Academy of Child and Adolescent Psychiatry, 44: 265-273, 2005

43. Baumgaertel A, Wolraich ML, Dietrich M. Comparison of diagnostic criteria for attention deficit disorders in a German elementary school sample. Journal of the American Academy of Child and Adolescent Psychiatry, 34: 629-638, 1995

44. Beck SJ, Young GH y Tarnowski KJ. Maternal characteristics and perceptions of pervasive and situational hyperactives and normal controls. Journal of the American Academy of Child and Adolescent Psychiatry, 29: 558-565, 1990 
45. Benjumea P, Morrajo MA. Trastornos hipercinéticos: estudio epidemiológico en doble fase de un apoblación sevillana. Anales de Psiquiatría. Jul; 9(7): 306-11, 1993

46. Benjumea P. Trastornos hipercinéticos. Guía para su diagnóstico. En: Ballesteros C, editor. Práctica clínica paidopsiquiátrica. Historia Clínica. Guías Clínicas. Madrid: Adalia: 116-128, 2006

47. Berkson J. Limitations of the application of fourfold table analysis to hospital data. Biometrics, 2:47-53, 1946.

48. Bernal M, Valdizán JR, García J. Estudio polisomnográfico nocturno en niños con trastorno por déficit de atención con hiperactividad. Revista de Neurología, 38 (supl 1): 103-110, 2004

49. Biederman J, Faraone SV, Milberger S, Jetton JG, Chen L, Mick E, et al. Is childhood oppositional defiant disorder a precursor to adolescent conduct disorder? Findings from a four-year follow-up study of children with ADHD. . Journal of the American Academy of Child and Adolescent Psychiatry. Sep;35(9): 1193-204, 1996

50. Biederman J, Faraone SV, Mick E, et al: Child behavior checklist findings further support comorbidity between ADHD and major depression in a referred sample. Journal of the American Academy of Child and Adolescent Psychiatry 35: 734-742, 1996b

51. Biederman J, Faraone SV, Milberger S, Jetton JG, Chen L, Mick E, et al. Is childhood oppositional defiant disorder a precursor to adolescent conduct disorder? Findings from a four-year follow-up study of children with ADHD. Journal of the American Academy of Child and Adolescent Psychiatry. Sep;35(9): 1193-204, 1996

52. Biederman J, Faraone SV, Monuteaux MC. Differential effect of environmental adversity by gender: Rutter's index of adversity in a group of boys and girls with and without ADHD. American Journal Psychiatry. Sep; 159(9):1556-1562, 2002 
53. Biederman J, Faraone SV, Taylor A, Sienna M, Williamson S, Fine C. Diagnostic continuity between child and adolescent ADHD: findings from a longitudinal clinical sample. Journal of the American Academy of Child and Adolescent Psychiatry. Mar, 37(3): 305-13, 1998

54. Biederman J, Mick E, Faraone SV, Braaten E, Doyle A, Spencer T, et al. Infl uence of gender on attention defi cit hyperactivity disorder in children referred to a psychiatric clinic. American Journal Psychiatry. Jan,159(1):36-42, 2002

55. Biederman J, Mick E, Faraone SV, Burback M. Patterns of remission and symptom decline in conduct disorder: a four-year prospective study of an ADHD sample. Journal of the American Academy of Child and Adolescent Psychiatry. Mar, 40(3): 290-298, 2001

56. Biederman J, Monuteaux MC, Kendrick E, et al: The CBCL as a screen for psychiatric comorbidity in paediatric patients with ADHD. Arch Dis Child 90:1010-1015, 2005.

57. Biederman J, Wilens T, Mick E, et al.: Is ADHD a risk factor for phychoactive substance use disorders? Findings from a four-year prospective follow-up study. Journal of the American Academy of Child and Adolescent Psychiatry, 36: 21-29, 1997

58. Biederman J, Faraone SV, Keenank K, Knee O y Tsuang M. Family genetic and psychosocial risk factors in DSM-III attention defict disorder. Journal of the American Academy of Child and Adolescent Psychiatry, 29: 526-33, 1990

59. Bird HR. Epidemiology of chidhood disorders in a cross cultural context. Journal Child Psychology Psychiatry 37: 35-49, 1996

60. Botting N, Powls A, Cooke RW, Marlow N. Attention deficit hyperactivity disorders and other psychiatric outcomes in very low birthweight children at 12 years. Journal Child Psychology Psychiatry, Nov,38(8): 931-41, 1997 
61. Braaten EB, Biederman J, DiMauro A, et al: Methodogical complexities in the diagnosis of major depression in youth: an analysis of mother and youth self-reports. $\mathrm{J}$ Child Adolesc Psychopharmacol 11: 395-407, 2001

62. Bradley W. The behavior of children receiving benzedrine. American Journal of Psychiatry. 1937; 94:577-85.

63. Brown RT, Amler RW, Freeman WS, Perrin JM, Stein MT, Feldman HM, et al. Treatment of attention-defi cit/hyperactivity disorder: overview of the evidence. Pediatrics. 2005 Jun;115(6): e749-e757.

64. Brown TE. Attention-deficit disorder diagnostic form for adolescents. San Antonio. Tex.: Psychological corporation. 1996a.

65. Brown TE. Attention-deficit disorder diagnostic form for adults. San Antonio. Tex.: Psychological corporation, 1996b

66. Brown TE. Attention-deficit disorder Scales for Adolescents and adults. San Antonio. Tex.: Psychological corporation, 1996c

67. Brown TE. Brown attention-deficit disorder Diagnostic Form for Adolescents-revised. San Antonio. Tex.: Psychological corporation. 2001a

68. Brown TE. Attention-deficit disorder Diagnostic Form for children. San Antonio. Tex.: Psychological corporation. 2001b

69. Brown TE. Attention-deficit disorder Scales for children and Adolescents: Manual. San Antonio. Tex.: Psychological corporation. 2001c

70. Brown TE. ADHD Comorbidities: Handbook for ADHD Complications in Children and Adults. Edited by Thomas E. Brown. Published by American Psychiatric Publishing, pp.5, 2009. 
71. Brown TE. Attention deficit disorder: The Unfocused Mind in Children and Adults. New Haven, CT, Yale University Press, 2005 a.

72. Brown TE. Emerging understandings of attention deficit disorders and comorbidities, in attention/deficit disorders and comorbidities in children, adolescents and adults. Edited by Brown TE. Washington, DC, American Psychiatric Press: 3-55, 2000

73. Brown TE: Executive functions and attention deficit hyperactivity disorder: implications of two conflicting views. International Journal of Disability, Development and Education 53: 35-46, 2006.

74. Bush G, Valera EM, Seidman LJ. Functional neuroimaging of attention-defi cit/hyperactivity disorder: a review and suggested future directions. Biological Psychiatry. Jun 1;57(11):1273-84, 2005

75. Cardo E, Servera M, Llobera J. Estimation of the prevalence of attention deficit hyperactivity disorder among the standard population on the island of Majorca. Revista de Neurología. Jan 1,44(1):10-4, 2007

76. Carlson G.A., Meyer S.E.: Phenomenology and diagnosis of bipolar disorder in children, adolescents and adults: complexities and developmental issues. Journal for Development and Psychopathology, 18:939-969, 2006

77. Carlson G.A., Weisbrot DM, Crowell J: Unpublished data, January 22, 2005

78. Carroll JM, Maughan B, Goodman R, et al: Literacy difficulties and psychiatric disorders: evidence for comorbidity. Journal of Child Psychology and Psychiatry 46: 524532,2005

79. Casey R y Schlosser S. Emotional responses to peer praise in children with and without diagnosed externalising disorder. Merrill Palmer Quartely, 40: 60-81, 1996 
80. Castellanos FX, Tannock R. Neuroscience of attention-deficit/hyperactivity disorder: the search for endophenotypes. Nature Reviews Neuroscience. Aug; 3(8):617-28, 2002

81. Castellanos FX, Sonuga-Barke EJ, Scheres A, et al.: Varieties of attentiondeficit/hyperactivity disorder-related intra-individual variability. Biological Psychiatry $57: 1416-1423,2005$

82. Costello EJ, Mustillo S, Erkanli A, et al: Prevalence and develompment of psychiatric disorders in chilhood and adolescence. Archives of General Psychiatry 60: 873-844, 2003

83. Currie J, Stabile M: Child mental health and human capital accumulation: the case of ADHD. Journal of Health Economics 25: 1094-1118, 2006

84. Criado Álvarez JJ, Romo BC. Variability and tendencies in the consumption of methylphenidate in Spain. An estimation of the prevalence of attention deficit hyperactivity disorder. Revista de Neurología, Nov 1; 37(9):806-810, 2003

85. Dally K: The influence of phonological processing and inattentive behavior of reading acquisition. Journal of Educational Psychology 98: 420-437, 2006.

86. Douglas, VI. "Cognitive Control Processes in Attention-Déficit/Hyperactivity Disorder". In handbook of disruptive behavior dirorders, ed. H. C. Quay and A. E. Hogan. New York: Kluwer Academic and Plenum. 105-138, 1999

87. Douglas, VI Can Skinnerian therapy explain attention deficit disorder?. A reply to Barkley. In L.M. Bloomingdale and J .Swanson (Eds). Attention deficit disorder: Current concepts and emerging trends in attentional and behavioural disorders of childhood. Oxford, England: Pergamon Press. 235-354, 1989. 
88. DuPaul GJ, McGoey KE, Eckert TL, VanBrakle J. Preschool children with attentiondeficit/hyperactivity disorder: impairments in behavioral, social, and school functioning. Journal of the American Academy of Child and Adolescent Psychiatry. May; 40(5):508-15, 2001

89. Ehlers S, Gillberg C, Wing L. A Screening Questionnaire for Asperger Syndrome and Other High-Functioning Autism Spectrum Disorders in School Age Children. Journal of Autism and Developmental Disorders, 29(2):129-141, 1999

90. Faraone SV, Perlis RH, Doyle AE, Smoller JW, Goralnick JJ, Holmgren MA, et al. Molecular genetics of attention-defi cit/hyperactivity disorder. Biological Psychiatry. Jun 1;57(11):1313-23, 2001

91. Faraone SV, Perlis RH, Doyle AE, Smoller JW, Goralnick JJ, Holmgren MA, et al. Molecular genetics of attention-defi cit/hyperactivity disorder. Biological Psychiatry. Jun 1;57(11):1313-23, 2005

92. Faraone SV, Sergeant J, Gillberg C, et al: Wordwide prevalence of ADHD: is it an American condition? World Psychiatry 2; 104-113, 2003.

93. Faraone SV, Biederman J, Jetton JG y Tsuang MT. Attention deficit disorder and conduct disorder: longitudinal evidence for a familial subtype. Psychological Medicine, 27: 291-300, 1997

94. Faraone SV, Biederman J, Kritcher-Lehamn B. y cols. Intellectual perfomance and school failure in children with attention deficit hyperactivity disorder and in their siblings. Journal of Abnormal Psychology, 102: 616-623, 1993

95. Faraone SV, Wilens TE, Pretty $C$, et al. Substance use among ADHD adults: implications of late onset and subthres-hold diagnoses. American Journal Addictions 16:24-34, 2007 
96. Farré-Riba A, Narbona J. Índice de hipercinesia y rendimiento escolar. Validación del cuestionario de Conners en nuestro medio. Acta Pediatr Esp. 47:103-9, 1989

97. Fergusson DM, Lynskey MT, Horwood LJ. Factors associated with continuity and changes in disruptive behavior patterns between childhood and adolescence. Journal of Abnormal Child Psychology. Oct; 24(5):533-53, 1996

98. Fischer M, Barkley RA, Fletcher KE, Smallish L. The adolescent outcome of hyperactive children: predictors of psychiatric, academic, social, and emotional adjustment. Journal of the American Academy of Child and Adolescent Psychiatry. Mar; 32(2): 324-32, 1993

99. Fitzsimons GM, Bargh JA. Automatic self-regulation, in handbook of self-regulation: Research, theory and applications. Edited by Baumeister RF, Vohs KD. New York, Guilford: 151-170, 2004

100. Gadow KD, Nolan EE, Served J et al: Anxiety and depression symptoms and response to methylphenitate in children with attention-deficit/hyperactivity disorder and tic disorder. Journal of Clinical Psychopharmacology 22:267-274, 2002

101. Geary, DC. Children's mathematical development: Research and practical applications. Washington, DC: American Psychological Associattion, 1994

102. Ghelani K, Sidhu R, Jain U, et al: Reading comprehension and reading related abilities in adolescent with disabilities and attention-deficit hyperactivity disorder. Dyslexia 10: 364-384, 2004.

103. Goldman LS, Genel M, Bezman RJ, Slanetz PJ. Diagnosis and treatment of attention-deficit/ hyperactivity disorder in children and adolescents. Council on Scientific Affairs, American Medical Association. JAMA. Apr 8; 279(14):1100-7, 1998 
104. Goldston DB, Walsh A, Mayfield Arnold E, et al: Reading problems, psychiatry disorders, and functional impairment from mind to late adolescence. Journal of the American Academy of Child and Adolescent Psychiatry, 46:25-32, 2007.

105. Gómez-Beneyto M, Bonet A, Català M, Puche E, Vila V. Prevalence of Mental Disorders Among Children in Valencia, Spain. Act Psychiatric Scandinavia, 89: 352-7, 1994

106. Greenhill, LL. Diagnosing attention-deficit/hyperactivity disorder in children. Journal of Clinical Psychiatry, 59: 31-41, 1998

107. Harrington R, Myatt $T$. Is preadolescent mania the same condition as adult mania? A British perspective. Biol Psychiatry 53: 961-969, 2003.

108. Hart EL, Lahey BB, Loeber R, Applegate B, Frick PJ. Developmental change in attentiondeficit hyperactivity disorder in boys: a four-year longitudinal study. Journal of Abnormal Child Psychology. Dec; 23(6):729-49, 1995

109. Hassin RA, Uleman JS, Barg JA (eds): The New York Uncoscious. New York, Oxford University Press, 2005.

110. Hirschfeld RM, Vornik LA: Recognition and diagnosis of bipolar disorder. Journal Clinical Phychiatry 65 (suppl. 15): 5-9, 2004

111. Holmes, J., Payton, A., Barret, J., Harrington, R., McGuffin, P., Owen, M., Ollier, W., Worthington, J., Gill, M., Kirley, A., Hawi, Z., Fitzgerald, M., Asherson, P., Curran, S., Mill, J., Gould, A., Taylor, E., Kent, L., Craddock, N. y Thapar, A. Association of DRD4 in children with ADHD and comorbid conduct problems. American Journal Medical Genetic, $114,150-153,2002$ 
112. Clasificación Internacional de Enfermedades, décima de edición, apartado de psiquiatría, recogido por la Organización Mundial de la Salud.

113. James, W. Principles of psychology. New York: Dover. 1890

114. Jennsen PS: Comorbidity and child psychopathology: recommendations for the next decade. Journal of Abnormal Child Psychology 31: 293-300, 2003

115. Jensen PS, Martin D, Cantwell DP. Comorbidity in ADHD: implications for research, practice, and DSM-V. Journal of the American Academy of Child and Adolescent Psychiatry. Aug; 36(8):1065-79, 1997

116. Johnston C, Mash EJ. Families of children with attention-defi cit/hyperactivity disorder: review and recommendations for future research. Clinical Child and Family Psychology Review. Sep; 4(3): 183-207, 2001

117. Judd LL, Akiskal HS: The prevalence and disability of bipolar spectrum disorders in the US population: reanalysis of the ECA database taking into account subthreshold cases. Journal of Affective Disorders 73: 123-131, 2003

118. Kadesjo B, Gillberg C. The comorbidity of ADHD in the general population of Swedish school-age children. Journal of Child Psychology and Psychiatry. May; 42(4):487-92, 2001

119. Kellam SG, Ensminger ME, Simon MB: Mental health in first grade and teenage drug, alcohol and cigarette use. Drug and Alcohol Dependence 5: 273-304, 1980

120. Kircher TT, Brammer JL, Levelt W, et al: Pausing for thought: engagement of left temporal cortex during pauses in speech. Neuroimage 21: 84-90, 2004. 
121. Klein RG, Mannuzza S. Long-term outcome of hyperactive children: a review. Journal of the American Academy of Child and Adolescent Psychiatry. May; 30(3):383-7, 1991

122. Klein RG, Mannuzza S. Long-term outcome of hyperactive children: a review. Journal of the American Academy of Child and Adolescent Psychiatry, May; 30(3): 383-7. 1991

123. Knellwolf AL, Deligne J, Chiarotti F, Auleley GR, Palmieri S, Boisgard CB, et al. Prevalence and patterns of methylphenidate use in French children and adolescents. Eur Journal of Clinical Pharmacolology. Mar; 64(3): 311-7. 2008

124. Kirley A, Loewe N, Mullins C, McCarron M, Daly G, Irwin W, Fitzgerald M, Gill M, y Hawi Z. Phenotype syudies of the DRD4 gene polymorphisms in ADHD: Association with oppositional defiant disorder and positive family history, American Journal of Medical Genetics Part B: Neuropychiatric, 131B, 38-42, 2004

125. Lahey BB, Applegate B, McBurnett K, Biederman J, Greenhill L, Hynd GW, et al. DSM-IV field trials for attention deficit hyperactivity disorder in children and adolescents. American Journal of Psychiatry. Nov;151(11):1673-85, 1994

126. Lambert N, Hartsough C, Sassone D, et al.: Persistence of hyperactivity symptoms from childhood to adolescence and associated outcomes. American Journal of Orthopsychiatry 57:22-32,1987.

127. Lambert NM, Hartsough CS, Sassone D, Sandoval J. Persistence of hyperactivity symptoms from childhood to adolescence and associated outcomes. American Journal of Orthopsychiatry. Jan; 57(1):22-32, 1987

128. Lauferr MW, Denhoff E. Hyperkinetic behavior syndrome in children. Journal of Pediatrics. Apr; 50(4):463-74, 1957 
129. Lehn H, Derks EM, Hudziak JJ, Heutink P, van Beijsterveldt TC, Boomsma DI. Attention problems and attention-defi cit/hyperactivity disorder in discordant and concordant monozygotic twins: evidence of environmental mediators. Journal of the American Academy of Child and Adolescent Psychiatry. Jan; 46(1):83-91, 2007

130. Leung PWL, Luk SL, Ho TP, Taylor E, Mak FL, Bacon-Shone J. The diagnosis and prevalence of hyperactivity in Chinese schoolboys. British Journal of Psychiatry; 168: 486496, 1996

131. Lewinsohn PM, Klein DN, Seeley JR: Bipolar disorder during adolescence and young adulthood in a community sample, Bipolar Disorders 2: 281-293, 2000.

132. Lewinsohn PM, Klein DN, Seeley JR: Bipolar disorder in a community sample of older adolescents: prevalence, phenomenology, comorbidity, and course. Journal of the American Academy of Child and Adolescent Psychiatry, 34: 454-463, 1995

133. Linnet KM, Dalsgaard S, Obel C, Wisborg K, Henriksen TB, Rodriguez A, et al. Maternal lifestyle factors in pregnancy risk of attention defi cit hyperactivity disorder and associated behaviors: review of the current evidence. American Journal of Psychiatry. Jun;160(6):1028-40, 2003

134. Livingston RL, Dykman RA, Ackerman PT: The frecuency and significance or additional self-reported psychiatric diagnoses in children with attention deficit disorder. Journal of Abnormal Child Psychology 18: 465-478, 1990.

135. Loney J, Kramer J, Milisch RS. The hyperactive childs grows up: predictors of symptoms, delinquency, and achievement of follow-up. In Psychosocial Aspect of Drug Treatment for Hyperactivity. Edited by Gadow KD, Loney J. Boulder, CO, Westview Press, 381-416, 1981 
136. Loney JKM. The hyperactive child grows up: Predictors of symptoms, delinquency and achievement at follow. En: Gadow K \& Loney J, editores. Psychosocial aspects of drug treatment for hyperactivity. Boulder, CO: Westview Press: 351-415, 1982

137. Lynskey MT, Fergusson DM. Childhood conduct problems, attention defi cit behaviors, and adolescent alcohol, tobacco, and illicit drug use. Journal of Abnormal Child Psychology. Jun; 23(3):281-302, 1995

138. Mannuzza S, Klein R. Long Term Prognosis in Attention Deficit Hyperactivity Disorder. Child and Adolescent Psychiatric Clinics of North America. Jun; 9(3):711-20, 2000

139. Mannuzza S, Klein RG, Bessler A, et al.: Adult outcome of hyperactive boys: educational achievement, occupational rank, and psychiatric status. Archives of General Psychiatry 50:565-576, 1993

140. Mannuzza S, Klein RG, Bessler A, Malloy P, LaPadula M. Adult psychiatric status of hyperactive boys grown up. American Journal of Psychiatry.Apr; 155(4): 493-8, 1998

141. Mannuzza S, Klein RG, Moulton JL, III. Lifetime criminality among boys with attention deficit hyperactivity disorder: a prospective follow-up study into adulthood using official arrest records. Psychiatry Research. Sep 30; 160(3): 237-46, 2008

142. Maughan B, Rouge R, Messer J, et al.: Conduct disorders and oppositional defiant disorder in a national sample: developmental epidemiology. Journal of the American Academy of Child and Adolescent Psychiatry 45:609-621, 2004

143. Mayes SD, Calhoun SL: WISC-IV and WISC- III profiles in children with ADHD. Journal of Attention Disorders 9: 486-493, 2006 
144. Mayes D, Calhoum L y Crowell W. Learning Disabilities and ADHD: Overlapping Spectrum Disorders. Journal of Learning Disabilities, 33, 417-423, 2000

145. Mc Gee R, Prior M, Williams S, et al: the long term significance of teacher-rated hyperactivity and reading ability in childhood: findings from two longitudinal studies. Journal of Child Psychology and Psychiatry 43:1004-1017, 2002.

146. Merrell C, Tymms PB. Inattention, hyperactivity and impulsiveness: their impact on academic achievement and progress. British Journal of Educational Psychology. Mar; 71(Pt 1): 43-56, 2001

147. Milberger S, Biederman J, Faraone SV, et al.: attention-deficit hyperactivity disorder and comorbid disorders: issues of overlapping symptoms. American Journal of Psychiatry 152: $1793-1799,1995$

148. Millichap JG. Etiologic classification of attention-deficit/hyperactivity disorder. Pediatrics. Feb;121(2): e358-e365, 2008

149. Miranda A, García R y Jara P. Acceso al léxico y comprensión lectora en los distintos subtipos de niños con trastornos por déficit de atención con hiperactividad, Revista de Neurología, 2, 125-138, 2001

150. Miranda A, Meliá-de Alba A, Marco R, Roselló B y Mulas F. Dificultades en el aprendizaje de matemáticas en niños con trastorno por déficit de atención e hiperactividad. Revista de Neurología, 42 (supl 2), 163-170, 2006

152. Miranda A, Presentación MJ y López C. Contextos familiar y escolar de niños con Trastorno de déficit de atención con hiperatividad, agresivos y no agresivos, En f. Lara (comp.), Psicología evolutiva y de la educación. Actas del IV Congreso INFAD: 469-480. Burgos: Universidad de Burgos, 1995 
153. Monuteaux MC, Faraone SV, Herzing K, et al: ADHD and dyscalculia: evidence for independent familial transmission. Journal of Learning Disabilities 38: 86-93, 2005.

154. MTA Cooperative Group. A 14-month randomized clinical trial of treatment strategies for attention-defi cit/hyperactivity disorder. The MTA Cooperative Group. Multimodal Treatment Study of Children with ADHD. Archives of General Psychiatry. Dec; 56(12): 1073-86, 1999

155. Newcorn G, Halperin J, Healy J, et al. Are ADDH and ADHD the same or different?. Journal of the American Academy of Child and Adolescent Psychiatry, 28: 734-738, 1989

156. Nigg J, Nikolas M, Burt SA. Measured gene-by-environment in relation to attention deficit/hyperactivity disorder. Journal of the American Academy of Child and Adolescent Psychiatry.49 (9): 863-873, 2010

157. Oram J, Fine J, Okamoto C, et al: Assesing the language of children with AttentionDeficit Hyperactivity Disorder: role of executive function. American Journal of SpeechLanguage Pathology 8: 72-89, 1999.

158. Organización Mundial de la Salud. OMS. CIE-10. Clasificación Estadística Internacional de Enfermedades y Problemas Relacionados con la Salud. Décima Revisión. Volumen 1. Washington: Organización Panamericana de la Salud, 1995.

159. Orjales, I. Déficit de atención con hiperactividad. Manual para padres y educadores. Madrid. CEPE. 2005

160. Pastor PN, Reuben CA: Diagnosed Attention-Deficit Hyperactivity Disorder and learning disability: United States 2004-2006. National Center for Health Statistics. Vital Health Stat 10 (237). July 2008. 
161. Paternite C, Loney J. Childhood hyperkinesis: Relationships between symptomatology and home environment. En: Whalen CK, Henker B, editores. Hyperactive children: The social ecology of identification and treatment. New York: Academic Press; 1980.

162. Pennington BF, Grossier D, Welsh MC: Contrasting cognitive deficits in attention deficit/hyperactivity disorder versus reading disability. Dev Psychol 29:511-552, 1993

163. Pennington BF y Ozonoff S. Executive functions and developmental psychopathology. Journal for Child Psychology and Psychiatry, 37, 51-87, 1996

164. Pliszka SR: Effect of anxiety on cognition, behavior, and stimulant response in ADHD. Journal of the American Academy of Child and Adolescent Psychiatry 28: 882887,1989

165. Pliszka SR: Comorbidity of attention deficit hyperactivity disorder and overanxious disorder. Journal of the American Academy of Child and Adolescent Psychiatry 31: 197203, 1992

166. Pliszka SR, Carlson CL, Swanson JM. ADHD with Comorbid Disorders: Clinical Assessment and Management. New York: Guilford; 1999.

167. Pliszka SR, Glahn DC, Semrud-Clikeman M, Franklin C, Perez R, III, Xiong J, et al. Neuroimaging of inhibitory control areas in children with attention defi cit hyperactivity disorder who were treatment naive or in long-term treatment. American Journal of Psychiatry. Jun; 163(6):1052-60, 2006

168. Polanczyk G, de Lima MS, Horta BL, Biederman J, Rohde LA. The worldwide prevalence of ADHD: a systematic review and metaregression analysis. American Journal of Psychiatry. Jun; 164(6): 942-8, 2007 
169. Pope HG, Kouri EM, Hudson JI. Effects of supraphysiologic doses of testosterone on mood and aggression in normal men: a randomised controlled trial. Archives of General Psychiatry 2000; 57: 133-140

170. Quinn P, Wigal S. Perceptions of girls and ADHD: results from a national survey. The Medscape Journal of Medicine, 6(2):2, 2004

171. Rabiner D, Coie JD: Early attention problems and children's reading achievement: a longitudinal investigation. The Conduct Problems Prevention Research Group. Journal of the American Academy of Child and Adolescent Psychiatry, 39: 859-867, 2000.

172. Ribases M, Hervás A, Ramos-Quiroga JA, Bosch R, Bielsa A, Gastaminza X, et al. Association study of 10 genes encoding neurotrophic factors and their receptors in adult and child attention-defi cit/hyperactivity disorder. Biological Psychiatry. May 15; 63(10): 935-45, 2008

173. Robins PM: A comparison of behavioral and attentional functioning in children diagnosed as hyperactive or learning disabled. Journal of Abnormal Child Psychology 20:165-82, 1992

174. Rohde LA, Szobot C, Polanczyk G, et al: Attention-deficit/hyperactivity disorder: do research and clinical findings support the notion of a cultural construct for the disorder? Biological Psychiatry 57: 1436-1441, 2005.

175. San Sebastián J, Soutullo C y Figueroa A. Trastorno por déficit de atención e hiperactividad. Manual de psiquiatría del niño y del adolescente, 4: 54, 2010 
176. Satterfi eld JH, Schell A. A prospective study of hyperactive boys with conduct problems and normal boys: adolescent and adult criminality. Journal of the American Academy of Child and Adolescent Psychiatry, Dec; 36(12):1726-35, 1997

177. Scahill L, Schwab-Stone M, Merikangas KR, et al.: Psychosocial and clinical correlates of ADHD in a community sample of school-age children. Journal American Academy Child Adolescent Psychiatry 38: 976-984, 1999

178. Scottish Intercollegiate Guidelines Network (SIGN). Attention defi cit and hyperkinetic disorders in children and young people. 2005

179. Seidman LJ, Valera EM, Makris N. Structural brain imaging of attention-defi cit/hyperactivity disorder. Biological Psychiatry. Jun 1;57(11):1263-72, 2005

180. Semrud-Clikeman M, Bierderman J, Sprich-Buckminster S, et al: Comorbidity between ADDH and learning disability: a review and report in a clinically referred sample. Journal of the American Academy of Child and Adolescent Psychiatry 31:439- 448, 1992.

181. Semrud-Clikerman M, Biederman J, Sprich-Buckminster S, Lehman BK, Faraone y Norman D. Comorbidity between ADDH and learning disability: A review and report in a clinically referrred sample. Journal of the Academy of Child and Adolescent Psychiatry, 31: 439-448, 1992

182. Sergeant, J. y Van Der Meere, J. (1990). Convergence of approaches in localizing the hyperactivity deficit. En T. M. Ollendick y R. J. Prinz. Advances in Clinical Child Psychology, 207-246.

183. Serrano P, Friederichsen A, Piña S, García F, Almeida LG y Leo G. Frecuencia de complicaciones perinatales en pacientes con trastorno por déficit de atención con hiperactividad, otras enfermedades psiquiátricas infantiles y sujetos sanos. Psiquiatria Biológica, 10, 183-188, 2003 
184. Shalev RS; Manor O; Gross-Tsur V: Developmental dyscalculia: a prospective sixyear follow-up. Developmental Medicine \& Child Neurology 47: 121-125, 2005.

185. Shaw P, Eckstrand K, Sharp W. Attention-defi cit/hyperactivity disorder is characterized by a delay in cortical maduration. The Proceedings of the National Academy of Sciences of the United States of America: 104(49):19649-54, 2007

186. Shaywitz BA, Klopper JH, Gordon JW. Methylphenidate in 6-hydroxydopaminetreated developing rat pups. Effects on activity and maze performance. Archives of Neurology. Jul;35(7): 463-9, 1978

187. Shaywitz SE. Dyslexia. N Engl J Med 338:337-312, 1998

188. Shaywitz SE. Overcoming dyslexia. New York: Alfred A. Knopf. 2003.

189. Smalley SL, Kustanovich V, Minassian SL, Stone JL, Ogdie MN, McGough JJ, et al. Genetic linkage of attention-defi cit/hyperactivity disorder on chromosome 16p13, in a region implicated in autism. The American Journal of Human Genetics. Oct;71(4):959-63, 2002

190. Spencer T, Wilens, et al. "Attention deficit hyperactivity disorder with Mood Disorders". In Attention deficit hyperactivity disorder and comorbiditiesin Childres, adolescents, and adults, ed. Brown TE. Washington, D.C.: American, 2000

191. Spencer T, Biederman M, Coffey B, et al: The 4-year course of tic disorders in boys with attention deficit hyperactivity disorder. Archives of General Psychiatry 56:842-847, 1999

192. Spencer T, Biederman J, Faraone S, et al:: Impact of tic disorders on ADHD outcome across the life cycle: findings from a large group of adults with and without ADHD. America Journal Psychiatry, 158: 611-617, 2001b 
193. Still GF. Some abnormal psychical condiction in chidren. Lancet :1008-12, 1902

194. Szatmari P, Boyle M, Offord DR: ADHD and conduct disorder: degree of diagnostic overlap and differences among correlates. Journal of the American Academy of Child and Adolescent Psychiatry 28: 865-872, 1989a

195. Szatmari P, Offord DR y Boyle MH. Ontario child healt study: prevalence of attention deficit disorder with hyperactivity. Journal of Child Psychiatry and Psychology, 30: 219230, 1989

196. Tannock R, Ickowicz A, Oram J, et al: Language impairment and audiological status in ADHD: preliminary results. Poster presentation at the Annual Child Psychiatry Day, The Hospital for Sick Children, Toronto, ON, Canada, February 1995a.

197. Tannock R. Attention deficit hyperactivity disorder, advancesing cognitive, neurobiological and genetic research. Journal of Child Psychiatry and Psychology, 39: 6599, 1998

198. Taylor E, Chadwick O, Heptinstall E, Danckaerts M. Hyperactivity and conduct problems as risk factors for adolescent development. Journal American Academy Child Adolescent Psychiatry. Sep, 35(9): 1213-26, 1996

199. Taylor E, Chadwick O, Heptinstall E, Danckaerts M. Hyperactivity and conduct problems as risk factors for adolescent development. Journal of the American Academy of Child and Adolescent Psychiatry. 1996 Sep; 35(9): 1213-26.

200. Thapar A, Harold G, Rice F, Langley K, O'Donovan M. The contribution of geneenvironment interaction to psychopathology. Development and Psychopathology,19(4): $989-1004,2007$ 
201. Toro J, Cervera M, Osejo E, et al: Obssesive-Compulsive disorder in childhood and adolescence: a clinical study. Journal of Child Psychology and Psychiatry 33: 1025-1037, 1992.

202. Tredgold AF. Mental deficiency (Amentia). New York: Wood; 1908

203. Tuthill RW. Hair lead levels related to children's classroom attention-defi cit behavior. Archives of environmental Health. May, 51(3): 214-20, 1996

204. Vohs KD y Baumeister RF: Understanding self-regulation: an introduction, in Handbook of Self-Regulation: Research, Theory and Applications. Edited by Baumeister RF, Vohs KD. New York, Guilford, 1-9, 2004

205. Weiss G, Hechtman L, Milroy T, Perlman T. Psychiatric status of hyperactives as adults: a controlled prospective 15-year follow-up of 63 hyperactive children. Journal of the American Academy of Child and Adolescent Psychiatry. Mar, 24(2): 211-20, 1985

206. Weiss G, Hechtman L. Hyperactive Children Grown Up. 2. ${ }^{a}$ ed. New York: Guilford Press, 1993

207. Wender, P. Hyperactive child, adolescent, and adult: attention-deficit disorder throught the lifespan. New York: Oxford University Press, 1987

208. Wender, P. Attention-deficit disorder in adults. New York: Oxford University Press, 1995

209. Willcut EG, Pennington BF: Comorbidity of reading disability and ADHD: differences by gender and subtype. Journal of Learn Disabilities 33: 179-191, 2000.

210. Willcutt EG, Doyle AE, Nigg JT, et al: Validity of the executive funtions theory of the attention déficit/hyperactivity disorder: a meta.analytic review. Biological Psichyatry 57: 1336-1346, 2005. 
211. Willcutt EG, Pennington BF, Olson RK, et al: Neuropsychological analyses of comorbidity between reading disability and attention-deficit/hyperactivity disorder: in search of the common deficit. Dev Neuropsychol 27: 35-78, $2000 \mathrm{~b}$.

212. Willcutt EG, Pennington BF: Comorbidity of Reading disability and attentiondeficit/hyperactivity disorder: diferences by gender and subtype. Journal Learn disability $33: 179-191,2000$

213. Wolraich ML, Hannah JN, Pinnock TY, Baumgaertel A, Brown J. Comparison of diagnostic criteria for attention-deficit hyperactivity disorder in a country-wide sample. Journal of the American Academy of Child and Adolescent Psychiatry; 35: 319-324, 1996

214. Ygual A, Miranda A, Cervera, JF. Dificultades en las dimensiones de forma y contenido del lenguaje en los niños con trastorno por déficit de atención con hiperactividad. Revista de Neurología Clínica, 1, 193-202, 2000 